\title{
$\mathrm{D} . \mathrm{a} . \mathrm{m} \quad \begin{aligned} & \text { Documents d'archéologie méridionale } \\ & \text { Protohistoire du Sud de la France }\end{aligned}$
}

$25 \mid 2002$

Varia

\section{Le Cailar (Gard)}

Un nouveau comptoir lagunaire protohistorique au confluent du Rhôny et du Vistre

\section{Michel PY et Réjane ROURE}

\section{(2) OpenEdition}

1 Journals

Édition électronique

URL : https://journals.openedition.org/dam/365

DOI : 10.4000/dam.365

ISSN : 1955-2432

Éditeur

ADAM éditions

Édition imprimée

Date de publication : 20 août 2002

Pagination : 171-214

ISBN : 2-908774-15-1

ISSN : 0184-1068

Référence électronique

Michel PY et Réjane ROURE, «Le Cailar (Gard) », Documents d'archéologie méridionale [En ligne], 25 |

2002, mis en ligne le 13 octobre 2006, consulté le 06 avril 2023. URL : http://journals.openedition.org/ dam/365 ; DOI : https://doi.org/10.4000/dam.365 


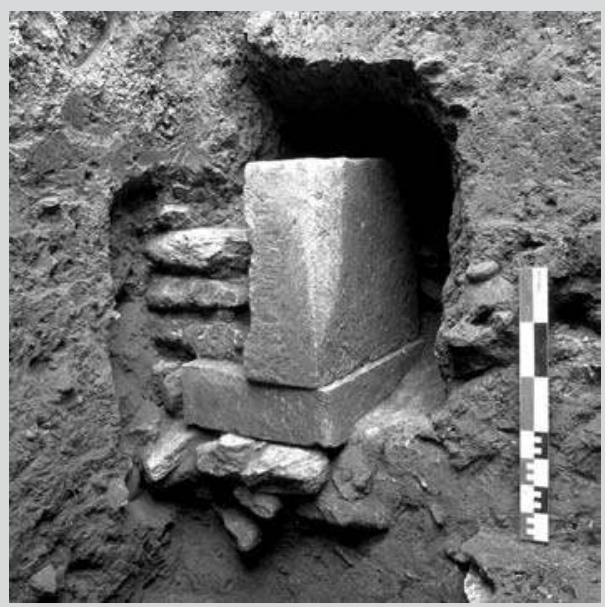

\title{
Le Cailar (Gard). Un nouveau comptoir lagunaire protohistorique au confluent du Rhôny et du Vistre
}

\author{
Michel PY et Réjane ROURE \\ avec la collaboration de Natàlia ALONSO MARTINEZ, \\ Jean-Claude BESSAC, Armelle GARDEISEN et Gaël PIQUES *
}

Cet article livre les premières données sur un nouveau comptoir lagunaire de l'âge du Fer en Languedoc oriental. Le Cailar (Gard) est situé au confluent du Vistre et du Rhôny, à l'extrémité de la Costière et au contact de la plaine littorale; probablement en bordure de la lagune dans l'Antiquité. Le faciès du mobilier recueilli (en particulier l'énorme quantité d'amphores massaliètes), auquel s'ajoutent certains aspects de l'architecture (notamment la taille de pierre), ne laisse guère de doute sur la nature de ce gisement qui fut à la fin du premier âge du Fer et au début du deuxième âge du Fer un débarcadère pour les marchands méditerranéens. Les données topographiques et stratigraphiques du sondage 1 sont analysées et accompagnées d'une étude précise du mobilier et des données paléo-environnementales.

Mots clés: Languedoc oriental, Gard, Le Cailar, comptoir lagunaire, premier et deuxième âgse du Fer, vestiges lapidaires, amphores, faciès céramique, archéozoologie, ichtyofaune, carpologie.
This article presents the first results from a new Iron Age lagoonal-trading outpost in the eastern Languedoc. La Cailar (Gard) is located at the confluence of the Vistre and the Rhony, on the edge of la Costière on the limit of the coastal plain; possibly on the lagoon edge during antiquity. The excavated assemblage (in particular, the enormous quantity of massailotte amphorae) along with certain architectural elements (notably, worked stone), leaves no doubt as to the function of this late, early Iron Age and early, late Iron Age trading post for Mediterranean merchants. The topographic and stratigraphic data from the sondage are presented along with a precise analysis of the finds and palaeoenvironmental evidence.

Keywords: Eastern Languedoc, Gard, La Cailar, lagoonal trading post, early and late Iron Age, worked stone remains, amphorae, ceramic assemblage, archaeozoology, fishbone, seed analysis. 


\section{Introduction}

\subsection{ENVIRONNEMENT GEOGRAPHIQUE}

Le village du Cailar est situé dans le département du Gard, à une vingtaine de kilomètres au sud-ouest de Nîmes. Il bénéficie d'une position géographique particulière: au confluent du Vistre et du Rhôny, au point de convergence de leur vallée. Il se trouve à l'extrémité de la Costière et au contact de la plaine littorale languedocienne (fig. 1).

L'environnement géographique du Cailar a subi plusieurs modifications importantes au cours des siècles, certaines naturelles, d'autres anthropiques. Tout d'abord, comme dans toute la partie méridionale du Languedoc, le système lagunaire a beaucoup évolué: l'étang littoral qui s'étendait à l'origine pratiquement jusqu'à l'orée du village, a reculé de plusieurs kilomètres vers le sud. Les trois étangs du Charnier, du Scamandre et de Grey situés actuellement à quelques kilomètres au sud-est du village sont les vestiges de la lagune primitive qui s'étendait entre Sète et la Camargue, rejoignant les étangs de Mauguio et du Méjean plus à l'ouest. Une anse de cette lagune subsistait encore au pied du village à la fin du XVIII siècle: elle est représentée sur la carte de Cassini (fig. 2) et apparaît encore clairement sur la carte pédologique de la région; elle est également perceptible grâce aux courbes de niveaux. La lagune a été progressivement comblée par les alluvions des fleuves venant s'y jeter, le Vistre et surtout le Vidourle, dont l'apport sédimentaire est très important (fig. 4).

La seconde modification notable dans la région du Cailar est quant à elle liée à l'intervention directe de l'homme: il s'agit de l'aménagement des cours du Vistre et du Rhôny, progressivement canalisés. Leurs tracés, multiples à l'origine, ont été modifiés dès le XIII' siècle (Pasquier 1993, 229, mentionne des travaux effectués avant 1243), les changements les plus significatifs étant cependant survenus à partir du $\mathrm{XIX}^{\mathrm{e}}$ siècle. Le Rhôny comptait autour du Cailar trois branches: le Rhôny-Vieil, la Piscine, le Rhôny actuel; le Rhôny-Vieil fut comblé au XVI ${ }^{\mathrm{e}}$ siècle, la Piscine - celle qui longeait l'ouest du village - en 1830.

1 Situation du Cailar parmi les principaux gisements protohistoriques du Languedoc oriental.
Les cours anciens sont encore visibles dans le paysage, sous forme de fossés plus ou moins colmatés et la carte dite de la "Baronnie du Caila", levée sur les lieux en 1726, nous donne un aperçu de leur écoulement naturel (fig. 3). On voit ainsi qu'au XVIII' siècle le village du Cailar se trouvait totalement enserré - et donc protégé - par les cours du Rhôny et du Vistre. C'était peut-être également le cas des agglomérations protohistorique et romaine.

Par ces deux vallées, Le Cailar était en relation directe avec d'une part la plaine nîmoise et d'autre part la Vaunage, où naît le Rhôny de la réunion de plusieurs petits ruisseaux descendus des collines dominant Clarensac; un chemin de chevrier le longeait encore au début du siècle. Le Vistre prend sa source sur la commune de Bezouce, au sud de l'agglomération nîmoise et suit la Costière jusqu'au village du Cailar, avant de se jeter dans le canal de la Radelle, sur la commune d'Aigues-Mortes. Avant les aménagements des canaux de la petite Camargue, il se déversait directement dans l'étang littoral. Il était navigable jusqu'au début du $\mathrm{XX}^{\mathrm{e}}$ siècle ${ }^{1}$ et Le Cailar était jusqu'à cette époque considéré comme un port, dont les aménagements se situaient au niveau du moulin installé à côté du village sur la rive droite du Vistre. Le Cailar était ainsi un point de passage obligé - un péage avait été installé à la Tour d'Anglas, un peu au sud du village - sur la route fluviale qui conduisait des étangs littoraux à la plaine nîmoise.

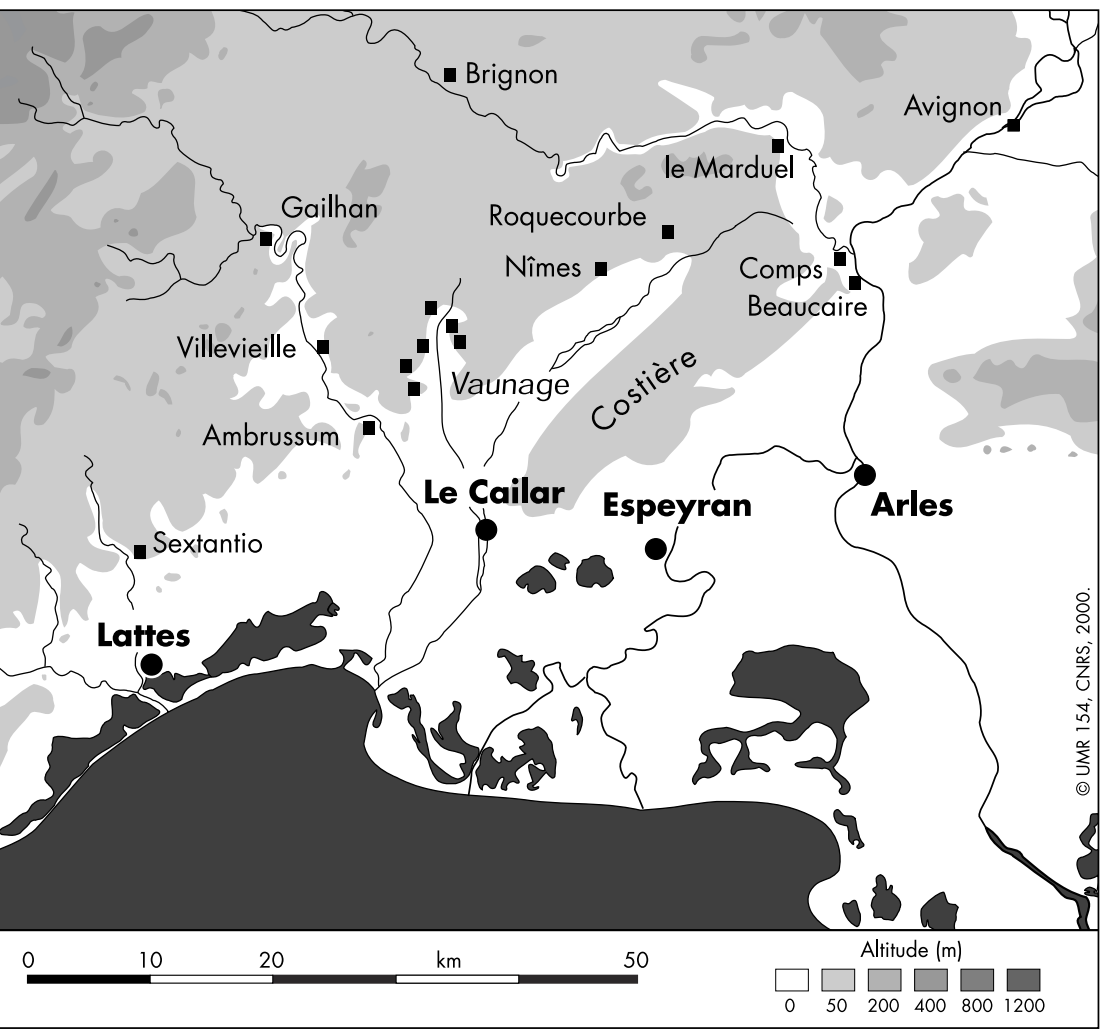




\subsection{DONNEES GEOLOGIQUES ET PEDOLOGIQUES.}

Le Cailar prend place sur un glacis quaternaire entaillé par les vallées du Vistre et du Rhôny qui ont formé deux cônes d'alluvions fluviales récentes (limons, sables), venant rencontrer parfois recouvrir - les limons palustres et saumâtres des anciens étangs littoraux. Ceux-ci ennoient eux-mêmes les formations quaternaires plus anciennes ainsi que la terrasse rhodanienne - la Costière, située juste au sud-est du village - formée par des alluvions fluviatiles anciennes (anté-Riss) et constituée de graviers et de galets correspondant à une formation détritique (fig. 4).

Autour du Cailar se trouvent donc des sols peu évolués d'apport alluvial, calcaires, à forts caractères d'hydromorphie, et localement légèrement salés, limono-argileux. Ces sols se rencontrent effectivement dans les extrémités aval des zones alluviales récentes principalement entre Villeneuve-lesMaguelone et Le Cailar; ils font la transition entre les sols d'apport alluvial limoneux et les sols hydromorphes. Les caractères d'hydromorphie apparaissent souvent dès l'horizon de surface et sont toujours très marqués en profondeur. Dans la vallée du Vistre, ces sols recouvrent des encroûtements friables, poreux, extrêmement calcaires, qui sont dus à la précipitation du calcaire à partir de la nappe alimentée par les eaux venant des Garrigues. Au sud du village, on rencontre rapidement des sols hydromorphes minéraux à redistribution du calcaire, limono-argileux, calcaires ou non calcaires, sur colluvions ou alluvions de l'Holocène. Au débouché du Vistre, il s'agit de sols hydromorphes non ou peu salés formés sur diverses alluvions fluviatiles, qui font la transition entre les sols alluviaux et les sols hydromorphes salés. Près des Bouillens (à l'est du Cailar donc), ces sols recouvrent du cailloutis rhodanien et, au contact de celui-ci, l'accumulation calcaire prend la forme d'un encroûtement cohérent.

Au nord du village, on trouve des graviers à 1,50 m du sol; au niveau des Arènes, un ancien puits rencontrait du rocher à un peu plus de $7 \mathrm{~m}$. Pour ce qui est des altitudes, on trouve 6,70 m à la gare, $4 \mathrm{~m}$ à l'entrée du cimetière et Léon Pasquier mesurait dans les années cinquante $9 \mathrm{~m}$ au lieu-dit du Castellas, entre les arènes et le cimetière (Pasquier 1993, 7); par contre on est seulement à $2 \mathrm{~m}$ ou $1 \mathrm{~m}$ NGF au sud du village, et même à $0 \mathrm{~m}$ ou $-0,20 \mathrm{~m}$ dans les Clapières. Le village du Cailar apparaît en fait comme une butte, sans doute du même type que celle de Pérols et correspondant comme elle à une légère remontée des alluvions anciennes de la Costière au milieu des sols hydromorphes du système lagunaire littoral. Les textes indiquent de fait que la partie ouest du village celle du Castellas vraisemblablement - n'a jamais été submergée, même lors des plus fortes crues conjuguées du Vistre et du Rhôny, ainsi que du Vidourle et du Rhône qui s'étalent tous deux jusqu'au Cailar en ces périodes. Léon Pasquier indique que la butte du Cailar apparaît alors comme une île au milieu des étangs (Pasquier 1993, 7). 


\subsection{APER ${ }^{2} U$ HISTORIQUE}

Le Cailar apparaît pour la première fois dans les textes en 675 sous le nom de Castellus $^{2}$, ce toponyme évoluera au cours des siècles en Caslarium (1243) puis en Le Caylar à partir du XVe siècle (Germer-Durand 1868). Les données historiques anciennes sur le village sont assez minces ${ }^{3}$. Léon Pasquier en a réuni l'essentiel dans un ouvrage publié à titre posthume par la Mairie du Cailar (Pasquier 1993). Le Cailar appartenait à la viguerie d'Aigues-Mortes et au diocèse de Nîmes, archiprêtré d'Aimargues. Il figure pour 11 feux dans le dénombrement de 1384. Le prieuré simple et séculier de Saint-Etienne-du-Caylar, en comprenant celui de Saint-Gilles-le-Vieux, son annexe, valait 4000 livres; tous deux étaient unis à la mense capitulaire de la cathédrale de Montpellier. La terre et le château du Cailar appartenaient, en 1112, au vicomte de Nîmes, Bernard Aton. Au $\mathrm{XVI}^{\mathrm{e}}$ s., cette terre passa par mariage dans la famille de Baschi, qui la possédait encore au milieu du siècle dernier; elle avait le titre de baronnie (Germer-Durand 1868). L'église Saint-Étienne du Cailar a été construite en 1091; le Cailar comptait semble-t-il une autre église, peut-être une simple chapelle, non loin du cimetière, affectée au XVII ${ }^{e}$ siècle au culte réformé, avant la construction du temple actuel en 1818.

Des vestiges de l'Antiquité sont signalés très tôt par Eugène Germer-Durand: "On trouve au Caylar de nombreux et remarquables restes d'antiquités » (Germer-Durand 1868,

52); par Émile Espérandieu dans son Répertoire (Espérandieu 1934, 16); l'ensemble des trouvailles sera bien entendu répertorié par Adrien Blanchet et Maurice Louis dans la Forma Orbis Romani du département du Gard (Blanchet, 1941). Un réexamen complet de ces données a été effectué récemment par Claude Raynaud pour la Carte Archéologique de la Gaule dont le tome concernant le Gard est paru en 1999 (Raynaud 1999). Plusieurs épitaphes ont été découvertes, plus ou moins anciennement, dans le village et à ses abords. L'existence à l'entour de multiples points d'occupation gallo-romaine et médiévale « dont l'ensemble constitue un pôle de peuplement continu du Ir au XIV ${ }^{\mathrm{e}}$ siècle » a pu être mise en évidence par les prospections systématiques.

Si les témoignages de l'époque romaine ont été remarqués dès le XVIII ${ }^{\text {e }}$ siècle, la présence d'un établissement protohistorique n'a été confirmée que récemment, même si E. Germer-Durand avait eu l'intuition dès 1868 de l'existence d'un oppidum de "l'époque celtique": «l'oppidum des Virinnenses, Virinnae (aujourd'hui Védrines, commune du Caylar et de Vauvert), se trouvait au confluent du Vistre et du Rhôny » (Germer-Durand 1868, p. V). Il y eut tout d'abord la découverte fortuite, dans le village, de deux chenets zoomorphes du deuxième âge du Fer (Garmy 1981), l'un en 1971 dans une rue près du

\section{PALUS}

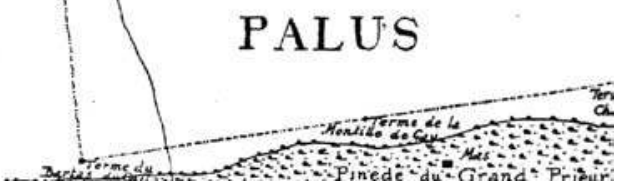

I 3 Carte de la "Baronnie du Caila", levée sur les lieux en juillet 1726 par M. de Rocheblave. 


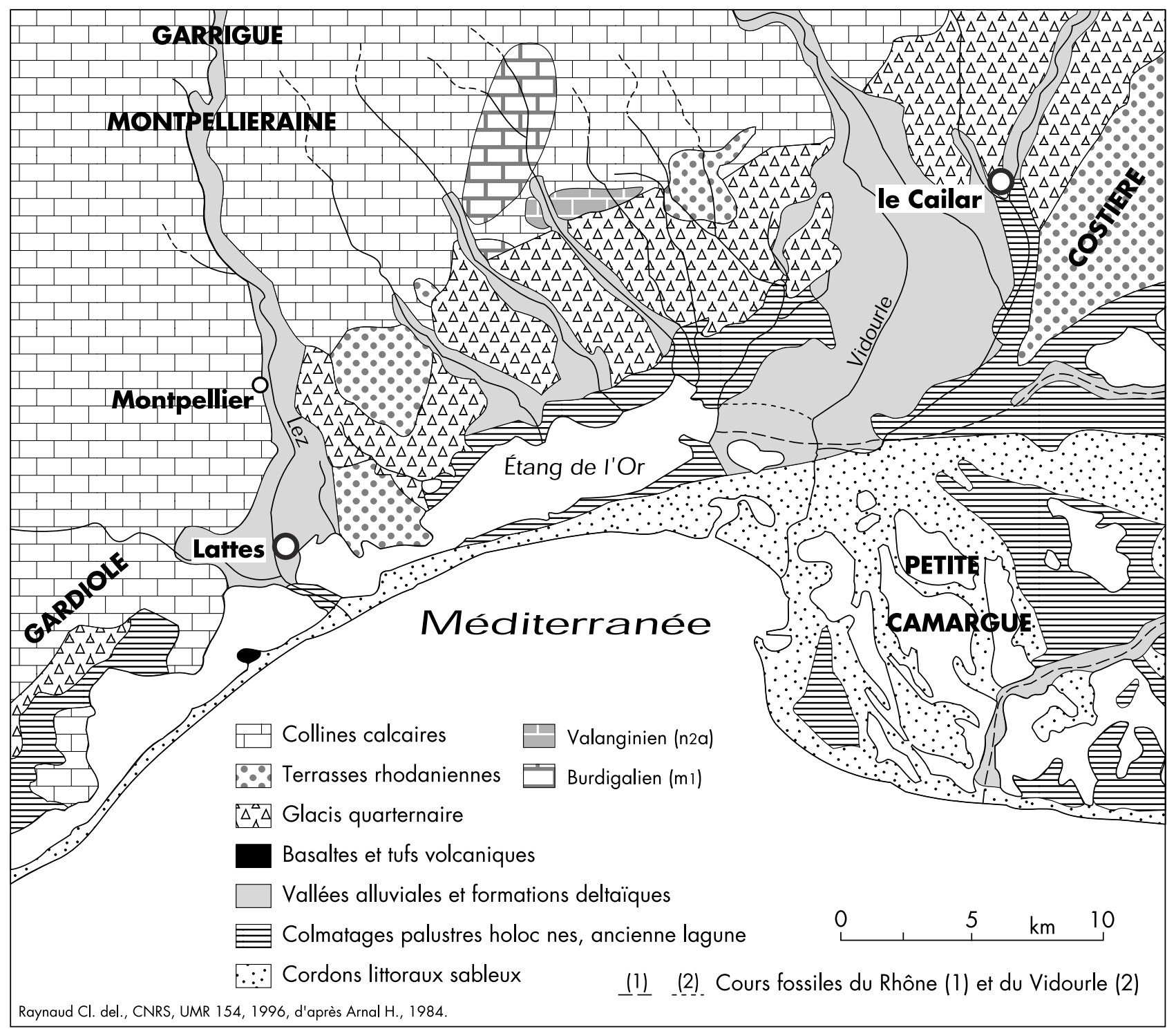

14 Carte géomorphologique du Bas-Languedoc.

temple, l'autre en 1980 dans la partie nord du village (fig. 5). Puis, en 1998, les prospections menées par Claude Raynaud ont confirmé l'existence d'un gisement antique particulièrement important "qui s'étend sur plusieurs hectares et correspond probablement à une agglomération protohistorique de plaine" (Raynaud 1999, 278). Il faut signaler enfin la fouille d'un tumulus de l'âge du Fer par le docteur Marignan à la fin du XIXe siècle, situé au lieu-dit Saint-Pastour, à la limite des communes de Vergèze et du Cailar, où l'on aurait exhumé « un squelette sans mobilier, (...) des débris de poterie, une pointe de javelot en fer, une bague en bronze, une amulette de terre cuite et un petit couteau en silex » (Marignan 1893); cependant cette découverte n'a pas été localisée par les prospections récentes.

\subsection{LES PHASES DE L'OCCUPATION DU SITE D'APRES LES PROSPECTIONS}

Les prospections effectuées depuis 1998 dans les basses vallées du Vistre et du Rhôny par Claude Raynaud et son équipe, outre la reconnaissance du site antique et de son extension topographique, ont occasionné la collecte d'un grand nombre de céramiques sur le gisement du Cailar. Ces documents proviennent d'une part de ramassages de surface dans les terrains agricoles situés immédiatement au nord et à l'ouest du cimetière ${ }^{4}$, et d'autre part de récupérations dans les terres produites par le creusement de nouveaux caveaux dans le cimetière lui-même ${ }^{5}$, concernant donc une 


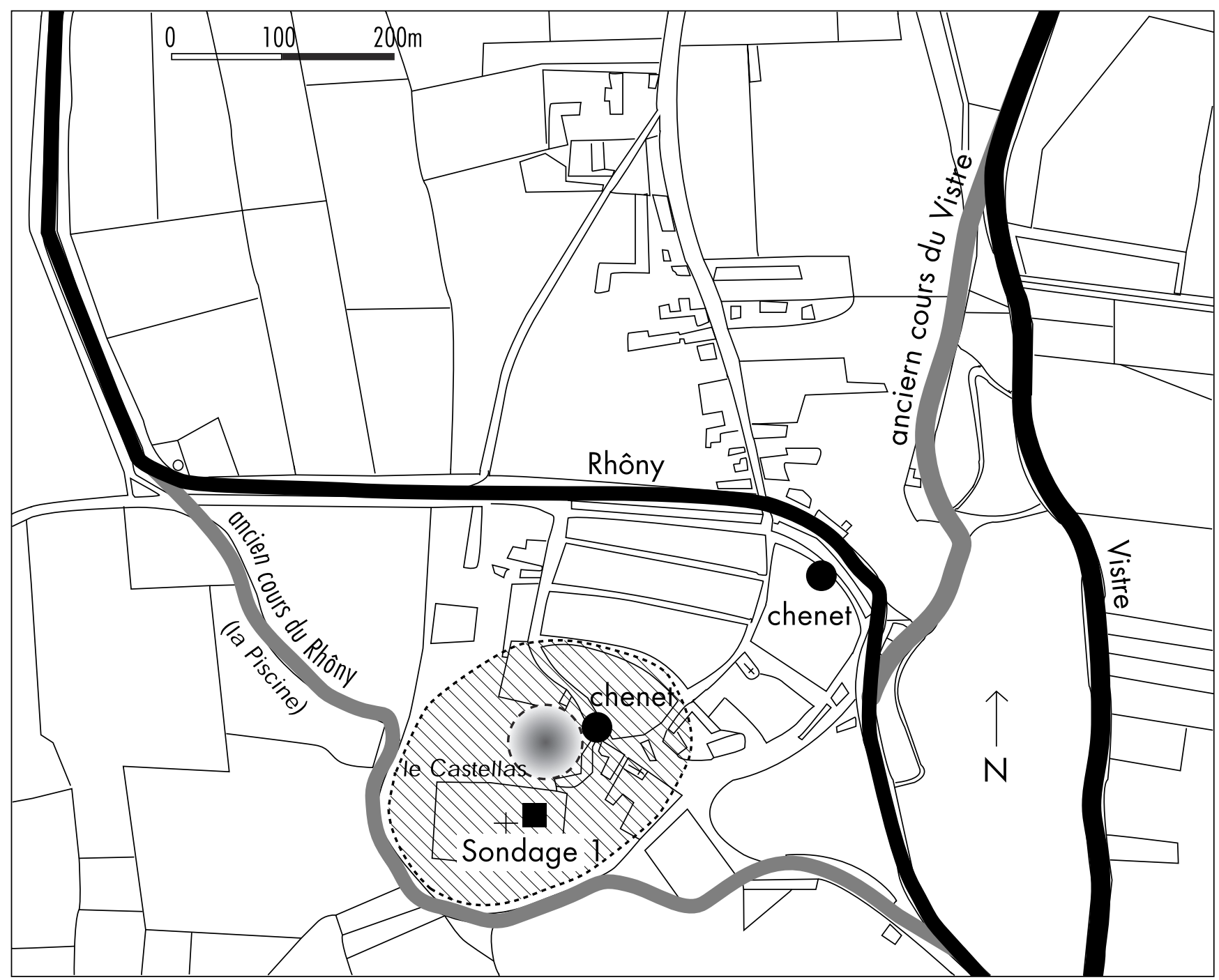

cours d'eau actuels

restitution des cours anciens

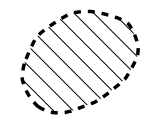

implantation probable du comptoir protohistorique

I 5 Plan cadastral du village du Cailar et principales composantes topographiques et archéologiques.

plus grande épaisseur. L'analyse typologique des éléments de forme des vases ainsi recueillis permet de se faire une idée globale de la durée et, dans une certaine mesure, de l'intensité de l'occupation des lieux.

\subsection{1. Âges du Fer}

- Amphore massaliète : bords A-MAS bd2: 2; A-MAS bd3: 1 ; A-MAS bd4: 2 ; A-MAS bd5: 12 ; A-MAS bd.6 : 11; A-MAS bd7: 8 ; A-MAS bd. $8: 6$; A-MAS bd9: 3 ; A-MAS bd9a ${ }^{6}: 1$; bord ind. : 1 ; anses : 87 .

- Amphore étrusque: A-ETR 3C: 1 anse; A-ETR $4: 1$ bord; 2 anses.

- Amphore gréco-italique: bords: 3 ; anses : 5 .

- Amphore italique: A-ITA Dr1A: 6 bords; A-ITA Dr1BC: 1 bord; anses: 31 ; fonds : 2 .
- Amphore africaine: A-AFR TrA : 1 bord ${ }^{7}$.

- Amphore punique: A-PUN C2c: 1 bord; indéterminée: 1 bord.

- Attique à vernis noir: coupe de type C AT-VN 398-413 : 1 bord; stemless: 1 fond à incisions rayonnantes; 1 fr. de panse.

- Attique à figures rouges: 1 fr. de stemless orné d'un drapé (fig. 15, $\left.\mathrm{n}^{\circ} 11\right) ; 2$ fr. jointifs d'une coupe-skyphos AT-FR Ky16b ornée à l'extérieur d'une palmette et de la base de deux personnages, et à l'intérieur de palmettes en creux reliées, deuxième quart du $\mathrm{IV}^{\mathrm{e}} \mathrm{s}$. (fig. $\left.15, \mathrm{n}^{\circ} 10\right)^{8}$. - Pseudo-attique: 1 fond annulaire de coupe-skyphos; 1 fond de coupe peint en rouge sous le fond et orné à l'intérieur d'un décor figuré en surpeint blanc (fig. 15, $\mathrm{n}^{\circ} 14$ ) 1 bord de coupe-skyphos PSEUDO-AT 605a.

- Céramique grise monochrome: 1 fond de coupe GR-MONO 5c.

- Céramique à pâte claire peinte: coupe à une anse CL-MAS 410: 3 bords, 1 anse; coupe-skyphos CL-MAS 431: 1 anse; coupes ind.: 2 fonds. 
- Céramique à pâte claire ancienne: cruche CLMAS 525: 3 bords; cruches ind.: 3 anses, 3 fonds. - Céramique grise peinte: 1 fond de coupe GRPEINTE 2-4.

- Mortiers massaliètes: MORT-M 621b: 1 bord; MORT-M 624b: 1 bord; MORT-M 633a: 1 bec verseur.

- Céramique commune tournée: urne CCT-LOR 1 : 2 fonds; coupe CCT-LOR 4a: 1 fond annulaire.

- Petites estampilles: 4 fr. de panse de bols PETEST 2783.

- Campanienne A ancienne: CAMP-A 23 : 1 bord à rainure supérieure ${ }^{9}$; CAMP-A 27ab: 2 bords à paroi fine; CAMP-A 42Bc: 1 panse; 1 fond mouluré type CAMP-A 48A ou 49B.

- Campanienne A moyenne: CAMP-A 27ab: 1 bord; CAMP-A 27Bb: 1 bord; CAMP-A 33b: 1 bord; CAMP-A 36: 1 bord.

- Campanienne A tardive: CAMP-A 2943: 1 bord. - Dolium: 1 bord DOLIUM bd3d; 1 bord de dolium tourné bd5c; 1 cordon digité; 1 trou de réparation.

- Céramique non tournée régionale: mortier CNTLOR A5 : 1 bord; urne CNT-LOR U2: 1 bord; urne CNT-LOR U4: 1 bord; urne CNT-LOR U5: 21 bords ; urne CNT-LOR U5m2: 1 bord ; coupe CNTLOR C1: 1 bord; coupe CNT-LOR C2: 3 bords; jatte CNT-LOR J1e: 1 bord; couvercle CNT-LOR V2c: 2 bords; divers: 4 fonds plats, 2 fonds annulaires, 1 anse.

\subsubsection{Antiquité ${ }^{10}$}

- Amphore gauloise: A-GAUL $1: 1$ bord; A-GAUL $4: 4$ bords; fond: 1 ; anses : 6 .

- Amphore de Bétique: A-BET Dr20: 2 anses.

- Sigillée italique: 1 fond de plat.

- Sigillée sud-gauloise : 1 fr. d'assiette SIG-SG 18b; 1 bord de coupe SIG-SG Dr37a.

- Céramique à enduit rouge interne pompéien : 1 bord de plat R-POMP $13 ; 1$ fr. de panse.

- Céramique claire engobée: 1 bord de bol à pâte grise CL-ENG B1.

- Céramique à paroi fine: 1 anse.

- Céramique à pâte claire récente: 1 couvercle d'amphore CL-REC $16 \mathrm{~h}$.

- Sigillée claire B grise : coupe CLAIR-B 15 : 1 bord.

- Sigillée claire B/luisante: coupe CLAIR-B 37a: 1 bord; coupe ind. 1 fond annulaire.

- Sigillée claire C: coupe CLAIR-C 71B : 1 bord.

- Céramique africaine de cuisine: plat AF-CUI 26: 1 fond.

- Céramique brune granuleuse ${ }^{11} ; 1$ fond.

- Céramique commune kaolinitique: urne KAOL A12: 1 bord; plat KAOL C6: 1 bord; marmite KAOL B8: 1 bord; cruche KAOL F5: 1 bord; divers : 1 carène, 2 fonds plats, 2 fonds à talon, 2 anses.

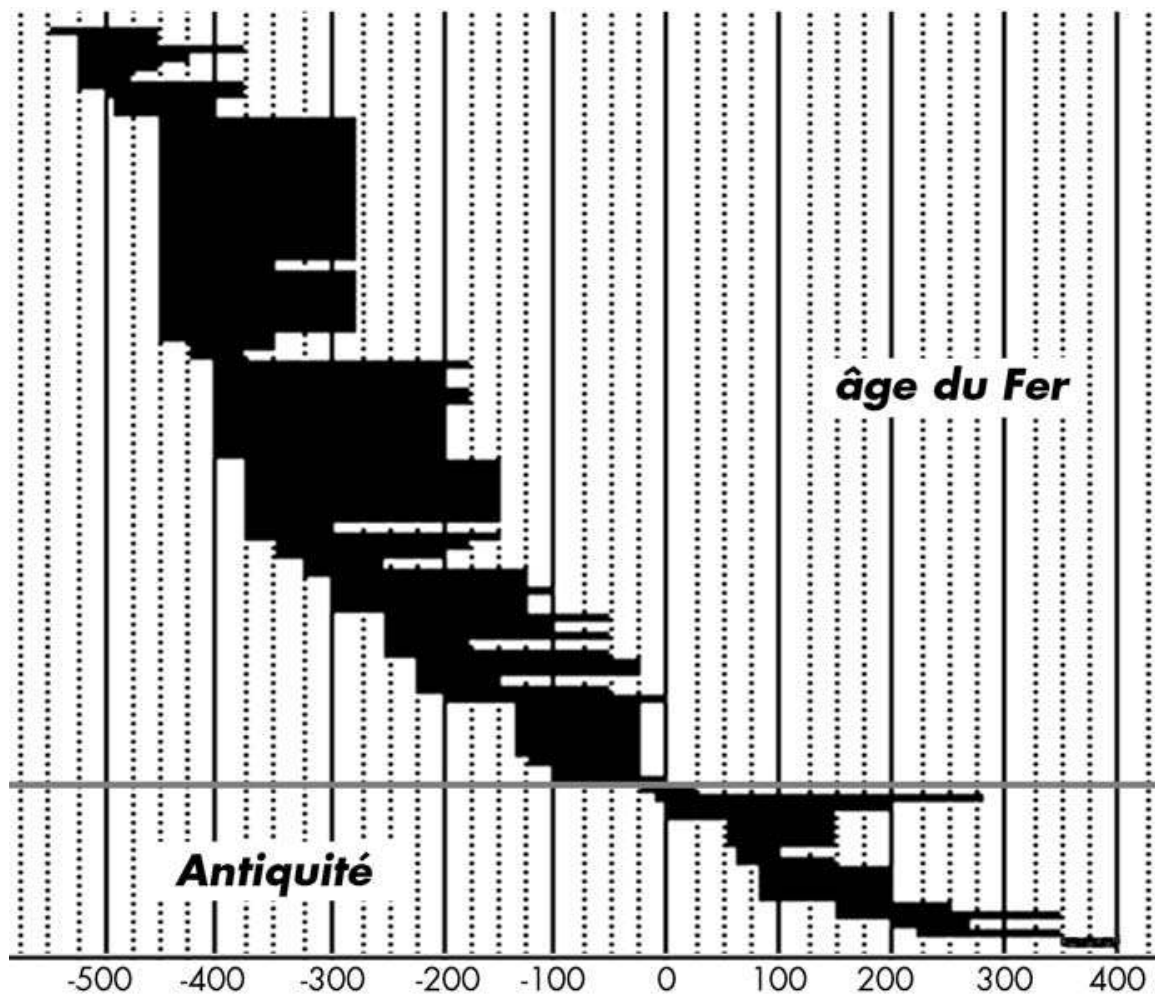

I 6 Histogramme des datations des découvertes de surface d'époque protohistorique et antique sur le site du Cailar.

\subsubsection{Moyen Âge}

- IX $X^{e}-X^{e}$ siècles ${ }^{12}$

- Céramique sableuse réductrice tournée: 1 fond plat large; pégaus: 3 anses, 1 bec ponté, 1 bec étiré pincé sur bord de type 2,1 bord de type 2 et 1 bord de type 3 .

- Céramique oxydante tournée: 2 fonds étroits, 2 bords de type 1 et 1 bord de type 2 .

- Céramique carolingienne à bandes peintes : 2 décors.

- XI'-début XIII ${ }^{e}$ siècles

- Céramique kaolinitique: 1 décor de bâtonnets allongés imprimés à la molette; 1 bord de type $3 ; 1$ bord de type 8 .

- Céramique de Saint-Victor-des-Oules : 1 bord de type 2, variante $1^{13}$

\section{- Fin XIII ${ }^{e}-X V^{e}$ siècles}

- Céramique verte et brune languedocienne: 1 fond de bol et $1 \mathrm{fr}$. à pâte calcaire, décor intérieur de stries brunes sur fond vert et blanc

- Céramique verte et brune hispano-mauresque: 1 bord de coupe tronconique décoré à l'intérieur de bandes de croisillons; 1 fond de coupe tronconique portant à l'intérieur un décor floral en panneaux (tiges et feuilles).

- Céramique grise calcaire (région montpelliéraine?): 2 anses en panier.

- Céramique de l'Uzège à glaçure plombifère verte et jaune ${ }^{14}: 1$ bord d'assiette aplati ; 5 anses de marmites en crochet; 5 bords de marmites ( 2 de type 3 et 3 de type 4 ); 1 anse et 1 bord de cruche avec départ d'anse; 1 bord de forme indéterminée. 


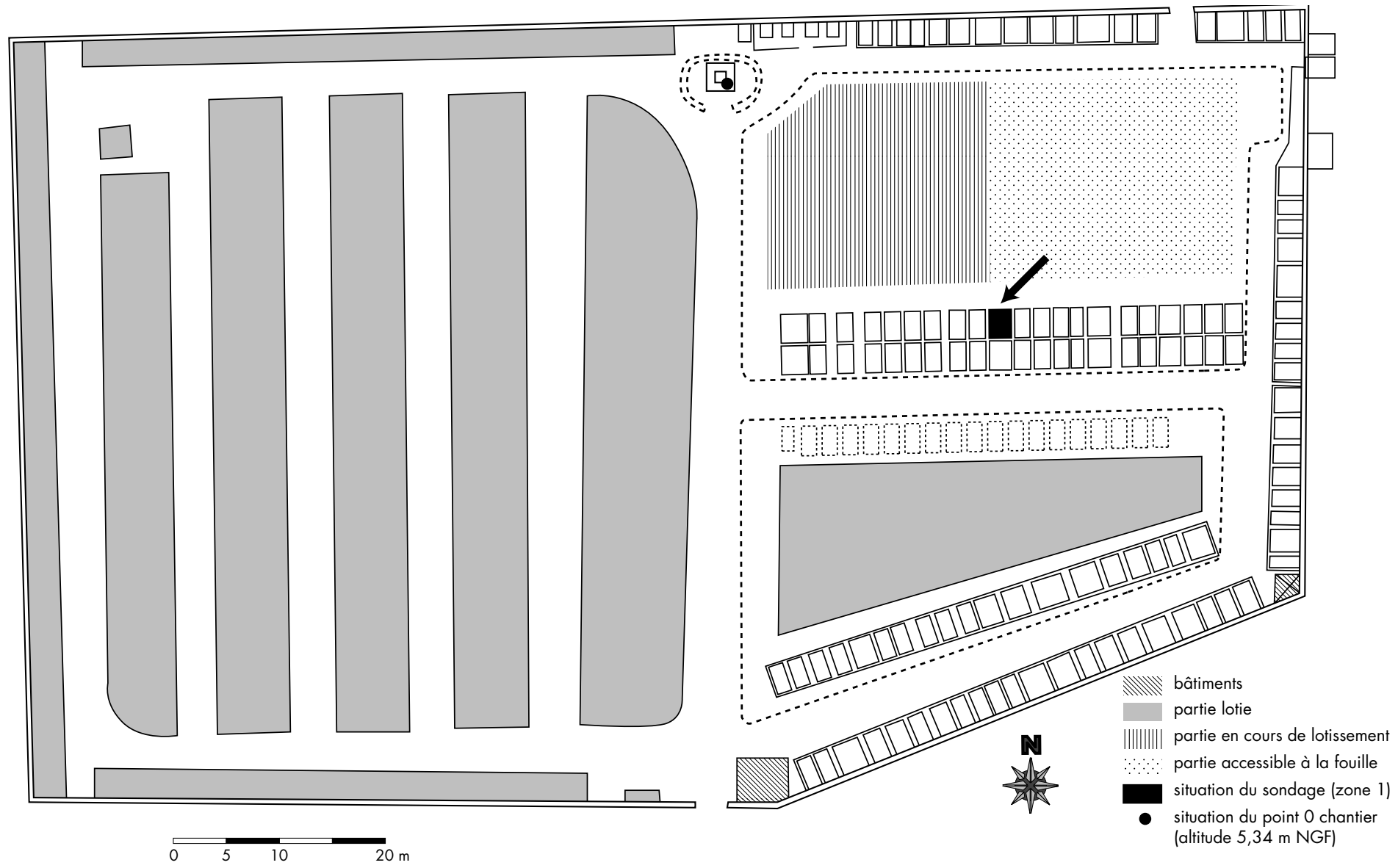

17 Plan du cimetière du Cailar et situation du sondage 1.

\subsubsection{Bilan}

Les documents recueillis en surface et dans les terres remaniées du cimetière doivent être interprétés avec précaution, car leur valeur statistique est dépendante de plusieurs facteurs externes qui peuvent en fausser la répartition. La seule approche sûre est celle reposant sur la présence de tel ou tel témoin, les conclusions que l'on peut tirer des absences ou des quantités étant plus aléatoires.

Les plus anciens documents attestés dans le lot analysé remontent à la fin du VI ${ }^{\mathrm{e}}$ ou au début du V $\mathrm{V}^{\mathrm{e}} \mathrm{s}$. (fig. 6). À part une forme de céramique grise monochrome qui peut remonter un peu plus haut (GR-MONO 5c), tous les types les plus anciens apparaissent entre 530 et 520, à savoir A-ETR 3C et 4 , A-MAS bd2 et bd3 et AT-VN 398-413. On sait que cette dernière forme n'est couramment produite à Athènes que jusque vers 480 (Sparkes 1970, 91), ce qui pourrait indiquer un terminus post quem proche de 500 .

La suite de l'âge du Fer semble couverte intégralement: en effet, la variété des catégories et des formes rencontrées laisse l'impression que rien d'essentiel ne manque qui contredirait l'hypothèse d'une permanence de la présence humaine sur le site: ainsi pour le $\mathrm{V}^{\mathrm{e}} \mathrm{s}$. av. n. è., outre les documents précités: A-MAS bd4, CL-MAS 621; pour les années 450-350: A-MAS bd5, bd6, CCT-LOR 1, 4a, CLMAS 431; pour le IV s.: A-MAS bd7, AT-FR Ky16b, PSEUDO-AT 605a, CL-MAS 525; pour le III ${ }^{\mathrm{e}} \mathrm{s}$. : A-MAS bd8, CL-MAS 624b, GR-PEINTE 2-4, PET-EST 2783; pour les III'-II ${ }^{\mathrm{e}}$ s. : A-MAS bd9, bd9a, A-GR-ITA, CL-MAS 633a, CAMP-A 23, 27a-b, 42Bc, 49A; pour le II ${ }^{\mathrm{e}}$ s. CAMPA 33b, 36; pour les $\mathrm{II}^{\mathrm{e}}-\mathrm{I}^{\mathrm{er}} \mathrm{s}$ : : A-ITA Dr1A, A-AFR TrA, CAMP-A 27Bb; pour le I $^{\text {er }}$ s. enfin A-ITA Dr1BC, A-PUN C2c, CAMP-A 2943.

En terme de quantité, on remarque que les phases anciennes du deuxième âge du Fer $\left(\mathrm{V}^{\mathrm{e}}-\mathrm{IV}^{\mathrm{e}} \mathrm{s}\right.$. ) sont mieux représentées que les phases récentes, mais ce critère, on l'a dit, doit être utilisé avec prudence.

Comparativement à la Protohistoire, l'Antiquité romaine est illustrée par un nombre beaucoup plus réduit de taxons (fig. 6), ce qui sans doute n'est pas sans signification: en effet, moins de $20 \%$ des éléments datables entre -500 et +400 illustrent les quatre premiers siècles de notre ère, ce qui à tout le moins suggère une différence dans l'importance et/ou dans l'intensité de l'occupation du site entre les 
deux périodes. Dans le détail, on remarque que le Haut Empire est encore assez bien muni, tandis que le Bas Empire n'est représenté que par des tessons épars.

Ce tassement relatif annonce d'une certaine manière l'absence apparente de toute documentation pour l'Antiquité tardive, à savoir les $\mathrm{V}^{\mathrm{e}}-\mathrm{VIII}{ }^{\mathrm{e}} \mathrm{s}$. de notre ère.

Les témoignages d'occupation redeviennent réguliers à partir des $I^{\mathrm{e}}-\mathrm{X}^{\mathrm{e}} \mathrm{s}$., au moment où se développe l'établissement castral ${ }^{15}$ dont on ressent ultérieurement la présence jusqu'au $\mathrm{XV}^{\mathrm{e}} \mathrm{s}$. à travers des céramiques assez diverses qui illustrent la permanence des activités d'échanges à l'échelon régional.

\section{Le sondage 1}

\subsection{PRESENTATION}

Les conditions d'intervention sur le site du Cailar ont imposé une surface de fouille limitée à seulement $5 \mathrm{~m}^{2}$, dans la fosse d'implantation d'un caveau funéraire située dans la partie orientale du cimetière du village (fig. 7), à savoir un rectangle de 2,5 $\mathrm{m}$ dans le sens nord-sud sur $2 \mathrm{~m}$ dans le sens est-ouest. Les deux premiers mètres de sédiments (à partir de la surface du sol moderne) avaient été préalablement excavés en vue de la construction du caveau, faisant apparaître au fond de la cavité quelques structures bâties, situées à la cote $3,30 \mathrm{~m}$ NGF (voir ci-après fig. 28) ${ }^{16}$. Ces structures, associées à du mobilier archéologique d'époque protohistorique, ont attiré l'attention des membres du groupe de prospection qui surveillaient le site ${ }^{17}$ et motivé une intervention rapide et limitée sous la forme d'un sondage d'évaluation, qui a été mené du 27 mars au 2 avril $2000{ }^{18}$.

Sur une surface aussi réduite, les résultats ne pouvaient être évidemment d'une grande portée sur le plan topographique, la minuscule fenêtre ouverte dans le gisement antique n'étant susceptible de fournir que des informations très partielles. Les apports sont plus significatifs dans les domaines de la stratigraphie et de la chronologie, la fouille ayant révélé une accumulation insoupçonnée de niveaux d'habitat sur une grande épaisseur, malgré deux importances contingences négatives:

- d'une part, les niveaux d'occupation les plus récents, à l'emplacement sondé, étaient détruits sur une épaisseur de deux mètres, d'abord par le creusement des tombes en pleine terre du vieux cimetière, qui, relativement serrées et profondes, ont largement entamé la sédimentation antique; ensuite par le creusement récent du caveau, qui a évacué la totalité des couches supérieures du secteur fouillé.
Quelques observations ont cependant pu être faites à propos de ces séquences récentes sur les bermes de l'excavation.

- d'autre part, les niveaux d'occupation les plus anciens situés en dessous de la cote 1,80 NGF (soit au-delà de $3,50 \mathrm{~m}$ de profondeur) n'ont pas pu être fouillés pour des raisons de sécurité; pousser plus bas aurait en effet nécessité de coffrer le sondage, ce qui dépassait largement les moyens mis à disposition de l'opération ${ }^{19}$. Tout ce que l'on peut dire, c'est que des structures bâties et des sédiments anthropiques existent bel et bien sous le niveau d'arrêt de la fouille, et qu'aucune observation n'indique la proximité du substrat naturel. Il en résulte qu'on ignore les caractères et la chronologie des premières phases d'occupation du site, qui peuvent remonter notablement plus haut que les plus anciens restes observés en place.

\subsection{STRATIGRAPHIE ET MOBILIERS DU SONDAGE 1}

On examinera ici les données topographiques et stratigraphiques issues du sondage 1, ainsi que les mobiliers associés à chaque niveau ${ }^{20}$, en procédant de bas en haut, c'està-dire dans l'ordre du temps. Les données de fouille et le mobilier ont été enregistrés à l'aide du système Syslat: pour se conformer aux normes de ce système (Py 1997, 23-47), le site du Cailar a été affecté du code "CLR", et le sondage dont il est question a été dénommé "secteur 1" de la "zone 1". En conséquence, les unités stratigraphiques ont été numérotées à partir de 1001.

La séquence d'occupation observée en place occupe en stratigraphie une épaisseur d'un peu plus d'un mètre et couvre en chronologie absolue une période d'environ un siècle, du milieu du $\mathrm{V}^{\mathrm{e}} \mathrm{s}$. au milieu du $\mathrm{IV}^{\mathrm{e}} \mathrm{s}$. av. n. è. Les éléments de datation fournis par le mobilier recueilli permettent de répartir les différents niveaux d'occupation correspondant à cette séquence par quart de siècle.

\subsubsection{Niveaux du troisième quart du Ve s. av. n. ̀̀.}

Des restes attribuables au troisième quart du $\mathrm{V}^{\mathrm{e}} \mathrm{s}$. av. n. è. ont été relevés à la base du sondage dans un étroit espace le long de la berme orientale. Il s'agit d'abord d'un mur d'orientation nord-sud (MR1038), longeant cette berme, dont l'épaisseur n'est pas intégralement connue $(>40 \mathrm{~cm})$ et dont le solin, fait de grandes pierres plates en calcaire coquillier blanc (us.1038), a été presque entièrement épierré (tranchée 1025), seules quelques assises étant conservées à l'extrémité méridionale sous un mur postérieur (fig. 8, 9 et 10).

À l'ouest de ce mur, un élément de sol (us.1037) a été mis en évidence. Il s'agit d'un sol de terre battue, cendreux, présentant plusieurs structures visibles dans l'étroite bande qui 




I 8 Vue d'ensemble du sondage 1 du Cailar, au niveau des sols 1036 et 1037

a pu être fouillée. Au sud, outre des tessons recassés à plat, c'est une fosse circulaire aux parois rubéfiées (probable foyer en fosse) contenant un remplissage de terre apparemment naturelle à petits coquillages lagunaires (FS1041). Au nord, c'est un élément de pavage d'adobes disposées en damier (SL1039: cinq adobes visibles de forme carrée et de $35 \mathrm{~cm}$ de côté en moyenne) supportant la base d'un four en terre (FR1040). Ce four est constitué d'une sole de limon jaune mêlée de cailloutis, entourée par un cercle d'argile rubéfiée arasé au niveau de la sole, qui correspond apparemment à la base des parois d'un four en cloche.

Au-dessus de ce sol se tient un remblai assez épais (us.1035), formé à base d'adobes concassées, servant d'assise à un sol supérieur. Ce niveau contient des tessons disposés en tous sens, des fragments de scories au sud, mais peu de charbons de bois. Il semble correspondre à une destruction partielle des structures portantes de l'habitation lors d'une réfection.

Un nouveau sol (us.1029=1036), établi sur ce remblai, devait comme le précédent buter à l'est contre le mur MR1038. C'est une surface de terre battue marquée par des charbons de bois abondants, des gros tessons à plat et des petits galets, et, au centre du sondage, par un foyer construit en argile (FY1032) portant de nettes traces de rubéfaction en son centre (fig. 12). Ce foyer est établi au-dessus d'un radier en cuvette. La fosse de préparation est comblée de tessons d'amphores de Marseille et de plusieurs fragments de vases à pâte claire; les tessons sont disposés sur plusieurs épaisseurs (us.1032); en complément, on remarque quelques galets et petits cailloux. Sur ce radier se surimpose une strate d'argile rougie mal conservée dans son ensemble, qui devait s'étendre sur environ $80 \mathrm{~cm}$ de diamètre.

Peu de temps après, une large banquette (BQ1026) est construite directement sur le sol précédent, contre le mur oriental et parallèlement à lui (fig. 12 et 13). Cette banquette est parementée uniquement du côté ouest. La base est faite de deux à trois assises de pierres de grosseurs très diverses (mais de même matériau: calcaire coquillier), posées à plat, avec une arase relativement plane où se remarquent encore quelques tessons d'amphore massaliète régulateurs et par endroits des traces de limon jaune semblant correspondre à des restes d'enduit. La banquette est légèrement plus large au 
sud, où son sommet comporte jusqu'à quatre rangs de pierres côte à côte, qu' au nord où elle est moins bien conservée (longueur 2,40 m, largeur de 30 à $60 \mathrm{~cm}$ ). Entre cette banquette et le mur MR1038 se trouve une bande terre (us.1028) qui servait de joint avec le mur (fig. 9 et 11). Il s'agit de limon compact, pauvre en traces et en mobilier.

La phase d'occupation de la pièce munie de la banquette BQ1026, datable aux environs de 425, est illustrée par une mince strate de sédimentation cendreuse (us.1031) contenant quelques galets et graviers ainsi que des charbons de bois; cette couche n'a été fouillée que sur une étroite bande à l'ouest du sondage. À sa base, on observe une dalle rectangulaire de molasse calcaire qui passe sous la banquette BQ1026, tandis qu'au nord une adobe plantée de chant est disposée contre le parement de celle-ci.

\subsubsection{Mobiliers du troisième quart du $V^{e}$ s. av. n. è.}

\section{Us 1035}

- Inventaire: céramique: 76 fr.; faune: 6 os ; bronze: 1 fr. d'ardillon de fibule; fer: 6 scories de réduction.

- Comptages: cér. grise monochrome: 2 fr.; cér. attique: 4 fr.; cér. à pâte claire peinte: 6 fr.; cér. à pâte claire ancienne: 6 fr.; amphore étrusque: 1 fr.; amphore massaliète: 52 fr.; cér. non tournée régionale : $3 \mathrm{fr}$; dolium: 2 fr.

- Typologie:

amphore étrusque: amphore A-ETR 4A: 1 bord (fig. 14, $\mathrm{n}^{\circ} 6$ ).

amphore massaliète: bord A-MAS bd3: 1 bord (fig. $14, \mathrm{n}^{\circ} 5$ ); bord A-MAS bd4: 1 bord (fig. 14, $\mathrm{n}^{\circ}$ 7); amphore A-MAS ind.: 1 anse.

cér. attique à vernis noir: Acrocup AT-VN 442-445 ou coupe sans tige AT-VN 493-495: 1 bord (fig. $14, \mathrm{n}^{\circ} 1$ ); coupe AT-VN ind. : 1 anse, 1 décor (fig. 14, $\mathrm{n}^{\circ} 2$ ).

cér. à pâte claire peinte: coupe à anses CLMAS 425: 1 fond (fig. 14, $\mathrm{n}^{\circ} 4$ ); coupe à anses CL-MAS 427: 1 bord (fig. $14, \mathrm{n}^{\circ} 3$ et fig. $21, \mathrm{n}^{\circ} 7$ ); CL-MAS ind. 2 décors.

- Commentaire: le bord de coupe attique à lèvre incurvée peut se rattacher soit à une Acrocup tardive (vers le milieu du Ve s.: cf. Sparkes 1970, $\left.n^{\circ} 443\right)$, soit à une coupe sans tige du type Agora 493 (vers 430 av. n. è.). La coupe claire

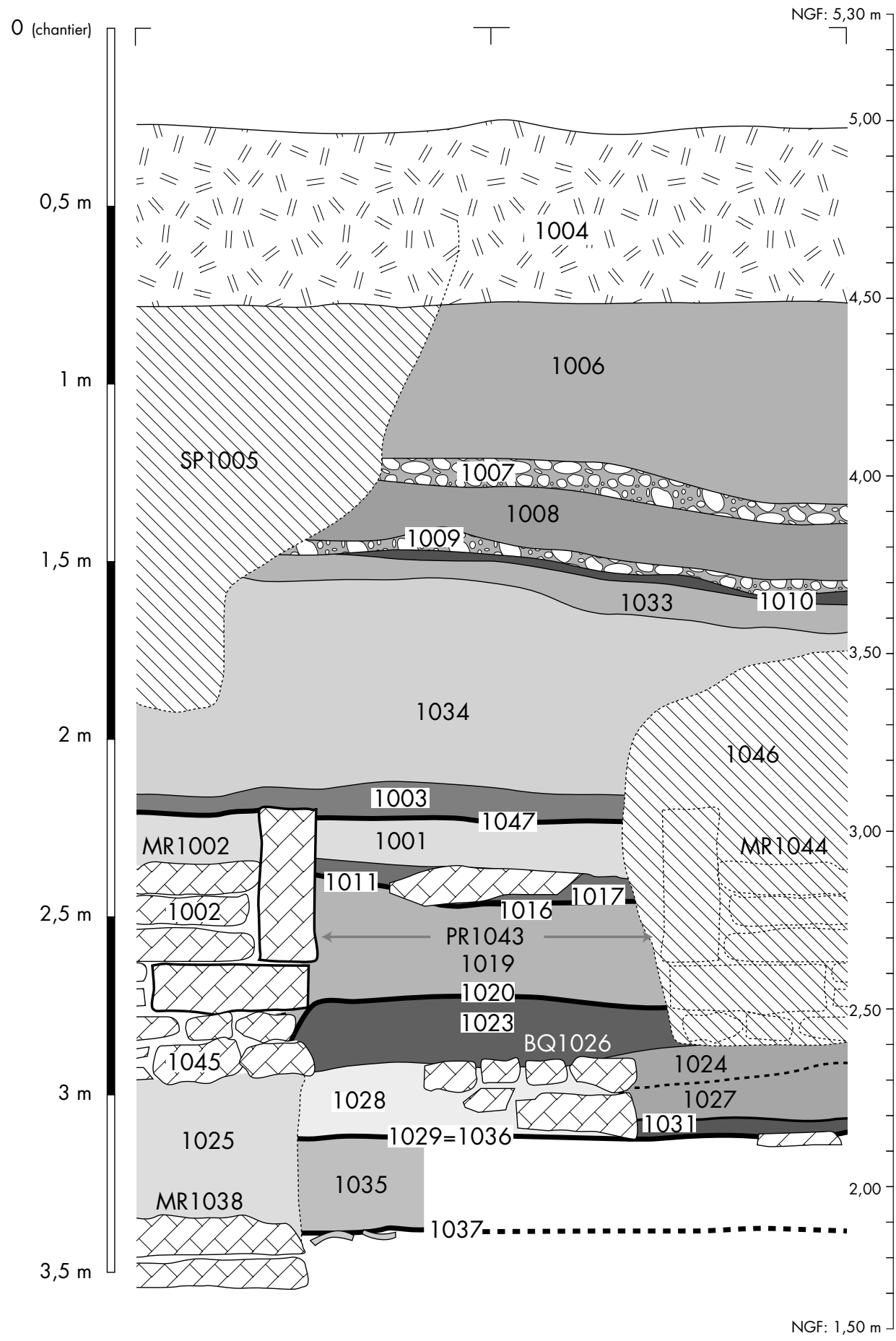

19 Stratigraphie est-ouest du sondage 1 du Cailar à l'aplomb de la berme sud

massaliète à décor de larmes CL-MAS 427 est connue au $\mathrm{V}^{\mathrm{e}}$ s. à Villevielle (Py 1975, fig. 61, n 4 ) et à Ensérune (Jannoray 1955, 53, fig. 4; Py 1979, fig. 6, $\mathrm{n}^{\circ} 21-23$ ) et au début du IV ${ }^{\mathrm{e}}$ s. à Mauressip (Py 1990, 549, doc.161, nº 8). Si l'amphore étrusque $4 \mathrm{~A}$ possède une chronologie assez large (du milieu du Ve au milieu du IV'e s. : Py 2001, 38-40), 


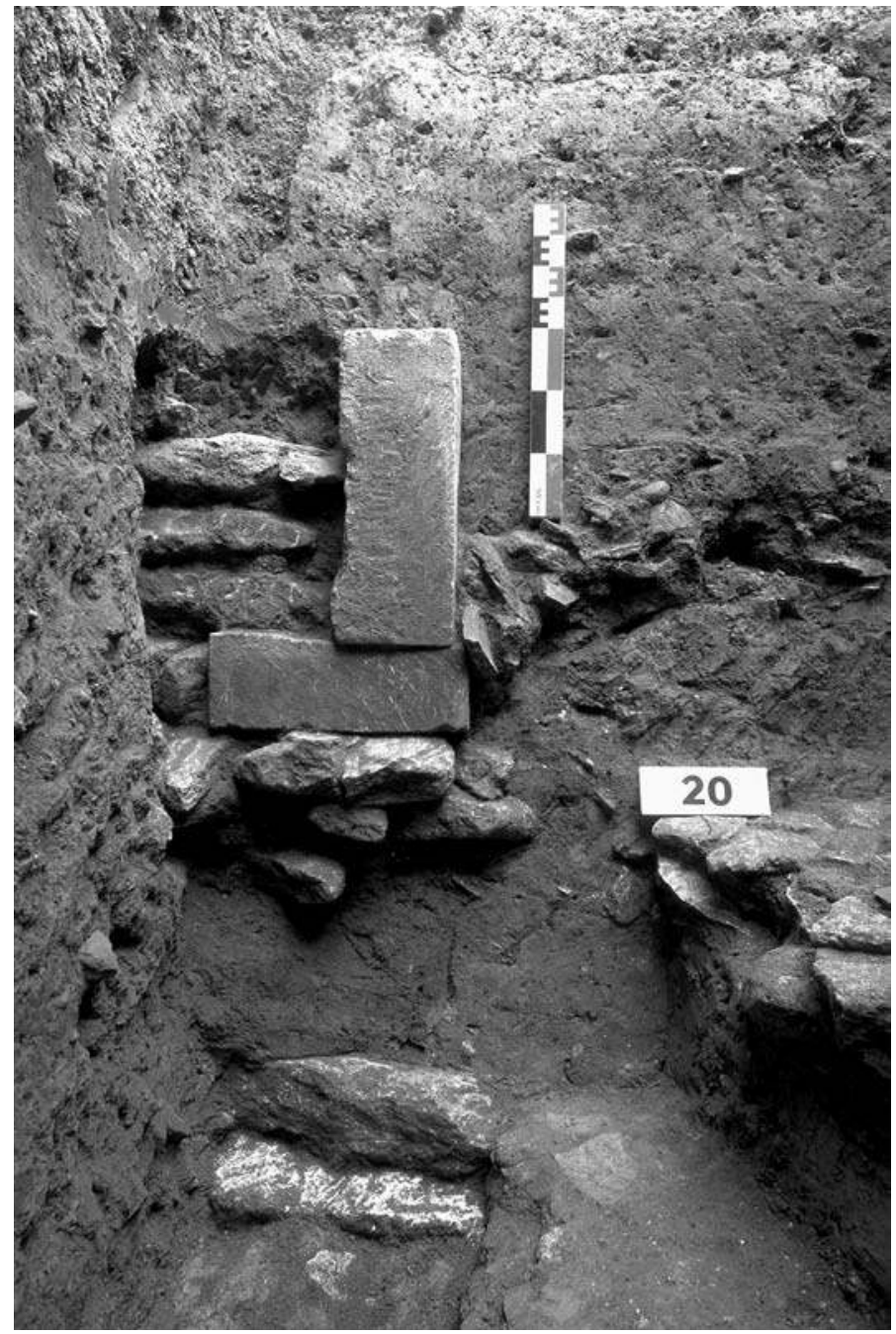

10 Le Cailar, sondage 1. Succession des murs MR1038 et MR1002.

l'association des bords d'amphore massaliète A-MAS bd3 et bd4 est quant à elle caractéristique des deuxième et troisième quarts du $\mathrm{V}^{\mathrm{e}} \mathrm{s}$., le type bd3 disparaissant avant 425 .

\section{Us 1032}

- Inventaire: céramique : 54 fr.

- Comptages : cér. claire peinte : 5 fr.; cér. à pâte claire ancienne: 1 fr.; amphore massaliète: $48 \mathrm{fr}$.

- Typologie:

amphore massaliète: bord A-MAS bd4: 1 bord (fig. 14, $\mathrm{n}^{\circ}$ 8); amphore A-MAS ind.: 1 anse.

cér. à pâte claire peinte: CL-MAS ind.: 1 décor.

- Commentaire: seul élément de forme présent, le bord A-MAS bd4 compris dans le radier du foyer FY1032 est caractéristique du $\mathrm{V}^{\mathrm{e}} \mathrm{s}$.

\section{Us 1028}

- Inventaire: céramique: 58 fr.; faune: 6 os; terre: 1 fr. de torchis (vase ou enduit); pierre: 1 fr. de bloc taillé.
- Comptages : cér. claire peinte: 3 fr.; cér. attique: 1 fr.; cér. à pâte claire ancienne: 1 fr.; cér. commune tournée du Languedoc oriental: 1 fr.; amphore ibérique: 1 fr.; amphore massaliète: 51 fr.

- Typologie:

amphore massaliète: bord A-MAS bd 3: 1 bord (fig. 14, $\mathrm{n}^{\circ} 11$ ); bord A-MAS bd5: 1 bord (fig. 14, $\mathrm{n}^{\circ} 12$ ); amphore A-MAS ind.: 1 fond, 2 anses.

cér. attique à figures rouges: cratère AT-FR Cr3: 1 décor (fig. 15, n 3 ). cér. à pâte claire peinte: cruche CL-MAS ind. : 1 fond, 2 décors.

- Commentaire: pour le bord A-MAS bd3, se reporter cidessus (us. 1035); le type A-MAS bd5 apparaît quant à lui après le milieu du $\mathrm{V}^{\mathrm{e}} \mathrm{s}$. La conjonction de ces deux formes de bord dans le comblement de la banquette BQ1026 confirme une chronologie dans le troisième quart du siècle. L'élément de cratère en calice attique (fig. $15, \mathrm{n}^{\circ} 3$ ), orné d'une grecque et du bas d'un personnage, n'y contredit pas (voir un fragment du même type à Ensérune: Dubosse 1998, pl.5, nº 6, daté de la deuxième moitié du $\mathrm{V}^{\mathrm{e}} \mathrm{s}$.).

\section{Us 1031}

- Inventaire: céramique: $72 \mathrm{fr}$; faune: 14 os, 1 coquillage.

- Comptages: cér. claire peinte: 2 fr.; cér. attique: 1 fr.; cér. à pâte claire ancienne: 6 fr.; amphore massaliète: 54 fr.; amphore ibérique: $2 \mathrm{fr}$; amphore punique : 1 fr. ; cér. non tournée régionale : 3 fr. ; dolium : $3 \mathrm{fr}$

- Typologie:

amphore massaliète: bord A-MAS bd4: 1 bord (fig. 14, $\mathrm{n}^{\circ}$ 9); amphore A-MAS ind.: 2 fonds (fig. 14, $\mathrm{n}^{\circ} 10$ ), 5 anses.

cér. attique à figures rouges: coupe à tige AT-FR KyB : 1 décor (fig. 15, $\mathrm{n}^{\circ}$ 9).

cér. à pâte claire ancienne: cruche CL-MAS ind.: 1 bord, 1 fond, 1 anse.

- Commentaire: On retrouve ici encore le bord A-MAS bd4, majoritaire dans cette phase. Une datation vers 430425 est fournie par la coupe à tige de type $\mathrm{B}$ en céramique attique à figures rouges (fig. 15, n 9), qui trouve à Ensérune des comparaisons très proches (Dubosse 1998, pl.14, $\mathrm{n}^{\circ} 9$ et $\mathrm{pl} .15, \mathrm{n}^{\circ} 1$ ) attribuées au Peintre d'Érétrie (sur lequel voir Lezzi-Hafter 1988); voir aussi plusieurs fragments à Lattes dans des contextes du troisième ou du quatrième quart du Ve s. (Py 2001, n 1581, 1586, 1593, 1598).

\subsubsection{Niveaux du dernier quart du $V^{e}$ s. av. n. ̀̀.}

Durant le dernier quart du $\mathrm{V}^{\mathrm{e}}$ s., la maison précédente est abandonnée. Le secteur recoupé par le sondage 1 n'est semble-t-il provisoirement plus utilisé en tant qu'habitation, mais fonctionne comme zone de rejet pour des balayages domestiques, avant qu'une nouvelle habitation ne soit implantée. Plusieurs phases de nivellement finissent par masquer la totalité des structures antérieures.

Dans un premier temps, un remblai (fouillé en deux décapages: us.1027 et 1024) est étalé à l'intérieur de la pièce, à l'ouest de la banquette BQ1026. Il est constitué d'une 
matrice limoneuse avec des passées cendreuses et de nombreux charbons de bois de petite taille (mais pas de traces de foyer), ainsi que des tessons épars, ces derniers se présentant en tous sens (quelques-uns verticaux, plusieurs à plat). Dans l'angle nord-ouest, on note une poche d'argile jaune correspondant sans doute à des adobes fondues, sur $60 \mathrm{~cm}$ de large.

Dans un second temps, l'ensemble de la zone est comblé par une épaisse couche de dépotoir de structure très hétérogène (us.1023), avec des cendres et des charbons, souvent par poches compactes; des adobes concassées en morceaux petits et moyens; des fragments de vases en torchis brûlé, par plaques, au

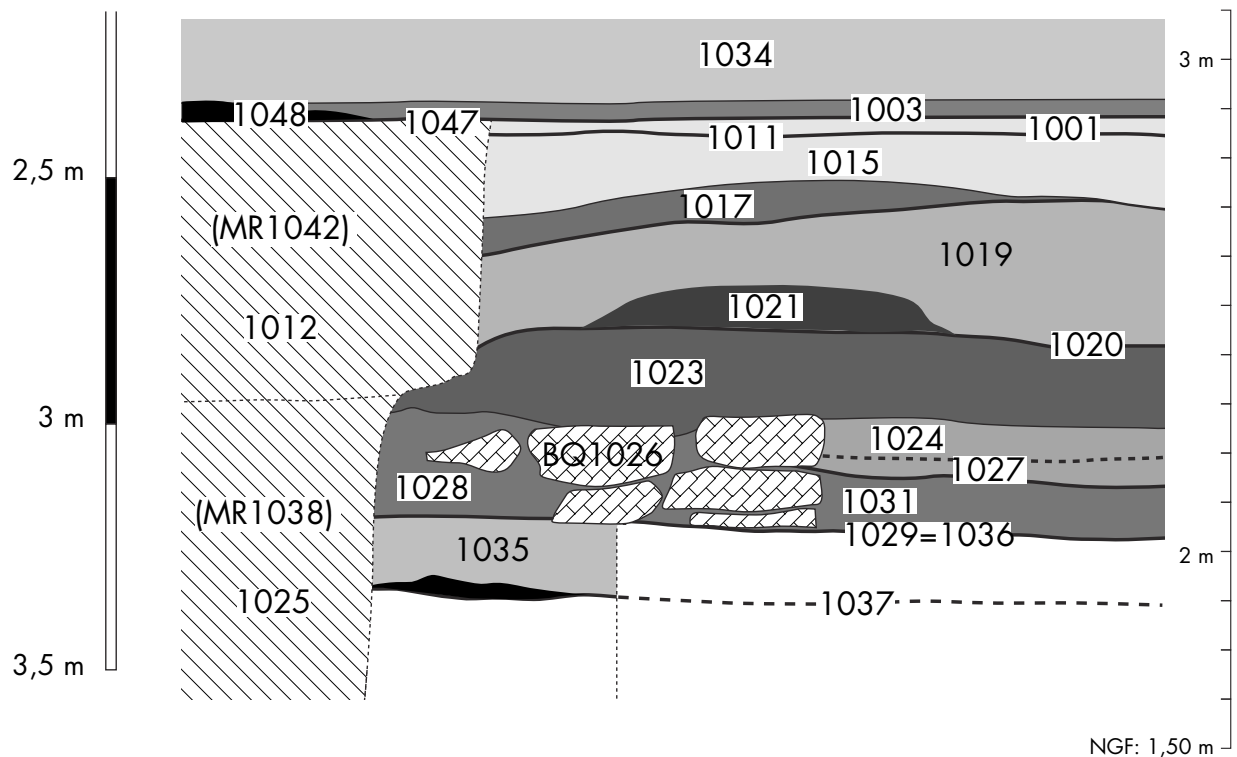

11 Stratigraphie est-ouest du sondage 1 du Cailar à l'aplomb de la berme nord. grosses, la plupart plus petites (5 à $10 \mathrm{~cm}$ ); des poches de limon de couleurs diverses (grises, gris-jaune); des amas de tessons (surtout d'amphore massaliète) en tous sens et dans toute l'épaisseur. L'impression est celle d'un comblement rapide, constituant d'abord un tas au sud-ouest, puis s'étalant ensuite sur le reste de la surface du sondage.

\subsubsection{Mobiliers du dernier quart du $V^{e}$ s. av. n. ̀̀.}

\section{Us 1027}

- Inventaire: céramique: $70 \mathrm{fr}$; faune: 4 os, 5 coquillages.

- Comptages: cér. claire peinte: 2 fr.; cér. grise monochrome: 1 fr.; cér. attique: 8 fr.; cér. à pâte claire ancienne: 3 fr.; amphore étrusque: $1 \mathrm{fr}$; amphore massaliète: $53 \mathrm{fr}$; cér. non tournée régionale: $1 \mathrm{fr}$; dolium: $1 \mathrm{fr}$.

- Typologie:

amphore étrusque: amphore A-ETR 3C: 1 tesson.

amphore massaliète: amphore A-MAS ind. : 1 anse.

cér. attique à figures rouges : coupe sans tige AT-FR Ky13/14 : 1 décor (fig. 15, $\mathrm{n}^{\circ} 6$ ).

cér. attique à vernis noir: bol AT-VN 777-808: 2 bords (fig. 14, $\mathrm{n}^{\circ} 13$ ). cér. à pâte claire peinte: coupe à anses CL-MAS $425: 1$ bord (fig. 14, $\left.\mathrm{n}^{\circ} 15\right)$.

cér. à pâte claire ancienne: coupe à une anse CL-MAS 410: 1 bord.

cér. grise monochrome: GR-MONO ind. : 1 décor (fig. 14, $\mathrm{n}^{\circ}$ 14).

- Commentaire: Presque dénué de céramique non tournée, ce petit lot provenant du remblai 1027 fait apparaître des catégories semblables à celles de la couche précédente, dans laquelle sont attestées la plupart des formes ici présentes. Les amphores étrusques $3 \mathrm{C}$, à pâte brun-rouge et épais engobe blanc, sont présentes couramment en Gaule méridionale entre 530 et 400 (Py 1985) et des éléments s'en rencontrent encore à Lattes jusqu'au milieu du IV e s. (Py 2001, 20-23).

\section{Us 1024}

- Inventaire: céramique: 197 fr.; faune: 13 os, 1 coquillage; bronze: 1 fibule en $6 \mathrm{fr}$.

- Comptages: cér. attique: 4 fr.; cér. claire peinte: 9 fr.; cér. grise monochrome: 2 fr.; cér. à pâte claire ancienne: 16 fr.; cér. commune tournée du Languedoc oriental: 2 fr.; mortier massaliète: 2 fr.; amphore massaliète: 155 fr.; amphore ibérique: 1 fr.; amphore grecque: 1 fr.; cér. non tournée régionale: $5 \mathrm{fr}$.

- Typologie :

amphore massaliète: bord A-MAS bd5: 2 bords (fig. 14, $\mathrm{n}^{\circ}$ 19); amphore A-MAS ind.: 5 anses.

cér. attique à vernis noir: bol AT-VN 777-808: 1 bord (fig. 14, $\mathrm{n}^{\circ} 16$ ); coupe AT-VN ind. : 1 anse, 1 décor (fig. 15, $n^{\circ} 4$ ).

cér. à pâte claire peinte: coupe-skyphos CL-MAS 429c: 1 bord (fig. 14, $\mathrm{n}^{\circ} 18$ ); coupe à anses CL-MAS 432: 1 bord (fig. 14, $\mathrm{n}^{\circ} 19$ ); cruche CL-MAS ind. : 1 décor (fig. $21, \mathrm{n}^{\circ} 4$ ); coupe CL-MAS ind. : 1 fond, 1 anse.

cér. à pâte claire ancienne: olpé CL-MAS 521/522: 1 fond; cruche CL-MAS ind. : 1 anse.

mortier massaliète: mortier CL-MAS ind. : 1 fond.

cér. grise monochrome: jatte GR-MONO 6d: 1 décor (fig. 14, ${ }^{\circ} 20$ ).

- Commentaire: On retrouve dans la partie supérieure du remblai nombre de caractères déjà observés: formes de bord d'amphore massaliète, bol attique à vernis noir à lèvre déversée, rareté des vases non tournés, etc. On soulignera la présence de deux formes intéressantes de céramique claire massaliète: le skyphos étroit à profil tendu CL-MAS 429c, forme absente de Dicocer[1] mais récemment définie à Lattes, où elle n'est actuellement attestée que dans des contextes de la deuxième moitié du $\mathrm{V}^{\mathrm{e}} \mathrm{s}$. (Py 2001, 693); et la coupe-skyphos à profil continu et paroi mince CL-MAS 432, forme rare imitée de l'attique et connue à Marseille 


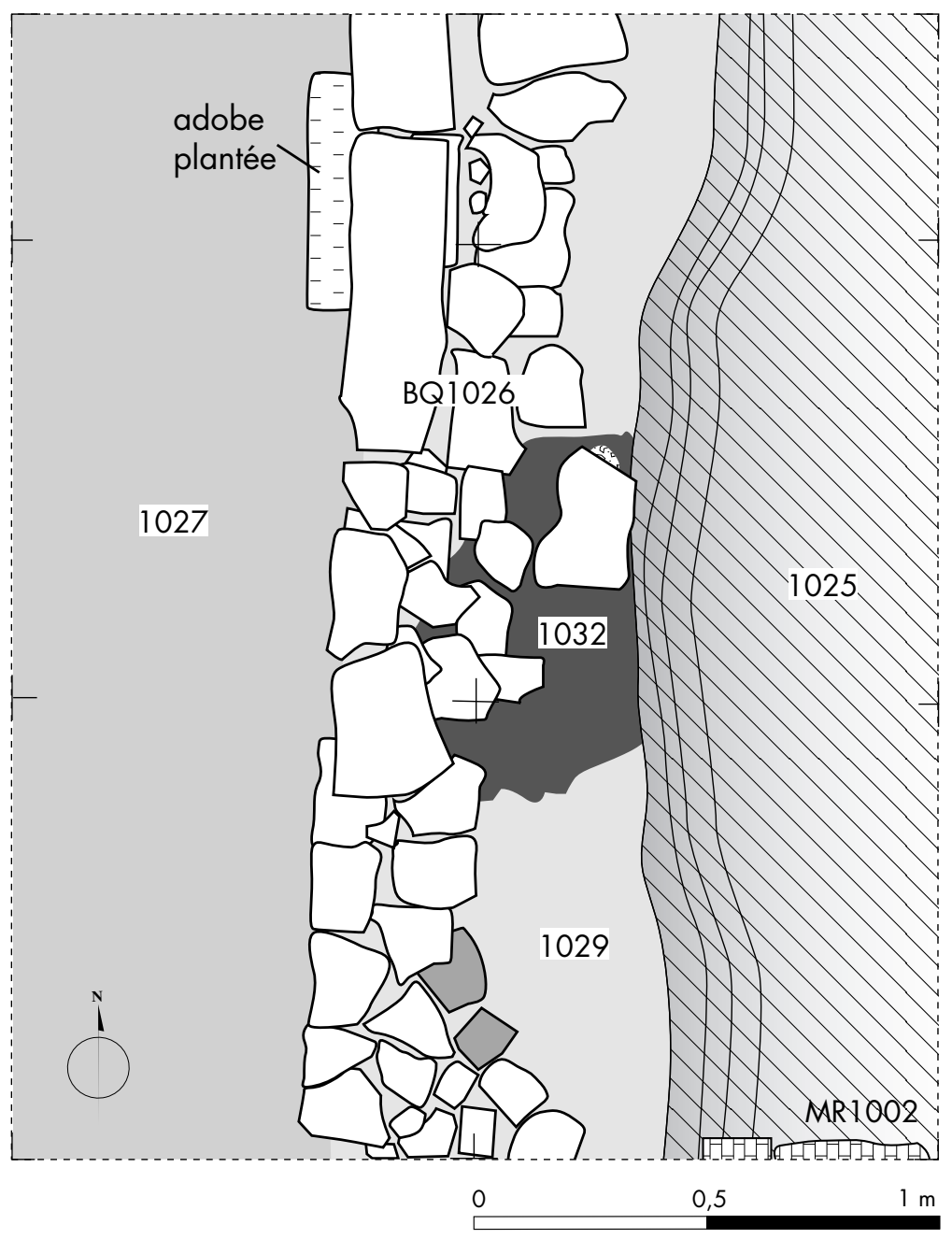

12 Le Cailar, sondage 1. Plan de la banquette BQ1026. cér. attique à vernis noir: coupe sans tige AT-VN 483-492: 1 bord, 1 décor; couvercle de lékanis AT-VN 1226-1239: 1 décor (fig. 15, $\mathrm{n}^{\circ} 8$ ).

cér. à pâte claire peinte: coupe à une anse CL-MAS 412: 1 bord (fig. 20, $\mathrm{n}^{\circ} 1$ ); coupe à anses CL-MAS 425: 2 bords; cruche CL-MAS 520/540: 1 fond, 1 anse; cruche CL-MAS 526: 1 bord; coupe CL-MAS ind. : 1 anse; cruche CL-MAS 524: 1 fond, 2 décors (fig. 21, $\mathrm{n}^{\circ} 1$ ); cruche CL-MAS 530/560: 2 décors (fig. $21, \mathrm{n}^{\circ} 2$ et 3).

cér. à pâte claire ancienne: gobelet à une anse CL-MAS 450: 1 bord (fig. 20, $\mathrm{n}^{\circ} 2$ ); olpé CL-MAS 521: 1 tesson; cruche CL-MAS ind.: 1 fond.

cér. commune tournée du Languedoc oriental: urne CCT-LOR $1: 1$ bord (fig. 20, $\mathrm{n}^{\circ} 3$ ); urne sans col CCT-LOR $3: 1$ anse. cér. non tournée régionale: coupe CNT-LOR C2: 2 bords (fig. 20, $\mathrm{n}^{\circ}$ 5); urne CNT-LOR U5a: 1 bord (fig. 20, $\mathrm{n}^{\circ}$ 6); couvercle CNT-LOR V2c: 1 bord (fig. $20, \mathrm{n}^{\circ} 4$ ); CNT-LOR ind. : 2 fonds.

dolium : bord DOLIUM bd10b : 1 bord; cordon lisse : 2 décors.

- Commentaire: Le mobilier relativement abondant livré par cette strate de dépotoir contient plusieurs éléments intéressants. Parmi les objets, une fibule fragmentaire (fig. $16, \mathrm{n}^{\circ} 4$ ) relève sans doute du type 9 de Tendille 1978, 89-93, que l'on rencontre dans le Midi de la fin du Ve s. (cf. Py 1992, fig. 46, n 14) au début du $\mathrm{III}^{\mathrm{e}} \mathrm{s}$. Un bouton bombé et creux à bélière, orné d'un liseré sur le pourtour (fig. 16, $\mathrm{n}^{\circ}$ 6), n'est pas sans évoquer certaines appliques d'Ensérune (Jannoray 1955, pl. LVII, 5). Quant à la molette en basalte, elle est faite dans un matériau particulier (lave gris clair, friable, à nombreuses inclusions blanches) que l'on a identifié récemment comme provenant du Latium ou de l'Étrurie: voir plusieurs exemples à Lattes aux $\mathrm{V}^{\mathrm{e}}$ et $\mathrm{IV}^{\mathrm{e}} \mathrm{s}$. (Reille 1999, 521) et une table à Montlaurès, non datée (Reille 2001, 204).

(Bats 1993), mais dont c'est à notre connaissance le premier exemplaire attesté en Languedoc dans cette technique.

\section{Us 1023}

- Inventaire: céramique: 809 fr.; 1 marque lambda en creux sans cartouche (fig. $20, \mathrm{n}^{\circ} 8$ ) et 1 marque peinte illisible (fig. 20, $\mathrm{n}^{\circ} 7$ ) sur amphore massaliète; faune: 53 os, 3 coquillages (moules); bronze: 1 arc de fibule à section ronde épaisse; 1 anneau ouvert à extrémités recouvrantes (fig. 16, $\mathrm{n}^{\circ} 5$ ); 1 bouton rond bombé à bélière (fig. 16, $\mathrm{n}^{\circ} 6$ ); terre: 1 fr. de corps de chenet inorné (brûlé); 2 fr. de torchis; pierre: 1 molette à profil biseauté en basalte ( 5 fragments) (fig. 17 , $\left.\mathrm{n}^{\circ} 2\right)$.

- Comptages : cér. pseudo-attique: 1 fr.; cér. attique: 5 fr.; cér. claire peinte : 50 fr.; cér. commune tournée du Languedoc oriental: 13 fr.; cér. à pâte claire ancienne : 29 fr.; amphore grecque : 2 fr.; amphore massaliète: 636 fr.; cér. non tournée régionale : 34 fr.; dolium: $39 \mathrm{fr}$.

- Typologie:

amphore massaliète: bord A-MAS bd4: 1 bord (fig. 20, $\mathrm{n}^{\circ}$ 9); bord A-MAS bd5: 19 bords (fig. 20, $\mathrm{n}^{\circ}$ 10); bord A-MAS bd6: 2 bords (fig. 20, $\mathrm{n}^{\circ} 11$ ); A-MAS ind. : 3 bords, 7 fonds, 24 anses.
Les amphores, presque toutes massaliètes, présentent à travers la typologie des bords (fig. 20, $n^{\circ} 9$-11) un faciès de transition: l'essentiel (19 ex. sur 23) appartient au type bd5, tandis que l'on relève un bord bd4 caractéristique du $\mathrm{V}^{\mathrm{e}} \mathrm{s}$. et 2 bords bd6 dont le développement caractérisera plutôt le $\mathrm{IV}^{\mathrm{e}} \mathrm{s}$. Une marque lambda en creux sans cartouche (fig. 18, $\mathrm{n}^{\circ} 3$ ) fournit un indice chronologique supplémentaire: son style la rapporte à la série la plus ancienne (groupe A1) et selon le système proposé à partir des fouilles de Lattes, elle daterait des environs de 407 av. n. è. (type $\lambda 1$ : Py 2001, 210, $\mathrm{n}^{\circ}$ 1137-1138, et 213-216).

Le couvercle de lékanis en céramique attique pourrait constituer un témoin attardé: le décor d'arêtes rayonnantes autour du pied (fig. 15, $\mathrm{n}^{\circ}$ 8) renvoie en effet à des exemplaires ordinairement datés de la première moitié du $\mathrm{V}^{\mathrm{e}} \mathrm{s}$. (cf. Sparkes 1970, $\mathrm{n}^{\circ}$ 1234). Des spécimens semblables existent notamment à Lattes (Py 2001, n 2071) et à Ensérune (Dubosse 1998, pl. 40, $\mathrm{n}^{\circ}$ 1). 
La céramique à pâte claire peinte se distingue ici par la présence de plusieurs vases fermés abondamment décorés. Une grande cruche à embouchure large, sans doute de type CL-MAS 524 (à moins qu'il ne s'agisse d'un cratère) porte sur le col un motif floral (fig. 21, ${ }^{\circ} 1$ ) peu usité dans le subgéométrique rhodanien, mais que l'on pourra rapprocher d'un exemplaire de Lattes des environs de 400 (Py 2001, $\mathrm{n}^{\circ}$ 3805). D'autres fragments de panse (fig. $21, \mathrm{n}^{\circ} 2$ et 3 ) présentent une ornementation plus compatible avec le groupe rhodanien, l'exemplaire $\mathrm{n}^{\circ} 2$, caractérisé par une peinture brun-noir à reflets métalliques, pouvant pour sa part provenir d'un atelier de la région nimoise (des productions identiques sont connues par exemple à Nimes: Py 1981, fig. 28, $n^{\circ}$ 5-7, vers 425-375; ou au Marduel: par exemple Py 1992, fig. 25, $\mathrm{n}^{\circ} 18$, vers 440-420).

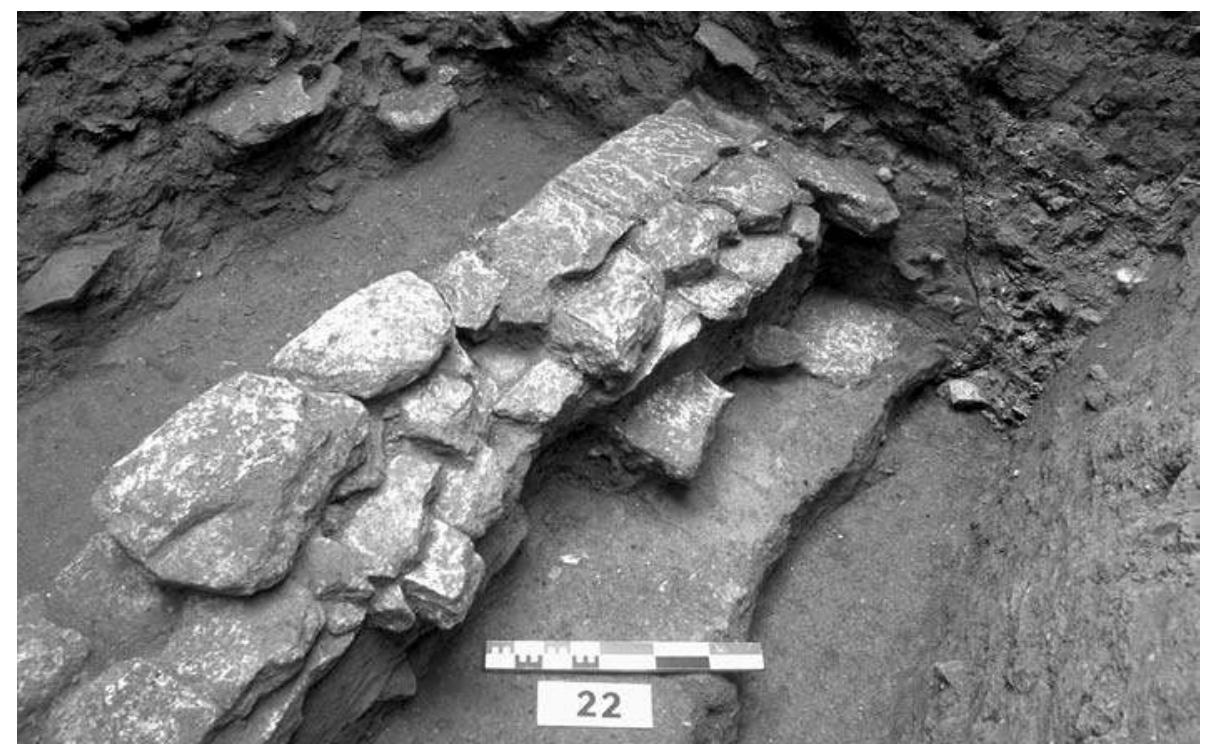

-13 Le Cailar, sondage 1. Vue de la face interne non parementée de la banquette BQ1026.

\subsubsection{Niveaux du premier quart du IV ${ }^{e}$ s. av. n. ̀̀.}

Après la phase de remblaiement de la fin $\mathrm{du}^{\mathrm{e}} \mathrm{s}$. vient, au début du IV ${ }^{\mathrm{e}} \mathrm{s}$., une nouvelle phase d'habitat marquée par la destruction de la maison antérieure et la construction d'une nouvelle habitation dont on a repéré l'angle d'une pièce ouvrant au sud par une porte.

De la phase de destruction témoignent la spoliation presque totale du solin du mur MR1038 et le remplissage de sa tranchée d'épierrement (us.1025) (fig. 8 à 13). Ce comblement est constitué de terre grise avec de nombreux charbons de bois, des tessons en tous sens, notamment plantés le long de la limite est, mais aussi des petits cailloux (surtout des éclats de pierre tendre) qui témoignent de l'épierrement du mur. Le bord est irrégulier: quasiment vertical au sud, il est sinueux et plus incliné au centre du sondage et redevient vertical au nord. Dans la partie centrale, on a l'impression qu'il y a eu un effondrement du bord; une pierre a glissé de la banquette BQ1026 et présente un fort pendage à la lisière de la tranchée. À la limite inférieure de la fouille (qui ne représente pas le fond de la tranchée, non atteint) les sédiments apparaissent différents selon les endroits: amas de limon avec adobes fondues au centre, apport charbonneux au sud, terre cendreuse pulvérulente au nord.

La cloison orientale est ensuite reconstruite (MR1042) à l'aplomb du mur antérieur, avec néanmoins un léger décalage vers l'ouest. Ce refend sera épierré en totalité et la tranchée comblée au milieu du IV ${ }^{\mathrm{e}} \mathrm{s}$. (us.1012) (fig. 11 et 12).

Le mur MR1042 s'appuyait au sud contre une façade interrompue par une large porte (PR1043) (fig. 9). Seule la par-

tie orientale de cette façade (MR1002) est conservée en élévation. Elle est formée d'une fondation en pierres non équarries de petites dimensions, liées par une terre meuble (us.1045), sur laquelle s'appuie une élévation de pierres plates posées en panneresse (us.1002). La plupart des blocs sont en calcaire coquillier fin, quelques-uns en calcaire dur. Deux grands blocs taillés en calcaire coquillier fin forment le piédroit de la porte. Le bloc d'angle inférieur (bloc $\mathrm{n}^{\circ} 1$ ) est disposé à plat sur la fondation, le deuxième (bloc $\mathrm{n}^{\circ} 2$ ) est posé de chant sur le premier, légèrement décalé vers l'est (fig. 22) ${ }^{21}$.

À l'ouest, le deuxième piédroit de la porte PR1043 et le tronçon de mur qui lui était lié (MR1044) ont été spoliés à l'aide d'une tranchée d'épierrement horizontale progressant d'ouest en est, peut-être à l'occasion du creusement d'une tombe adjacente (fig. 9 et 22). Le remplissage de cette excavation en tunnel (us.1046), de nature sableuse et de couleur grise, est très meuble et contient des tessons récents (notamment un bord d'amphore Gauloise 1 et des tessons de céramique commune kaolinitique des $\mathrm{XI}^{\mathrm{e}}-\mathrm{XII}^{\mathrm{e}} \mathrm{s}$.).

Le sol d'occupation correspondant à la mise en place de cette architecture (us.1020) est en légère pente vers le nordest. Fait de terre battue tachée de cendres, ce sol est concrétisé par deux foyers construits (fig. 23). Au nord, il s'agit du foyer FY1021, plaque arrondie de limon argileux jaune mêlé de particules de calcaire et de petits galets de rivière, d'une épaisseur de $5 \mathrm{~cm}$; la surface est rubéfiée au sommet et au centre. Au sud-est, c'est le foyer FY1022, composé de limon argileux jaune durci par le feu. On y remarque des traces rubéfiées d'un diamètre de $20 \mathrm{~cm}$ au centre. La plaque de forme grossièrement arrondie est entourée au sud par une bordure de petits blocs de pierre, à l'est par des tes- 
1

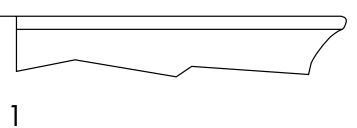

?

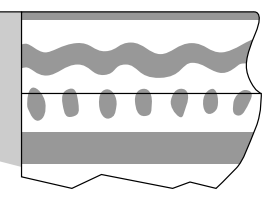

3

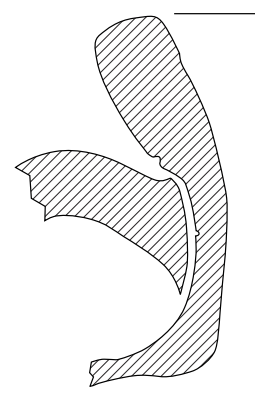

5
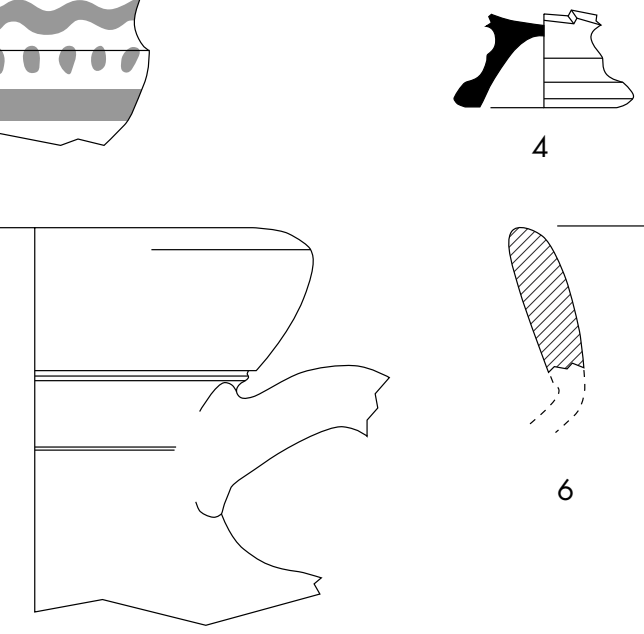

4
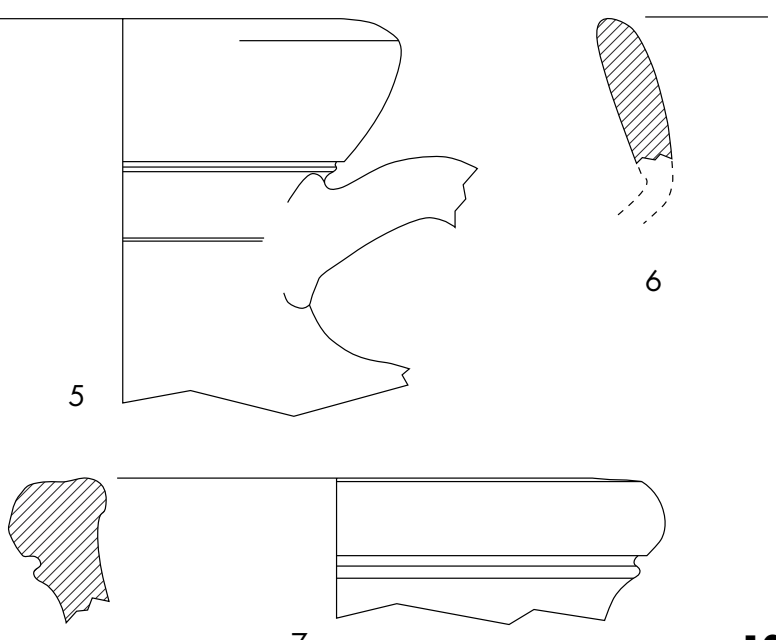

7
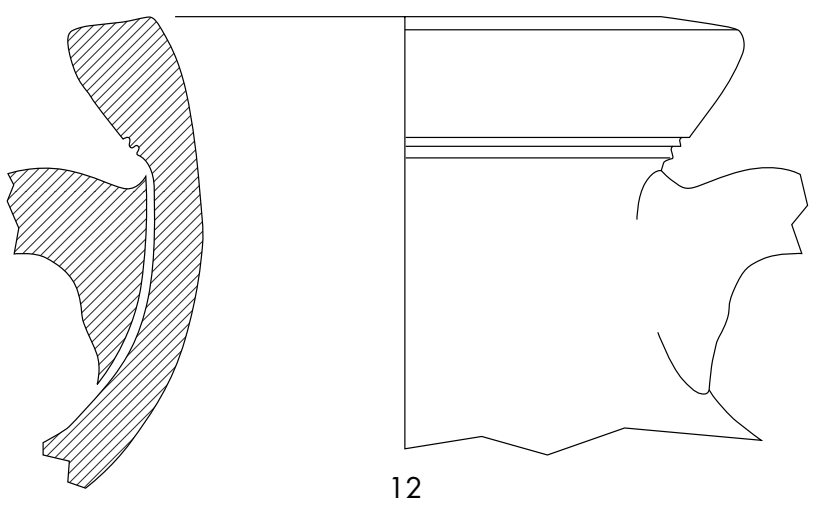

1
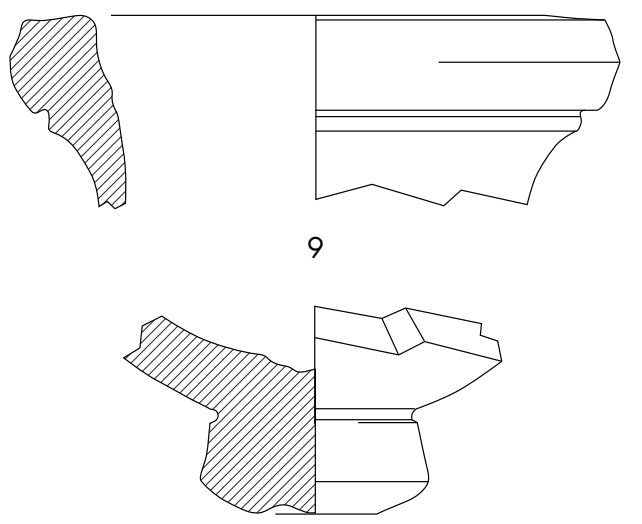

10

1031

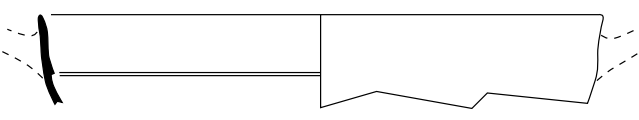

17

16
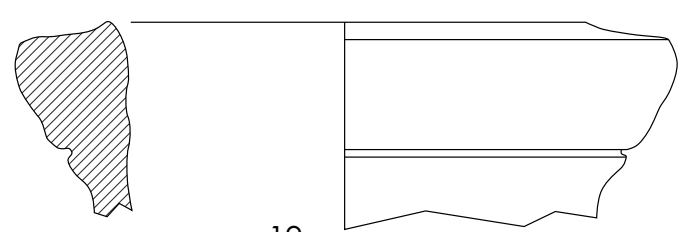

20

1024

14 Le Cailar, sondage 1. Mobiliers céramiques significatifs des Us 1024, 1027, 1028, 1031, 1032 et 1035. 


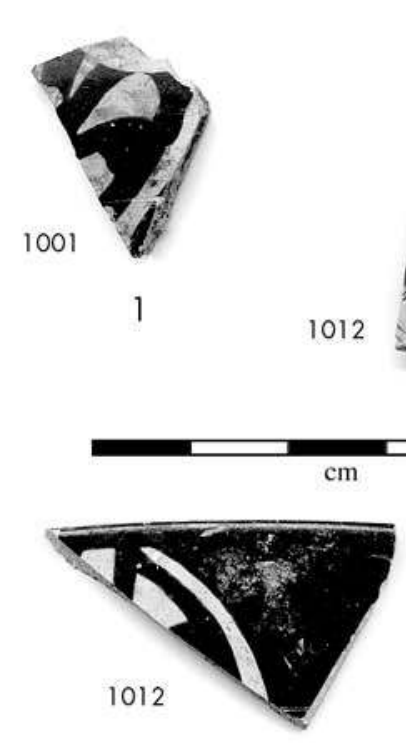

5

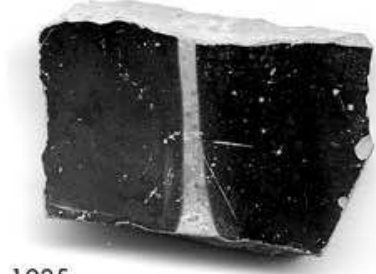

1025

7

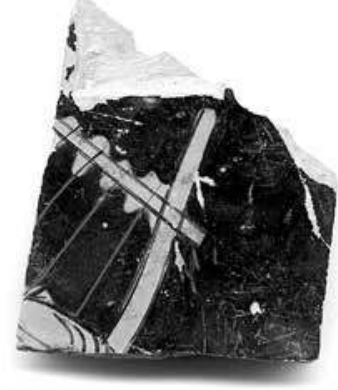

2
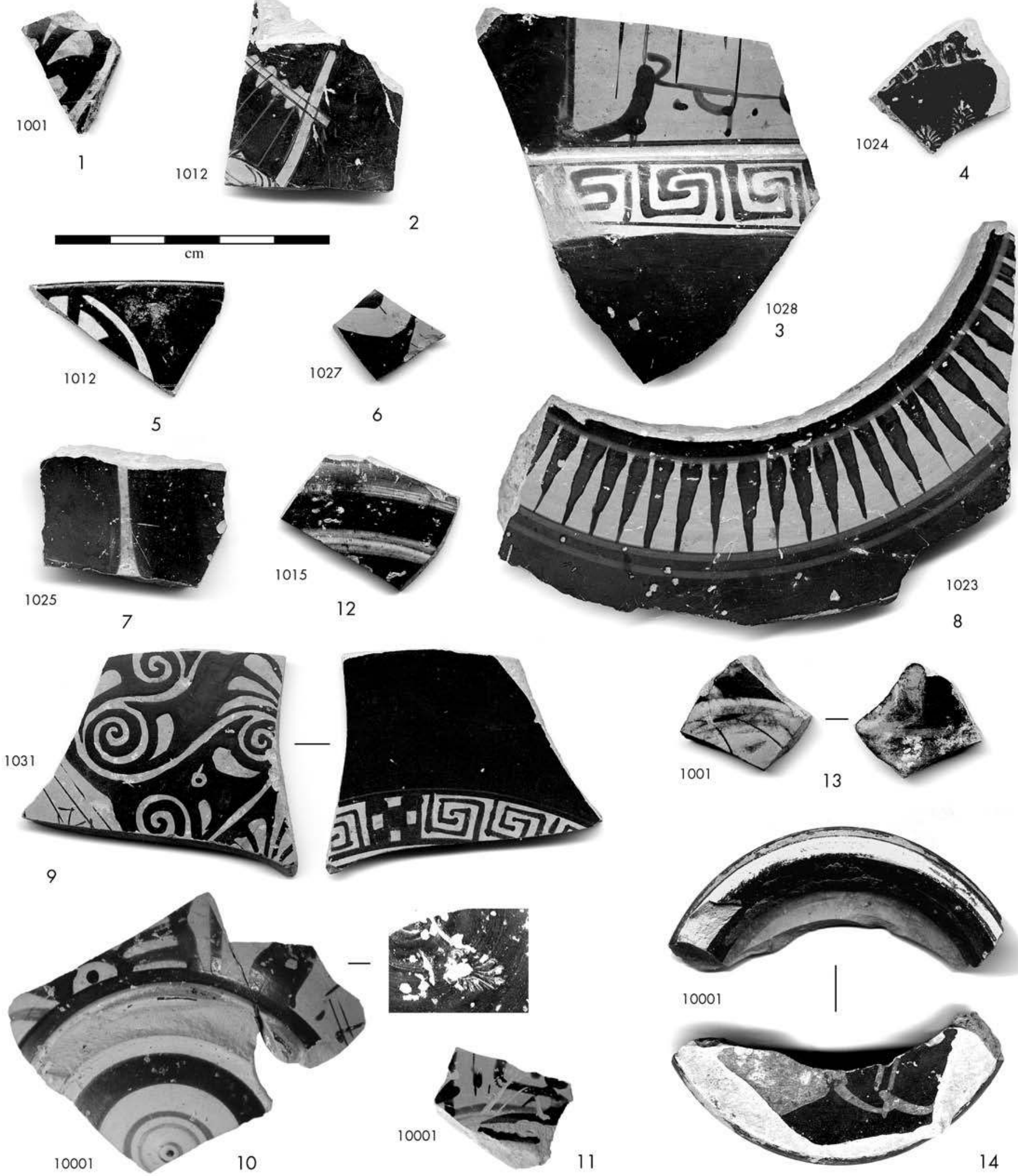

12
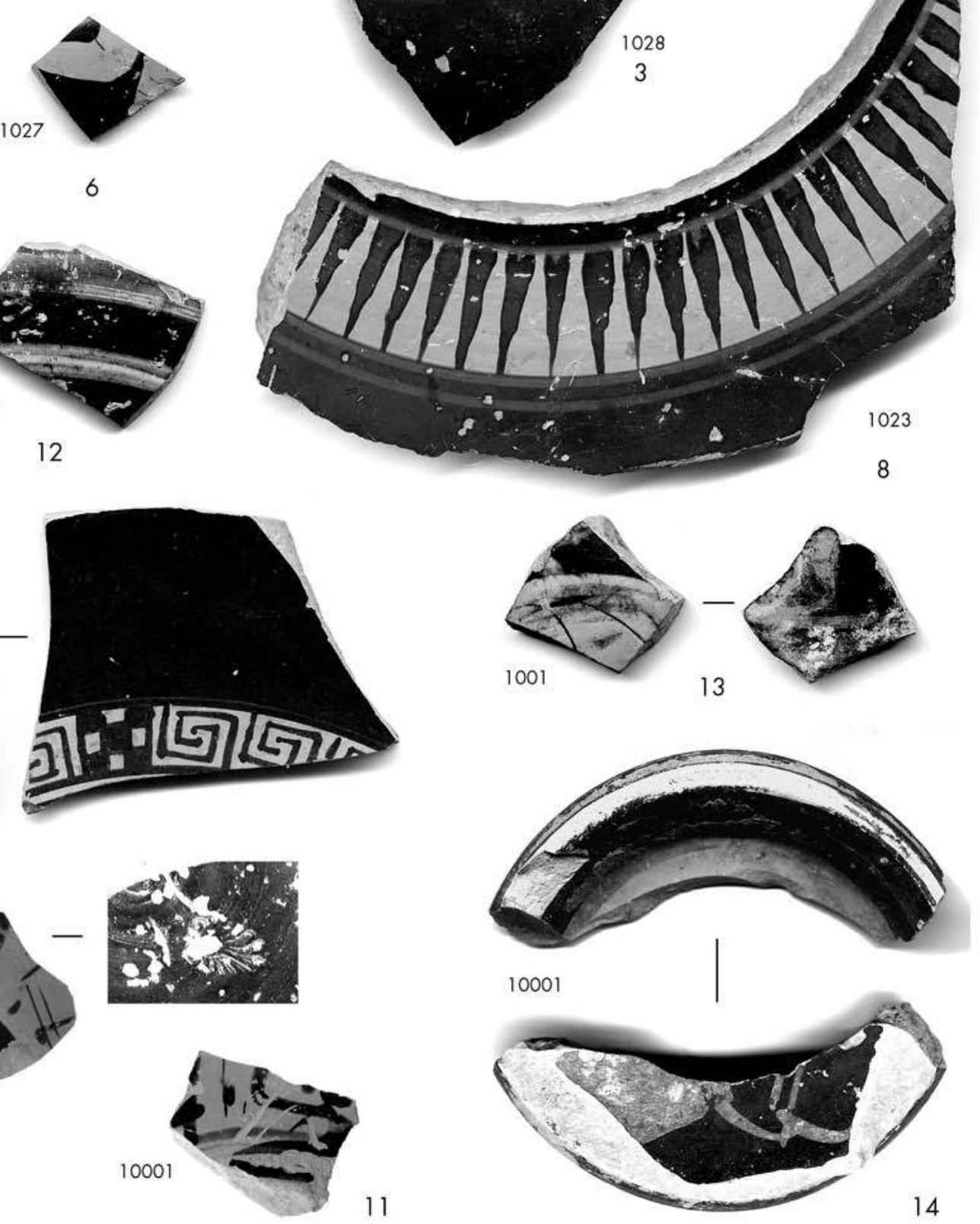

11

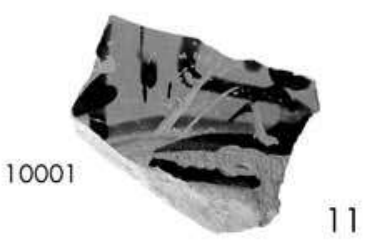

14

115 Le Cailar, céramique attique ( $\left.n^{\circ} 1-11\right)$, italique (?) ( $\left.n^{\circ} 12\right)$ et pseudo-attique ( $\left.n^{\circ} 13-14\right)$. 


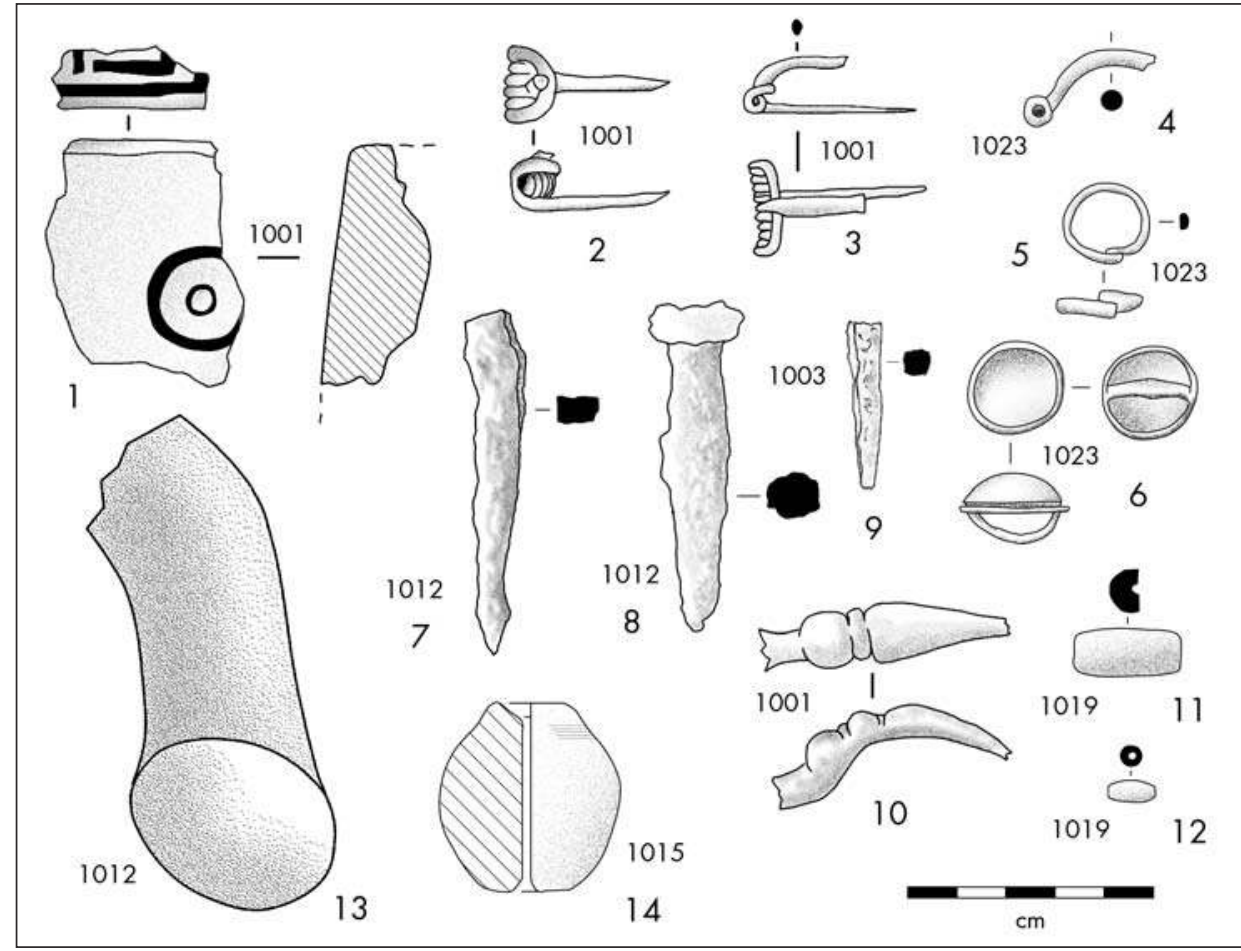

116 Le Cailar, sondage 1. Petit mobilier en terre $\left(n^{\circ} 1,13,14\right)$, bronze $\left(n^{\circ} 2-6\right)$, fer $\left(n^{\circ} 7-10\right)$, émail $\left(n^{\circ} 11\right)$ et corail $\left(n^{\circ} 12\right)$

sons d'amphore plantés et au sud-est par un gros galet. Sur la plaque, deux zones de cendre pure blanche incluant de gros charbons de bois et des graines carbonisées représentent les restes du dernier feu.

Le sol 1020 est ensuite recouvert par une épaisse couche de rejets provenant apparemment de l'incendie d'un secteur voisin (les matériaux n'ayant apparemment pas brûlé sur place). Ce remblai (us.1019) est composé majoritairement de cendres et de très gros charbons de bois (dont certains proviennent de petites poutres équarries). On trouve de très nombreux tessons par lits successifs, surtout d'amphore massaliète. La couche s'épaissit à la fois vers le nord et vers l'est, du fait du pendage de la surface sous-jacente 1020. Ce niveau est comme le précédent recoupé à l'est par la tranchée 1012. Il s'appuie au sud-est contre la pierre verticale servant de piédroit au mur MR1002, avec un blocage de cailloux et de tessons au contact de la pierre (fig. 22).

Un nouveau sol de terre battue (us.1016) prend appui sur le remblai 1019. Il supporte dans la partie sud du sondage un foyer construit (FY1018) constitué par une plaque de limon argileux reposant sur un épandage de cendres (fig. 23 et 24). La forme est allongée et irrégulière et l'épaisseur va de 1 à $3 \mathrm{~cm}$. Cette plaque est formée de limon argileux assez pur, de couleur beige, incluant quelques petits charbons.

Au-dessus du sol et de la plaque-foyer se forme progressivement une sédimentation consécutive à l'occupation domestique des lieux (us.1017). On observe des poches de cendre pure résultat de l'activité de foyers. Des tessons épars sont éclatés par le feu, tandis que de gros fragments de céramique (dont plusieurs fragments d'une même amphore massaliète) sont recassés horizontalement sur place. Une pierre plate est incluse à ce niveau dans l'ouverture de la porte: il s'agit peut-être d'un élément de seuil.

\subsubsection{Mobiliers de la tranchée 1025 (fin Ve-début IV ${ }^{e}$ s. av. n. è.)}

\section{Us 1025}

- Inventaire: céramique: 676 fr.; 2 marques peintes (trait et points) sur amphore massaliète; faune: 89 os, 2 coquillages, 1 lot d'écailles et 1 vertèbre de poisson; bronze: 1 fibule incomplète en 5 fr.; fer: 1 scorie; terre: 4 fr. de torchis; 1 fr. de foyer construit lisse; 1 fusaïole; pierre: 1 fr. de bloc ou de stèle taillée (bloc $\mathrm{n}^{\circ} 3$, étudié ci-après par J.-Cl. Bessac).

- Comptages : cér. attique: 4 fr.; cér. pseudoattique: 9 fr.; cér. grise monochrome: 2 fr.; cér. claire peinte: 22 fr.; cér. commune grecque: 2 fr.; mortier massaliète: 3 fr.; cér. à pâte claire ancienne: 36 fr.; cér. commune tournée du Languedoc oriental : 6 fr.; amphore massaliète : 446 fr.; cér. non tournée type étang de Berre: 4 fr.; cér. non tournée régionale: 83 fr.; dolium: 59 fr.

- Typologie:

amphore massaliète: bord A-MAS bd5: 15 bords (fig. 19, $\mathrm{n}^{\circ} 10$ ); amphore A-MAS ind.: 2 fonds, 10 anses; bord A-MAS ind.: 2 bords.

cér. attique à figures rouges: cratère AT-FR Cr4: 1 décor (fig. 15, $\mathrm{n}^{\circ} 7$ ). cér. attique à vernis noir: coupe sans tige AT-VN 483-492: 1 décor (fig. 19, $\mathrm{n}^{\circ} 3$ ); bol AT-VN 777-808: 2 bords (fig. 19, $\mathrm{n}^{\circ} 1$ et 2 ).

cér. pseudo-attique: coupe sans tige PSEUDO-AT 493: 1 bord (fig. 19, $\left.\mathrm{n}^{\circ} 4\right)$; PSEUDO-AT ind. : 1 fond.

cér. grise monochrome: coupe carénée GR-MONO 3 : 1 tesson; coupeskyphos GR-MONO 5f: 1 tesson.

cér. à pâte claire peinte : coupe carénée CL-MAS 222: 2 bords (fig. 19, $\mathrm{n}^{\circ} 7$ ); coupe à une anse CL-MAS 410: 2 bords, 2 anses (fig. 19, $\mathrm{n}^{\circ} 5$ ); coupe à anses CL-MAS 425: 1 bord; gobelet à une anse CL-MAS 453a: 1 bord (fig. $19, \mathrm{n}^{\circ} 6$ et fig. $21, \mathrm{n}^{\circ} 6$ ); cruche CL-MAS ind.: 2 anses, 1 décor.

cér. à pâte claire ancienne: coupe à une anse CL-MAS 410: 1 bord (fig. 19, n 8); olpé CL-MAS 521: 3 fonds; cruche CL-MAS 541: 1 bord (fig. $19, \mathrm{n}^{\circ} 9$ ); CL-MAS ind.: 1 fond; cruche CL-MAS ind.: 1 anse.

mortier massaliète: mortier CL-MAS ind.: 3 fonds.

cér. commune tournée du Languedoc oriental: urne CCT-LOR 1 : 1 bord (fig. 19, $\mathrm{n}^{\circ} 11$ ), 1 fond (fig. 19, $\mathrm{n}^{\circ} 12$ ); jatte CCT-LOR $4: 1$ bord (fig. 19, $\mathrm{n}^{\circ} 13$ ).

cér. non tournée type étang de Berre: urne CNT-BER U1: 1 bord. cér. non tournée régionale: coupe CNT-LOR C2: 3 bords (fig. 19, $\left.\mathrm{n}^{\circ} 15\right)$; jatte CNT-LOR J1c: 1 bord; jatte CNT-LOR J1d: 1 bord 
(fig. 19, $\mathrm{n}^{\circ}$ 14); urne CNT-LOR U5 : 1 bord; couvercle CNT-LOR V2b : 3 bords (fig. 19, $\mathrm{n}^{\circ} 16$ ).

dolium: décors de cordon lisse: 5 ; bord indéterminé: 1.

- Commentaire: Cette couche de remplissage de tranchée d'épierrement contient un mobilier recouvrant la fin du $\mathrm{V}^{\mathrm{e}}$ et le début du $\mathrm{IV}^{\mathrm{e}}$ s. : vont dans le sens d'une telle datation l'unicité du type de bord d'amphore massaliète (bd5, 15 ex.), type qui domine à Lattes le répertoire des années 425-375 (Py 2001, 150151); les formes de la céramique attique à figures rouges (cratère en cloche, rarement antérieur à 425) et à vernis noir (la coupe sans tige de la classe délicate à ressaut interne et le bol à lèvre déversé, apparus vers le milieu du Ve s., ne se répandent vraiment qu'à partir de la fin de ce siècle; le décor de rosace incisée sur la coupe sans tige est très fréquent entre 425 et 375 : cf. Sparkes 1970 , pl. 50 et 51 ; Py 2001, $\mathrm{n}^{\circ}$ 1824-1829); ou encore l'abondance de la céramique commune tournée (CCTLOR). On relève par contre la rareté de la céramique grise monochrome et l'apparition de deux nouvelles catégories, absentes des niveaux antérieurs: la céramique pseudoattique (avec une forme ancienne de coupe sans tige: PSEUDO-AT 493) et l'urne rhodanienne (CNT-BER U1). On notera également la présence d'un fragment de bloc de calcaire coquillier finement taillé, semblant appartenir à la base d'un élément mouluré du même type que celui retrouvé dans une couche plus récente (cf. infra, us.1019).

\subsubsection{Mobiliers du premier quart du IV ${ }^{e}$.} av. n. ̀̀.

\section{Foyer FY1021}

- Inventaire: céramique : 8 fr.

- Comptages: amphore massaliète: 7 fr.; cér. non tournée régionale: $1 \mathrm{fr}$.

\section{Foyer FY1022}

- Inventaire: faune: 4 os; terre: 1 bord de vase en torchis (fig. 25, $\mathrm{n}^{\circ} 4$ ); céramique: 59 fr.

- Comptages : cér. à pâte claire peinte : 2 fr. ; cér. à pâte claire ancienne : $3 \mathrm{fr}$; cér. commune tournée du Languedoc oriental: $1 \mathrm{fr}$.; amphore massaliète: 48 fr.; cér. non tournée régionale: $2 \mathrm{fr}$; dolium: $3 \mathrm{fr}$.

- Typologie:

amphore massaliète: bord A-MAS bd5 (fig. 25, $\mathrm{n}^{\circ} 3$ ): 2 bords; amphore A-MAS ind. : 1 fond, 4 anses.

cér. à pâte claire peinte: coupe CL-MAS ind.: 1 fond; cruche CLMAS ind.: 1 décor (fig. 21, $\mathrm{n}^{\circ}$ 5).

17 Le Cailar, sondage 1. Bloc taillé en calcaire (1) et angle de table de meule à va-et-vient en basalte (2).

cér. commune tournée du Languedoc oriental: urne CCT-LOR 1 : 1 bord (fig. $25, \mathrm{n}^{\circ} 1$ ).

cér. non tournée régionale: coupe CNT-LOR C2: 1 bord (fig. 25, $\mathrm{n}^{\circ} 2$ ).

- Commentaire: Ce petit lot de céramique provenant des radiers des deux foyers disposés sur le sol 1020 livre des documents peu discriminants du point de vue chronologique. On relèvera seulement la forme particulière du bord d'urne CCT-LOR 1 qui, malgré une pâte caractéristique de cette production, rappelle plutôt les productions étruscolatiales du type COM-ETR 1a (Py 1993, 343) ou COM-IT 1a (ibid., 358) (voir aussi CCT-LOC 1b: ibid., 159). 


\section{Us 1019}

- Inventaire: céramique: 782 fr.; 1 marque sur col d'amphore massaliète en creux dans cartouche (effacée: A ?); 1 graffite sur anse d'amphore massaliète ( 2 barres horizontales) (fig. 20, ${ }^{\circ} 22$ ); faune: 95 os, 4 coquillages, 4 écailles de poisson; fer: 1 tige (de clou?); pierre: 1 concasseur sur galet; 1 bloc de pierre taillée mouluré (fig. $17, \mathrm{n}^{\circ} 1$ ); ivoire: 1 perle tubulaire (fig. $16, \mathrm{n}^{\circ} 11$ ); corail: 1 petite perle en forme de tonneau (fig. $16, \mathrm{n}^{\circ} 12$ ).

- Comptages: cér. attique: 7 fr.; cér. à pâte claire peinte: 14 fr.; cér. grise monochrome: 3 fr.; cér. à pâte claire ancienne: 25 fr.; cér. commune tournée du Languedoc oriental: 29 fr.; amphore grecque : 2 fr. ; autres amphores: 2 fr.; amphore étrusque: 4 fr.; amphore massaliète: $558 \mathrm{fr}$; ; cér. non tournée régionale : 54 fr.; dolium: 84 fr.

- Typologie:

amphore étrusque: amphore A-ETR 4A: 1 bord (fig. 20, $\mathrm{n}^{\circ} 24$ ).

amphore grecque: amphore A-GRE ind.: 1 anse (fig. 20, $\mathrm{n}^{\circ} 23$ ).

amphore massaliète: bord A-MAS bd5 : 16 bords (fig. 20, $\mathrm{n}^{\circ} 19$ ); bord A-MAS bd6: 3 bords (fig. 20, $n^{\circ} 20$ ); amphore A-MAS ind. : 2 fonds (fig. 20, n² 21), 19 anses.

cér. attique à figures rouges: cratère AT-FR Cr3 : 4 fr. (fig. 26, n 1-4). cér. attique à vernis noir: œnochoé AT-VN 101-104: 1 bord.

cér. à pâte claire peinte: coupe à une anse CL-MAS 410: 1 bord. (fig. 20, $\mathrm{n}^{\circ} 12$ ); cruche CL-MAS ind.: 1 fond, 3 anses.

cér. à pâte claire ancienne: cruche CL-MAS ind.: 1 fond, 2 anses.

cér. grise monochrome: œnochoé GR-MONO $8: 1$ anse.

cér. commune tournée du Languedoc oriental: urne CCT-LOR 1 : 1 bord (fig. 20, $\mathrm{n}^{\circ} 13$ ), 3 fonds; jatte CCT-LOR 4 : 1 bord.

cér. non tournée régionale: coupe CNT-LOR C2: 4 bords (fig. 20, $\left.\mathrm{n}^{\circ} 14,15\right)$; urne CNT-LOR ind. : 1 décor; jatte CNT-LOR J1d: 1 bord (fig. 20, $\mathrm{n}^{\circ} 16$ ); urne CNT-LOR U5 : 3 bords.

dolium: bord DOLIUM bd5a: 2 (fig. $20, \mathrm{n}^{\circ} 17$ ); bord DOLIUM bd8c: 1 (fig. 20, $\mathrm{n}^{\circ} 18$ ); décor de cordon imprimé : 1 ; décor de cordon lisse : 3 ; fond: 1 .

- Commentaire: La couche de remblai 1019 a donné un lot abondant de documents, dont plusieurs méritent commentaire. Un bloc de calcaire coquillier fin présentant une taille particulièrement soignée (fig. $17, \mathrm{n}^{\circ} 1$ ) est étudié ci-après par Jean-Claude Bessac (bloc $\left.{ }^{\circ} 4\right)$. Parmi les objets autres que les poteries, on remarque deux perles, l'une en ivoire, l'autre en corail: cette présence du corail au milieu de l'âge du Fer ( $V^{e}-I^{e}$ s.) est assez habituelle dans le Midi de la France, soit sous forme de bâtonnets bruts, soit sous forme d'objets finis ou d'éléments de décoration (voir en dernier lieu sur ce point Rondi-Costanzo 1997).

Les fragments d'amphores sont très nombreux dans ce niveau. La quasi-totalité provient comme précédemment de Marseille, avec encore une majorité de bords bd5, mais déjà trois bords bd6. Un graffite sur anse (fig. $20, \mathrm{n}^{\circ} 22$ ) est sans doute une marque commerciale (prix ? Cf. Py 2001,

I8 Le Cailar, sondage 1. Marques sur cols d'amphores massaliètes.

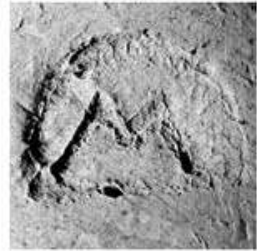

1015

1
234-235 et $\mathrm{n}^{\circ}$ 1267-1277). Une estampille sur col, assez dégradée (fig. $18, \mathrm{n}^{\circ} 4$ ), porte apparemment un alpha en creux inscrit dans un cartouche (groupe A2) et daterait des environs de 393 av. n. è. (Py 2001, 217, fig. 27). Les autres amphores sont très minoritaires: parmi elles, une amphore étrusque $4 \mathrm{~A}$ (fig. $20, \mathrm{n}^{\circ} 24$ ) est chronologiquement bien à sa place (cf. Py 1985 et en dernier lieu Py 2001, 38-40); une anse d'amphore (fig. 20, $\mathrm{n}^{\circ} 23$ ) à pâte dure, brun-rouge en épaisseur, brune en surface, à très fin dégraissant de mica blanc et de particules grises, pourrait être d'origine magnogrecque (Locres? Cf. infra, us.1018).

Quatre fragments (dont deux jointifs) de céramique attique à figures rouges appartiennent à un grand cratère en calice : trois d'entre eux (fig. 26, $\mathrm{n}^{\circ}$ 1-3) se rapportent au bas de panse bombé, limité à la partie supérieure par une grecque; le quatrième (fig. $26, \mathrm{n}^{\circ} 4$ ) fait partie d'un des tableaux figurés et montre un morceau de drapé. La forme (AT-FR Cr3) est faiblement diffusée en Occident entre le milieu du $\mathrm{V}^{\mathrm{e}} \mathrm{s}$. (voir notamment ci-dessus, us.1028) et le milieu du IV s. (Py 2001, 270-271).

\section{Foyer FY1018}

- Inventaire: céramique: 7 fr.; faune: 3 os.

- Comptages: cér. à pâte claire ancienne: 1 fr.; amphore massaliète: $4 \mathrm{fr}$; amphore magno-grecque : $1 \mathrm{fr}$; dolium: $1 \mathrm{fr}$.

- Typologie:

amphore magno-grecque: amphore A-MGR $7: 1$ bord (fig. $25, \mathrm{n}^{\circ} 5$ ). cér. à pâte claire ancienne: cruche CL-MAS 541: 1 bord.

- Commentaire: Le fragment de céramique le plus insigne provenant de ce radier de foyer est un bord d'amphore AMGR 7 à lèvre triangulaire très proéminente d'orientation quasiment parallèle à l'embouchure (fig. $25, \mathrm{n}^{\circ} 5$ ). La pâte est dure, rosée à cœur beige et contient un dégraissant épars de fin mica blanc. Cette sorte d'amphore a été identifiée à Ampurias dans un dépôt du deuxième quart du $I^{\mathrm{e}} \mathrm{s}$. et attribuée à la Grande-Grèce (Sanmarti 1995), et probablement à Locres par comparaison avec des rebuts de four retrouvés sur ce site (Barra 1989; 1992; voir aussi depuis Barra 1995). Des éléments semblables ont été recueillis à Lattes dans des contextes de la deuxième moitié du $\mathrm{V}^{\mathrm{e}} \mathrm{s}$. (Py 2001, n 366) ${ }^{22}$.

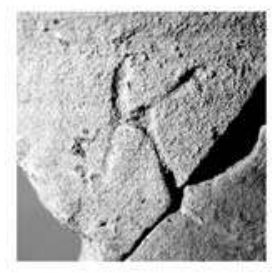

1017

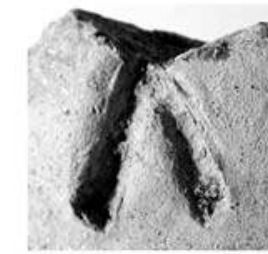

1023

3

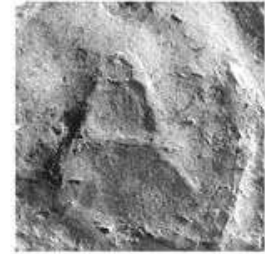

1019 


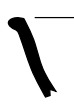

1

10

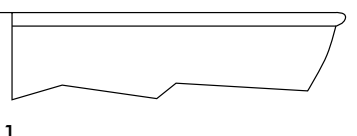

1

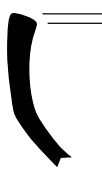

4
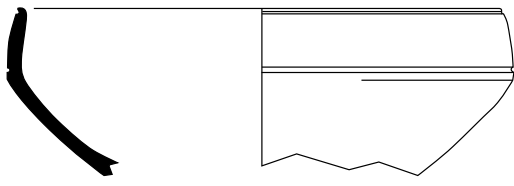

7
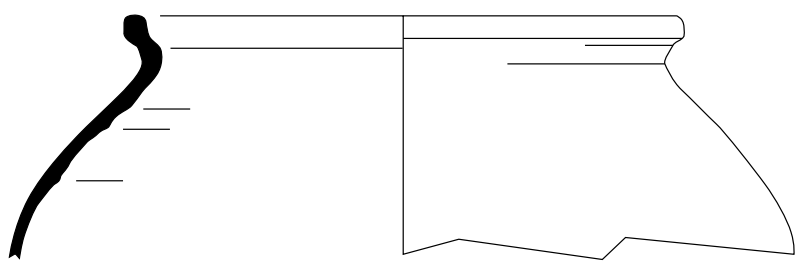

11

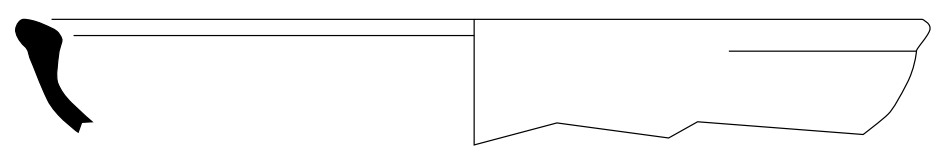

13

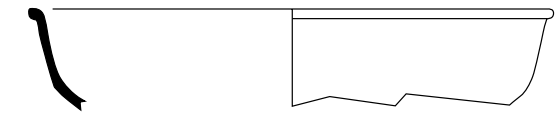

2

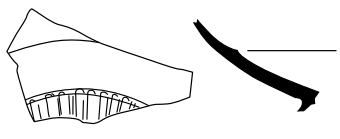

3

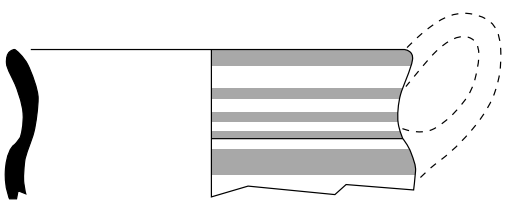

6

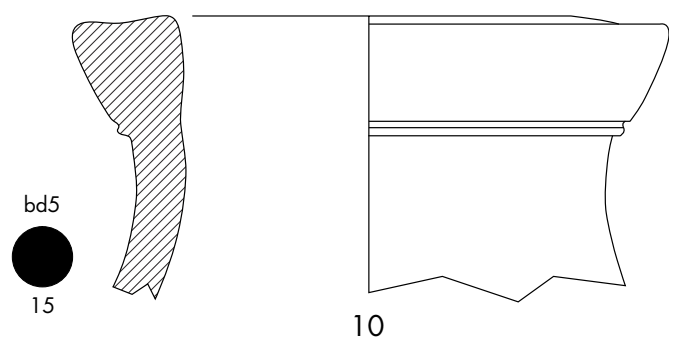

14

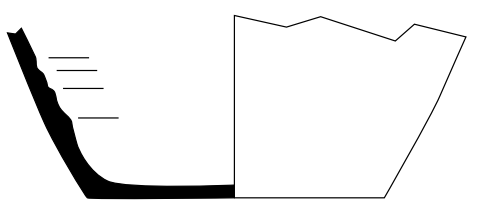

12

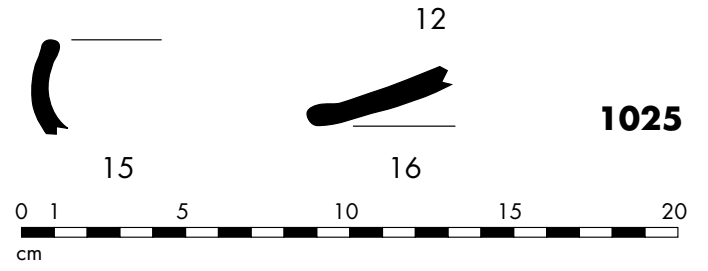

19 Le Cailar, sondage 1. Mobiliers céramiques significatifs de I'Us 1025.

\section{Us 1017}

- Inventaire: céramique: 158 fr.; 1 marque peinte et 1 estampille $\mathrm{K}$ sur cols d'amphore massaliète; faune: 21 os, 2 coquillages (moules), 1 mâchoire de dorade; fer: 3 scories.

- Comptages : cér. à pâte claire peinte: 8 fr.; cér. pseudo-attique: 1 fr.; cér. à pâte claire ancienne: 8 fr.; cér. commune tournée du Languedoc oriental: 5 fr.; amphore massaliète: 104 fr.; cér. non tournée régionale: $17 \mathrm{fr}$; dolium: $15 \mathrm{fr}$.

- Typologie:

amphore massaliète: bord A-MAS bd5: 3 bords; bord A-MAS bd6: 2 bords; amphore A-MAS ind.: 1 fond, 3 anses.

cér. pseudo-attique: coupe-skyphos PSEUDO-AT 581-608: 1 anse.

cér. à pâte claire peinte: coupe à une anse CL-MAS 410: 2 anses; cruche CL-MAS 520/540: 1 bord; coupe CL-MAS ind.: 1 anse.

cér. commune tournée du Languedoc oriental: urne sans col CCT-LOR $3: 1$ anse; jatte CCT-LOR $4: 1$ bord.

cér. non tournée régionale: urne CNT-LOR ind.: 2 décors dont un en incisions fines à trait simple sur le col (fig. 25, $\mathrm{n}^{\circ} 11$ ).

dolium: jarre DOLIUM ind. : 1 décor.
- Commentaire: Les amphores massaliètes issues de la sédimentation de sol 1017 présentent une répartition des types de bord entre bd5 et bd6 caractéristique du début du $\mathrm{IV}^{\mathrm{e}} \mathrm{s}$ (Py 2001, 164, fig. 20). Une estampille K en creux sans cartouche (groupe A1, type $\kappa 1$ ) (fig. $18, \mathrm{n}^{\circ} 2$ ), datable selon le système mis au point à Lattes des environs de 408 av. n. è. (Py 2001, 217), ne contredit pas cette chronologie compte tenu de la durée d'amortissement de l'amphore qui la supporte ${ }^{23}$. Parmi la vaisselle, un vase pseudo-attique se rapporte à une forme (PSEUDO-AT 581-608) qui apparaît aux environs de 400. Une anse de vase commun tourné semble se rapporter à une forme CCT-LOR 3, dont on sait maintenant que certains exemplaires pouvaient imiter les caccabai de la céramique commune grecque. On remarquera à ce propos que c'est à cette phase que les vases communs tournés sont les plus abondants (11,2\% de la vaisselle, contre $2,2 \%$ et $8,5 \%$ aux quarts de siècles précédents). 

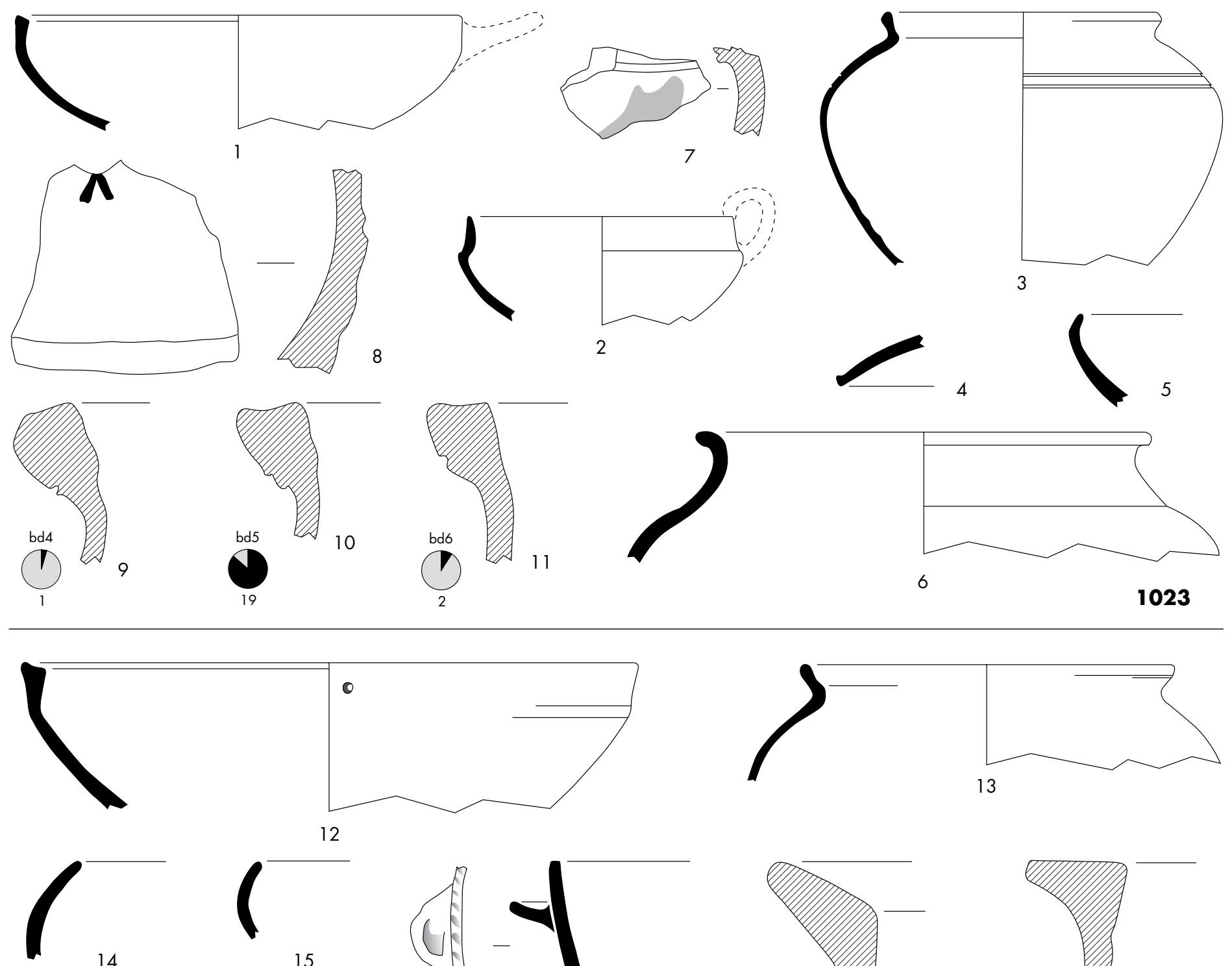

12
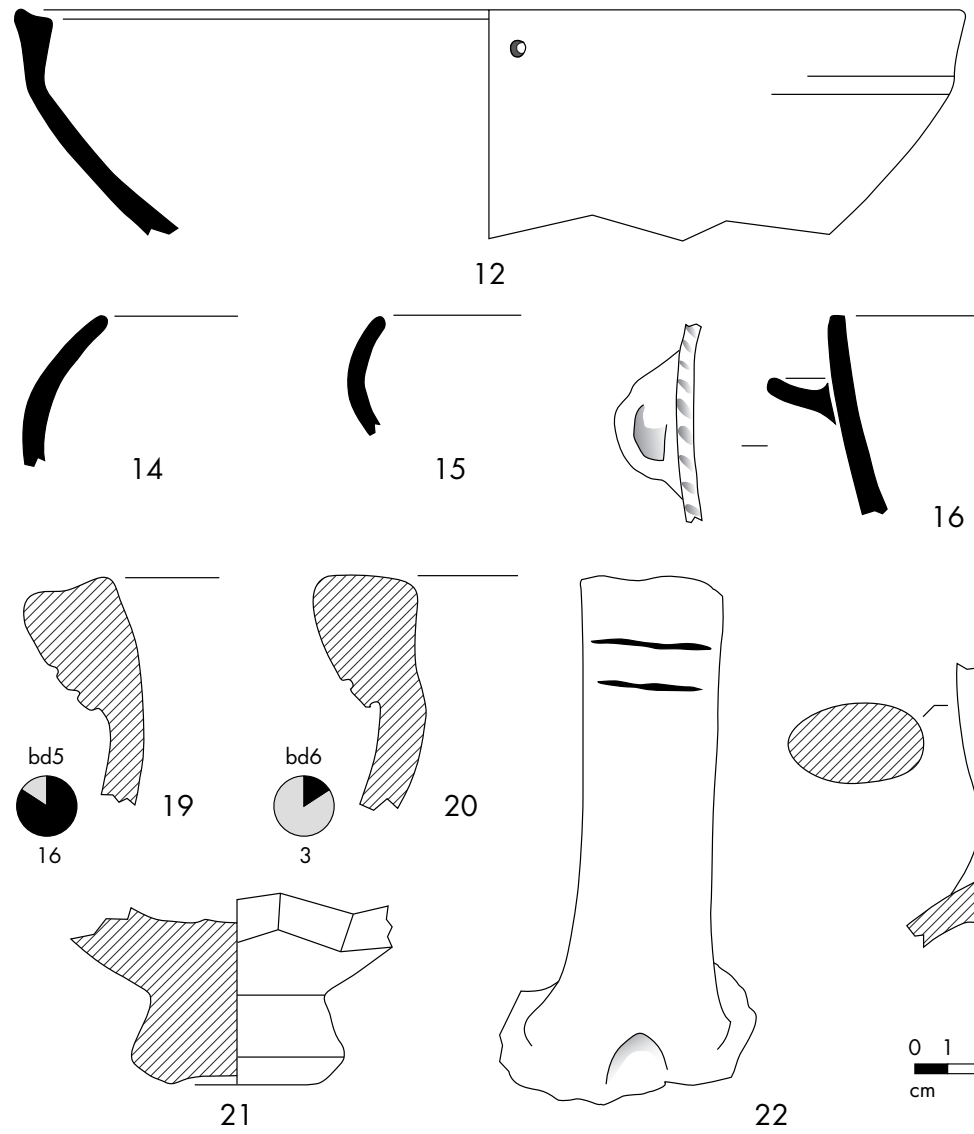

15
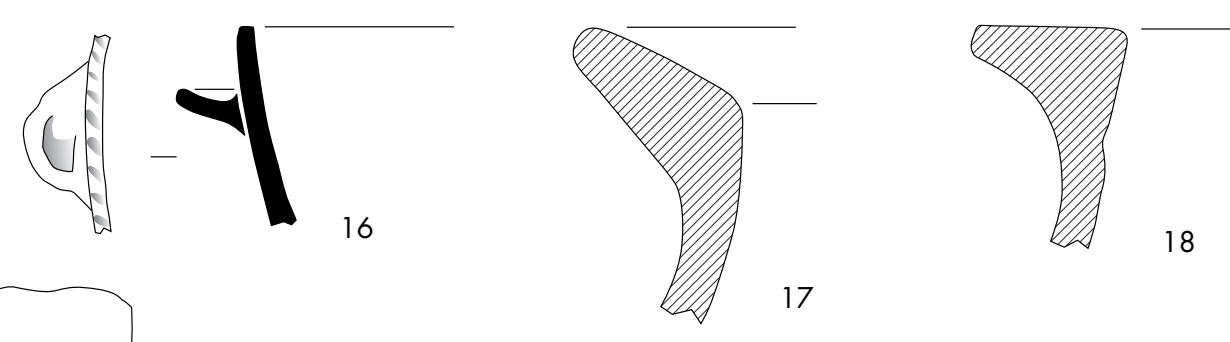

18

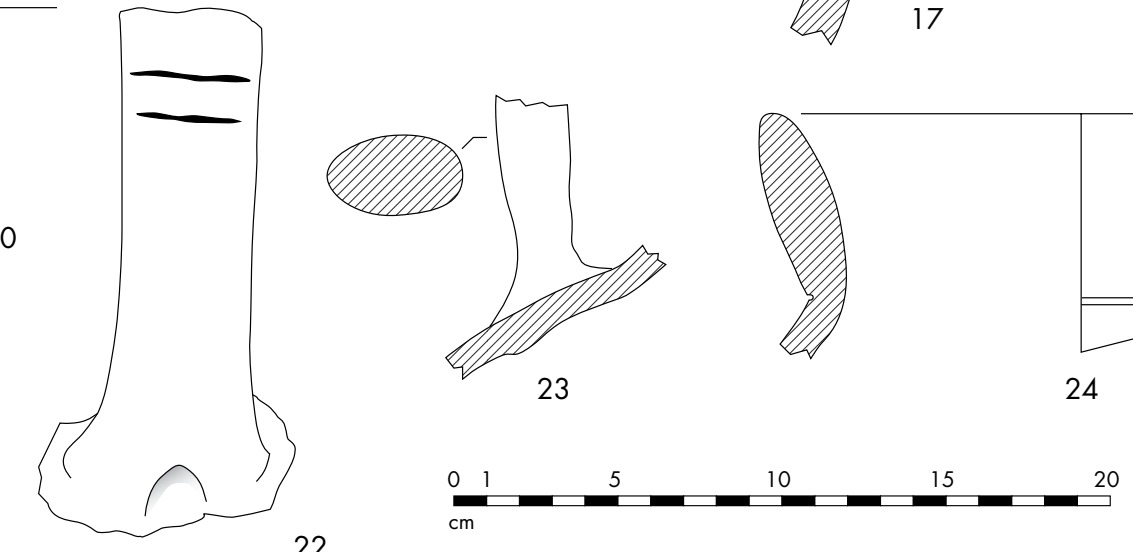

1019

I 20 Le Cailar, sondage 1. Mobiliers céramiques significatifs des Us 1019 et 1023. 


\subsubsection{Niveaux du deuxième quart du IV es. av. n. ̀̀.}

Sur la sédimentation 1017 prend place une strate assez épaisse et homogène de limon argileux et sableux compact, de couleur brune, parsemée de petits charbons (us.1015). La couche s'épaissit vers l'est et épouse une pente vers la tranchée 1012, sur laquelle sont posés des petites pierres et des tessons de céramique. Dans l'angle nord-ouest du sondage, une zone de charbons est recouverte par une plaque d'argile non cuite de $2 \mathrm{~cm}$ environ d'épaisseur, de couleur jaune clair, dont l'usage n'apparaît pas clairement. À l'angle nord-ouest du sondage, on note à l'intérieur de la couche 1015 une passée cendro-charbonneuse d'un centimètre d'épaisseur, conservée sous forme de lambeaux. Ces restes sont difficiles à interpréter: leur nature et leur disposition ne correspondent pas à ce que l'on attend d'une sédimentation de sol d'habitation, tandis que l'aspect lité exclut un remblai massif. Peut-être s'agit-il d'une phase d'abandon relatif de l'habitation, marquée par des activités diverses et non domestiques.

Cette couche sert de base à un sol de terre battue (us.1011), sans aménagement particulier, surmonté d'une mince strate de terre brun-gris très charbonneuse mais hétérogène dans le détail (us.1001), interprétable comme une sédimentation de sol, avec cendres et charbons provenant de feux domestiques et nombreux tessons très fragmentés sans recollages visibles inclus dans son épaisseur, le plus souvent en position horizontale.

Ce niveau d'occupation est le dernier qui soit en relation avec les murs MR1042 (à l'est) et MR1002 (au nord): en effet, cet épisode est suivi immédiatement par la destruction de la maison, remplacée par d'autres structures dont on n'a pas trace. Témoignent de cette destruction d'une part l'épierrement complet du mur MR1042 et le remplissage de la tranchée de spoliation par un remblai (us.1012) composé de matériaux rapportés de l'extérieur, dont la chronologie couvre la fin du $\mathrm{V}^{\mathrm{e}}$ et la première moitié $\mathrm{du}_{\mathrm{IV}}^{\mathrm{e}} \mathrm{s}$.; et d'autre part l'arasement du mur MR1002 au niveau du sommet de l'orthostate du piédroit de la porte.

\subsubsection{Mobiliers du deuxième quart du IVe s. av. n. ̀̀.}

\section{Us 1015}

- Inventaire: céramique: 612 fr. ; 1 marque $\mathrm{M}$ en creux dans cartouche sur col d'amphore massaliète (fig. $18, \mathrm{n}^{\circ} 1$ et fig. $25, \mathrm{n}^{\circ} 22$ ); faune: 101 os, 3 fr. de carapace de tortue, 1 os de poisson; bronze: 1 fibule (6 petits fr., ressort à six spires, corde intérieure); fer : 1 scorie de forge ; terre: 1 fusaïole (fig. $\left.16, \mathrm{n}^{\circ} 14\right) ; 1$ fr. de torchis.

- Comptages : cér. à pâte claire peinte: 20 fr.; cér. attique: 2 fr.; cér. pseudo-attique : 4 fr.; cér. italique à vernis noir: 1 fr.; cér. grise monochrome: 1 fr.; bucchero nero: 1 fr.; cér. à pâte claire ancienne: 32 fr.; cér. commune tournée du Languedoc oriental: $12 \mathrm{fr}$; mortier massaliète: 2 fr.; amphore ibérique: 1 fr.; amphore grecque: 1 fr.; amphore massaliète : 387 fr.; cér. non tournée type étang de Berre : 7 fr.; cér. non tournée régionale: $98 \mathrm{fr}$; dolium: $43 \mathrm{fr}$.
- Typologie:

amphore massaliète: bord A-MAS bd5 : 5 bords (fig. 25, $\mathrm{n}^{\circ} 20$ ); bord A-MAS bd6: 2 bords (fig. 25, $\mathrm{n}^{\circ}$ 21); bord A-MAS bd7: 1 bord (fig. 25, $\mathrm{n}^{\circ} 22$ ); amphore A-MAS ind.: 1 fond, 13 anses.

cér. attique à vernis noir: coupe AT-VN 474-482 ou 483-492: 1 décor (fig. 25, $\mathrm{n}^{\circ} 14$ ).

cér. pseudo-attique: kylix PSEUDO-AT 541: 1 bord (fig. 25, $\mathrm{n}^{\circ} 15$ ).

cér. italique à vernis noir: kylix ITAL-VN ind. : 1 décor (fig. 15, $\mathrm{n}^{\circ} 12$ ).

cér. à pâte claire peinte: coupe carénée CL-MAS 222: 1 bord (fig. 25, $\mathrm{n}^{\circ} 16$ ); coupe à une anse CL-MAS 412a: 3 bords (fig. 25, $\mathrm{n}^{\circ}$ 17-19); cruche CL-MAS ind. : 3 anses, 3 décors.

cér. à pâte claire ancienne: cruche CL-MAS ind. : 1 fond, 2 anses. mortier massaliète: mortier CL-MAS 631: 1 bord (fig. 25, $\mathrm{n}^{\circ} 23$ ).

cér. commune tournée du Languedoc oriental: urne CCT-LOR 1 : 1 fond.

cér. non tournée type étang de Berre: urne CNT-BER U1: 2 bords (fig. 25, $\mathrm{n}^{\circ} 24$ ).

cér. non tournée régionale: coupe CNT-LOR C1: 3 bords (fig. 25, $\mathrm{n}^{\circ} 27-28$ ); coupe CNT-LOR C2: 3 bords (fig. 25, $\mathrm{n}^{\circ} 29$ ); décor CNTLOR incision-fine : 1 décor; urne CNT-LOR ind. : 4 décors; CNT-LOR ind. : 6 fonds; urne CNT-LOR U5 : 1 bord; couvercle CNT-LOR V2c : 1 bord (fig. $25, \mathrm{n}^{\circ} 25$ ).

dolium: DOLIUM bd8c: 1 bord (fig. $25, \mathrm{n}^{\circ} 30$ ); DOLIUM bd8g: 1 bord (fig. 25, $\mathrm{n}^{\circ} 31$ ); décor de cordon lisse: 1 ; fond: 1 .

- Commentaire: Parmi les amphores massaliètes, on voit apparaître à côté des bords bd5 et bd6 le premier exemplaire de bord bd7, non mouluré (fig. 25, $\mathrm{n}^{\circ} 22$ ). Cette variante de bord, encore exceptionnelle au début du $\mathrm{IV}^{\mathrm{e}} \mathrm{s} .{ }^{24}$, ne se développe qu'à partir de 375 pour devenir de plus en plus fréquente jusqu' au milieu du $\mathrm{III}^{\mathrm{e}} \mathrm{s}$. (Py 2001, 170-182). Ce bord est en outre muni d'une marque $\mathrm{M}$ en creux dans un cartouche (fig. $18, \mathrm{n}^{\circ} 1$ ) qui, dans le système mis au point à Lattes, se rattache au groupe A2 et admet une datation aux environs de 382 av. n. è. (Py 2001, 217), compatible, compte tenu de la durée d'amortissement, avec la chronologie suggérée par le contexte.

La céramique attique n'est représentée que par un décor incisé sur vernis noir (rosace), d'un type plus fréquent avant 375 qu'après (cf. Py 2000, 182). Par contre, le "Bolsal" pseudo-attique est une forme couramment attestée durant l'ensemble du $\mathrm{IV}^{\mathrm{e}} \mathrm{s}$. Un fragment de panse à pâte beige très dure orné à l'extérieur de filets de rehaut blanc (fig. 15, $\left.\mathrm{n}^{\circ} 12\right)$ paraît attribuable à une production italienne ${ }^{25}$. Les autres vases de vaisselle appartiennent à des catégories courantes au $\mathrm{IV}^{\mathrm{e}} \mathrm{s}$. et ne fournissent guère de précisions supplémentaires. Relevons seulement que les formes de céramique claire peinte présentes dans cet ensemble (CL-MAS 222, CL-MAS 412a), caractéristiques de la fin du Ve et de la première moitié du IVe s., se raréfient après 350 , ce qui conforte le terminus ante quem proposé pour cette phase.

\section{Us 1001}

- Inventaire: céramique: 424 fr.; 1 graffite sur amphore massaliète; faune: 114 os, 5 coquillages (moules), 1 lot d'arêtes et d'os de poisson; 


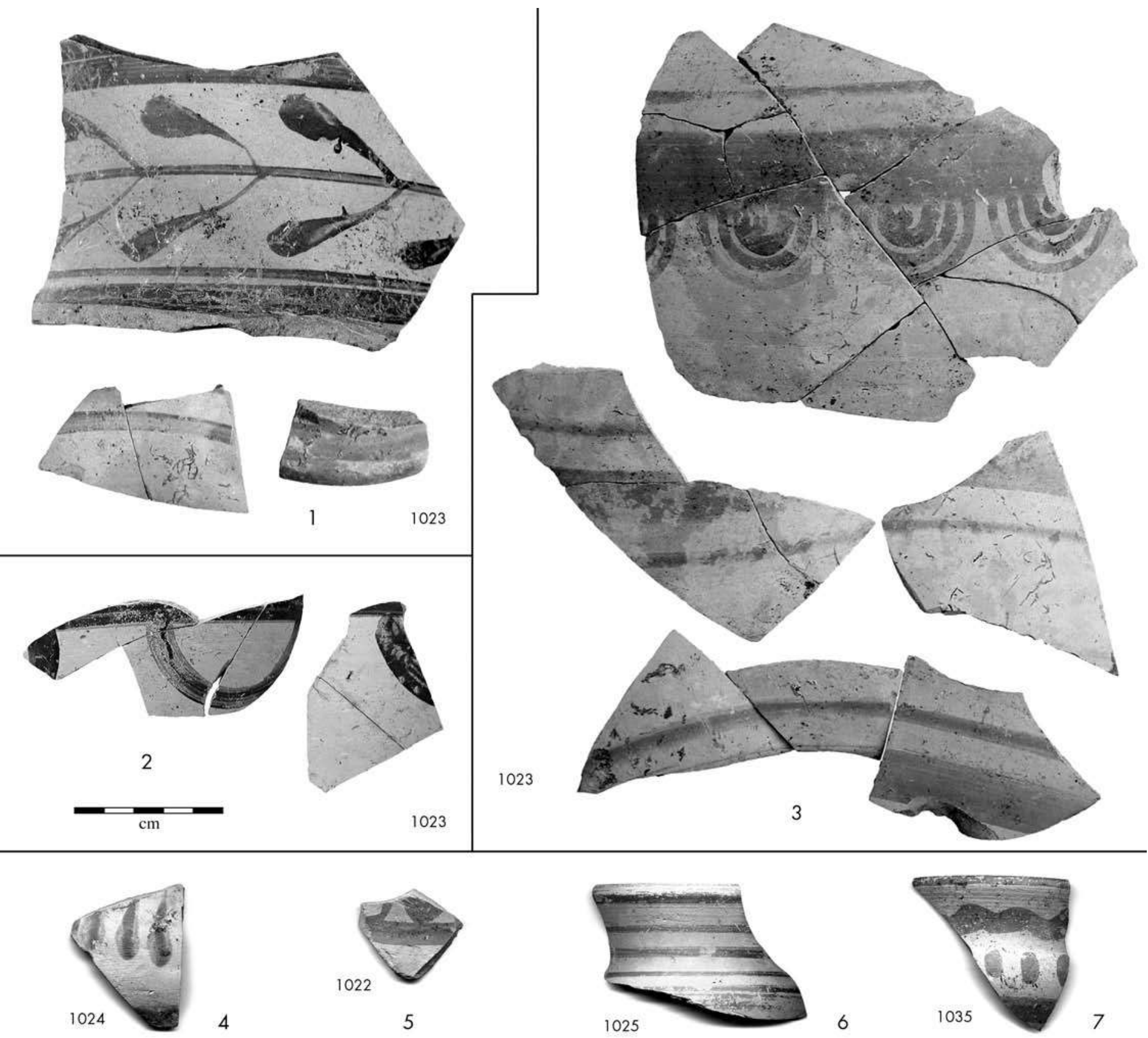

I 21 Le Cailar, sondage 1. Céramique à pâte claire peinte.

bronze: 2 ressorts de fibule (fig. $16, \mathrm{n}^{\circ} 2$ ); 1 fibule en plusieurs fragments (fig. $16, \mathrm{n}^{\circ} 3$ ); fer: 1 fr. ouvragé, probablement un arc de fibule (fig. 16, $\mathrm{n}^{\circ} 10$ ); terre: 1 fr. de chenet décoré (fig. 16, $\mathrm{n}^{\circ} 1$ ).

- Comptages: cér. attique: 10 fr.; cér. pseudo-attique: 8 fr.; cér. à pâte claire peinte: 19 fr.; autre cér. à pâte grise: 3 fr.; cér. à pâte claire ancienne: 37 fr.; mortier massaliète: 1 fr.; cér. commune tournée du Languedoc oriental : $10 \mathrm{fr}$; amphore massaliète : $210 \mathrm{fr}$; ; cér. non tournée type étang de Berre: 10 fr.; cér. non tournée régionale: 100 fr.; dolium: $16 \mathrm{fr}$.

- Typologie:

amphore massaliète: bord A-MAS bd7: 1 bord (fig. 27, $\mathrm{n}^{\circ} 13$ ); amphore A-MAS ind.: 4 anses. cér. attique à figures rouges: kylix AT-VN 513-517: 1 décor (fig. 15, $\left.\mathrm{n}^{\circ} 1\right)$.

cér. attique à vernis noir: bol AT-VN 777-808: 1 bord (fig. 27, $\mathrm{n}^{\circ} 2$ ); coupelle AT-VN 863-876: 1 bord; AT-VN ind.: 3 fonds, 1 décor (fig. 27, $\mathrm{n}^{\circ} 1$ ).

cér. pseudo-attique: coupe sans tige PSEUDO-AT 493: 1 bord (fig. 27, $\mathrm{n}^{\circ} 3$ ); coupe PSEUDO-AT ind.: 1 décor imprimé; 1 décor surpeint (fig. 15, $\mathrm{n}^{\circ} 13$ ).

cér. à pâte grise: coupe AUT-GR ind. : 1 fond.

cér. commune tournée du Languedoc oriental: urne CCT-LOR 1 : 1 bord (fig. $27, \mathrm{n}^{\circ} 11$ ). 


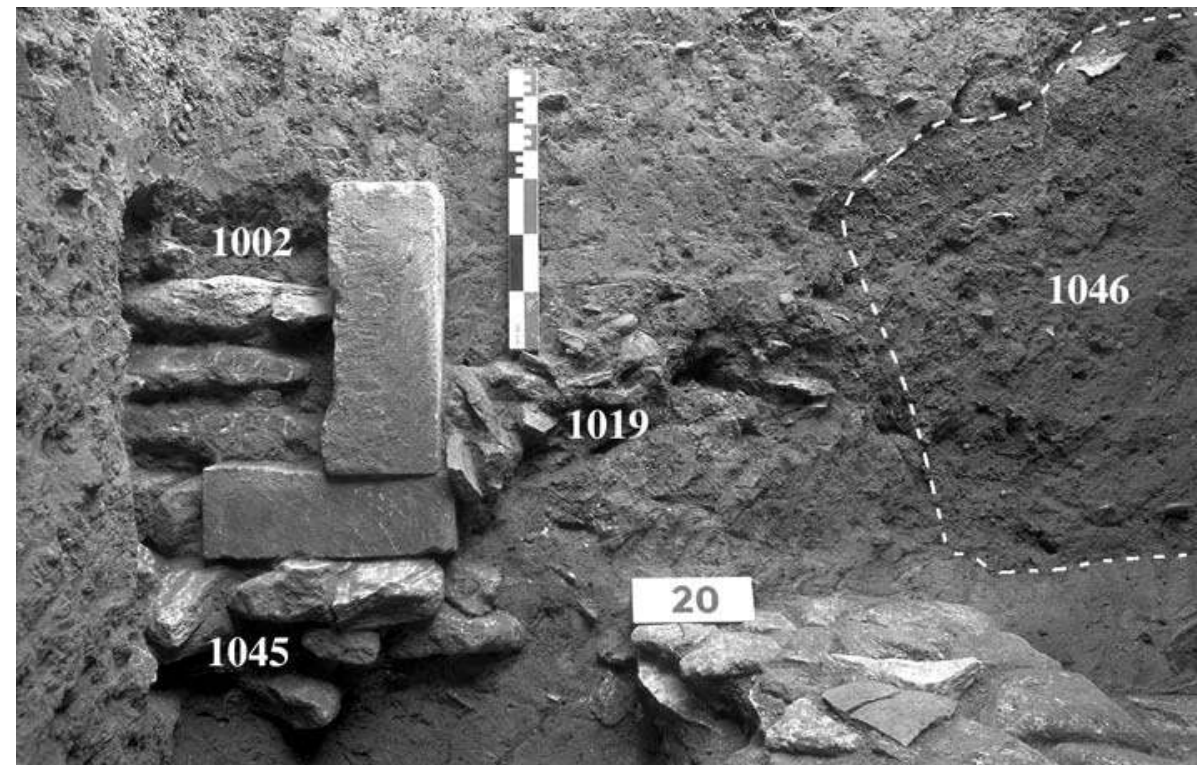

【 22 Le Cailar, sondage 1. Détail du piédroit du mur MR1002 et de la porte PR1043.

-23 Le Cailar, sondage 1. Plan des structures des niveaux supérieurs.

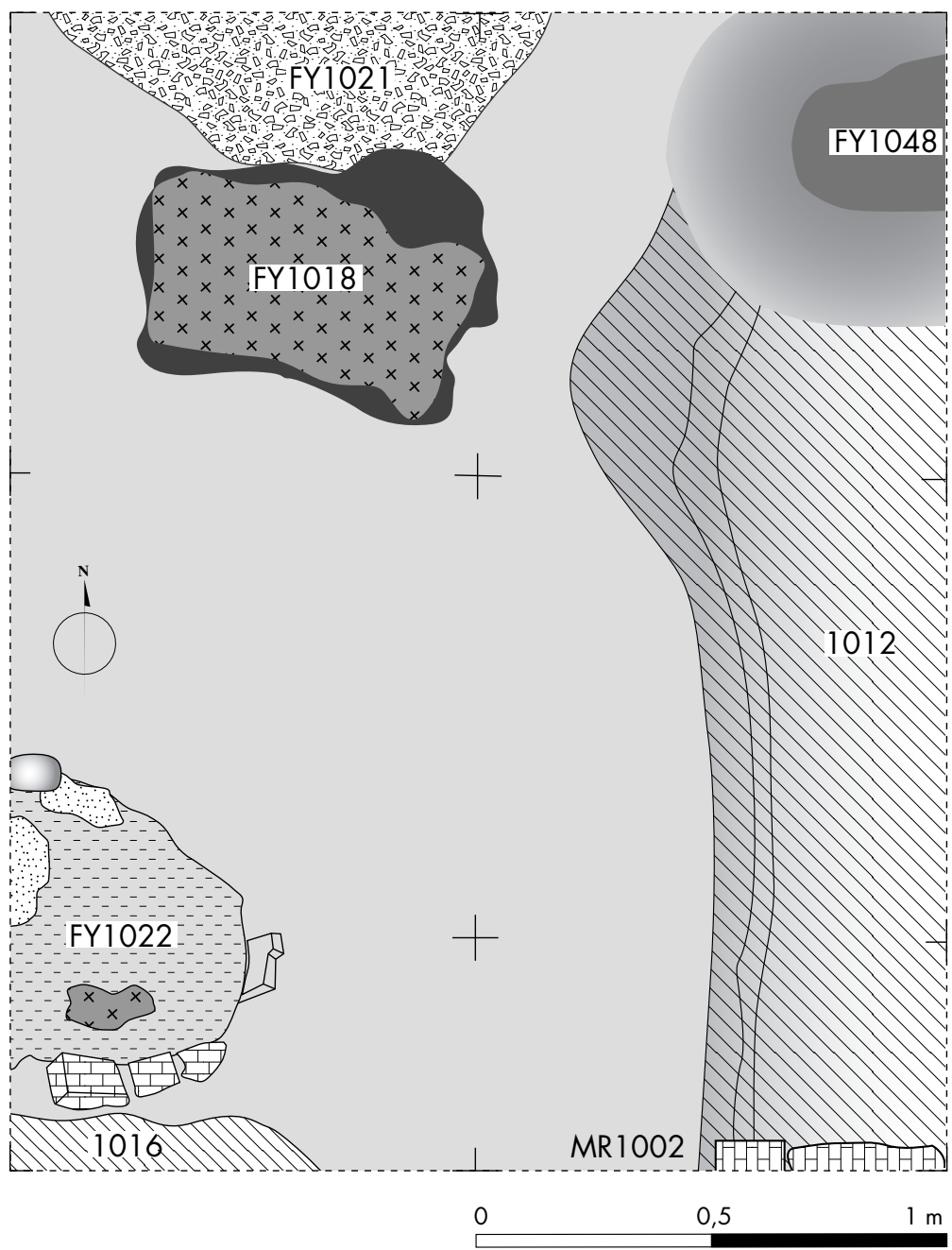

cér. à pâte claire peinte: bol caréné CL-MAS 332: 1 bord (fig. $27, \mathrm{n}^{\circ} 7$ ); coupe à une anse CLMAS 410: 4 bords (fig. 27, $\mathrm{n}^{\circ} 4-6$ ); coupe à anses CL-MAS 428: 1 bord.

cér. à pâte claire ancienne: cruche CL-MAS 520/540: 4 bords (fig. 27, $\mathrm{n}^{\circ}$ 8,9), 2 anses; cruche CL-MAS 527b: 1 bord (fig. 27, $\mathrm{n}^{\circ} 10$ ).

mortier massaliète: mortier CL-MAS 623a: 1 bord (fig. $27, \mathrm{n}^{\circ} 12$ ).

cér. non tournée type étang de Berre: urne CNTBER U1: 5 bords (fig. 27, $\mathrm{n}^{\circ} 14$ ).

cér. non tournée régionale: coupe CNT-LOR C1: 1 bord; coupe CNT-LOR C2: 2 bords (fig. $\left.27, \mathrm{n}^{\circ} 16,17\right)$; urne CNT-LOR U2: 1 bord; urne CNT-LOR U5 : 3 bords (fig. $27, \mathrm{n}^{\circ} 15$ ); urne CNT-LOR ind.: 4 fonds, 2 décors; couvercle CNT-LOR V2a: 2 bords (fig. 27, $\mathrm{n}^{\circ} 19$ ); couvercle CNT-LOR V2c: 1 bord (fig. 27, $\mathrm{n}^{\circ} 18$ ).

- Commentaire: Le fragment de chenet attesté dans ce niveau, orné d'une grecque excisée sur le dos et de cercles imprimés sur les flancs (fig. 16, $\mathrm{n}^{\circ} 1$ ), est comparable aux exemplaires déjà trouvés sur le site (Garmy 1981). Les fibules à arc filiforme et ressort parfois assez long à corde intérieure renvoient à des modèles régionaux de la fin $\mathrm{du} \mathrm{V}^{\mathrm{e}}$ et de la première moitié du $\mathrm{IV}^{\mathrm{e}} \mathrm{s}$. (cf. type 8 de Tendille 1978; Raux 1999, fig. 27 et 28).

La présence de la variante de bord d'amphore massaliète A-MAS bd7 est confirmée. Dans le vaisselier, on observe une bonne représentation de la céramique attique, avec notamment un fragment de coupe à figures rouges (fig. $15, \mathrm{n}^{\circ} 1$ ) orné d'une palmette qui rappelle les productions tardives du groupe de Vienne 116 ou du peintre Q. La coupelle AT-VN 863-876 appartient quant à elle à une forme produite entre le milieu du $\mathrm{V}^{\mathrm{e}}$ et le milieu du $\mathrm{IV}^{\mathrm{e}} \mathrm{s}$. La relative abondance de céramique pseudo-attique confirme une observation faite à Lattes sur la diffusion maximale de cette catégorie aux deuxième et troisième quarts du $\mathrm{IV}^{\mathrm{e}} \mathrm{s}$. (Py 2001, 1176). On soulignera l'intérêt de la présence d'un fragment de vasque de coupe ornée de surpeints blancs (fig. 15, $\mathrm{n}^{\circ} 13$ ) à l'extérieur (motif illisible) et à l'intérieur (plage arrondie avec incisions qui pourrait appartenir à une grande tête féminine : comparer à Py 2001, $\mathrm{n}^{\circ} 6038$ en pseudo-attique et $\mathrm{n}^{\circ} 1545$ en attique). Rappelons qu'un autre décor peint sur fond de pseudo-attique a été recueilli dans les prospections de surface (fig. $15, \mathrm{n}^{\circ} 14$ ). Ce genre de décoration figurée n'est pas fréquent sur la céramique pseudoattique marseillaise mais commence à être régulièrement signalé: notamment pour l'heure à Mauressip, à Ensérune, à Lattes (Py 2001, 1176, 1182-1184 et 1197) et à Arles (Arcelin 2000, 164). 


\subsubsection{Mobiliers de la tranchée 1012 (première moitié du IV ${ }^{e}$ s. av. n. è.)}

\section{Us 1012}

- Inventaire: céramique: 842 fr.; 1 marque peinte sur bord d'amphore massaliète (illisible); faune: 128 os, 9 coquillages, fer: 1 clou et 1 tige de clou (fig. $16, \mathrm{n}^{\circ} 7,8$ ); terre: 1 anse d'amphore étrusque réutilisée comme pilon (fig. 16, $\mathrm{n}^{\circ} 13$ ).

- Comptages : cér. attique: 11 fr.; cér. pseudo-attique: 5 fr.; cér. grise monochrome: 5 fr.; cér. à pâte claire peinte : 21 fr.; cér. ibéro-languedocienne: 1 fr.; cér. à pâte claire ancienne: 40 fr.; cér. commune tournée du Languedoc oriental: 17 fr.; mortier massaliète: 1 fr.; amphore grecque: 1 fr.; amphore ibérique: 3 fr.; amphore étrusque: $5 \mathrm{fr}$; amphore massaliète: 587 fr.; cér. non tournée type étang de Berre: 8 fr.; cér. non tournée régionale: 71 fr.; dolium: 66 fr.

- Typologie:

amphore étrusque: amphore A-ETR 3C: 2 tessons; amphore A-ETR $4: 1$ anse, 2 tessons.

amphore massaliète: bord A-MAS bd5: 12 bords (fig. 27, $\mathrm{n}^{\circ} 37$ ); bord A-MAS bd6: 4 bords (fig. 27, $\mathrm{n}^{\circ}$ 36); amphore A-MAS ind. : 15 anses. cér. attique à figures rouges: cratère AT-FR Cr4: 1 décor (fig. $15, \mathrm{n}^{\circ} 2$ ); coupe sans tige AT-FR Ky13: 1 bord (fig. 15, $\mathrm{n}^{\circ} 5$ et fig. 27, $\mathrm{n}^{\circ} 28$ ).

cér. attique à vernis noir: bol AT-VN 777-808: 1 bord (fig. 27, $\mathrm{n}^{\circ} 27$ ). cér. pseudo-attique: coupe sans tige PSEUDO-AT 493: 1 bord (fig. 27, $\left.\mathrm{n}^{\circ} 29\right)$.

cér. à pâte claire peinte: coupe à une anse CL-MAS 410: 2 bords (fig. 27, $\mathrm{n}^{\circ} 31,32$ ); cruche CL-MAS 520/540: 1 anse, 3 décors; CLMAS ind.: 2 fonds (fig. 27, $\mathrm{n}^{\circ} 30$ ), 2 anses.

cér. à pâte claire ancienne: bol CL-MAS 236: 1 bord (fig. 27, $\mathrm{n}^{\circ} 33$ ); cruche CL-MAS 520/540: 2 anses; olpé CL-MAS 521/522: 1 fond; cruche CL-MAS 541: 2 bords; cruche CL-MAS 543: 1 bord (fig. 27, $\left.\mathrm{n}^{\circ} 34\right)$.

cér. grise monochrome: coupe-skyphos GR-MONO 5f: 1 tesson; œnochoé GR-MONO 8 : 1 fond.

cér. ibéro-languedocienne: jarre IB-LANG ind. : 1 décor.

mortier massaliète: mortier CL-MAS ind.: 1 fond.

cér. commune tournée du Languedoc oriental: urne CCT-LOR 1 : 2 bords, 1 fond.

cér. non tournée type étang de Berre: urne CNT-BER U1: 1 bord.

cér. non tournée régionale: coupe CNT-LOR C1: 2 bords (fig. 27, $\mathrm{n}^{\circ} 35$ ); coupe CNT-LOR C2: 2 bords; CNT-LOR ind.: 4 fonds; jatte CNT-LOR J1d: 1 bord; urne CNT-LOR U5 : 4 bords ; couvercle CNTLOR V2b: 1 bord.

dolium: jarre DOLIUM ind.: 1 bord, 2 fonds.

- Commentaire: L'anse étrusque réutilisée comme broyeur, ainsi que le montre son extrémité polie, est un instrument assez courant en Languedoc durant la plus grande partie du deuxième âge du Fer. En témoignent les exemples suivants : Gailhan, Ve s.: Dedet 1980, fig. 67. Le Marduel, Ve s.: Py 1992, 280; III ${ }^{\mathrm{e}}$ s.: Py 1989, fig. 61. Nages, II ${ }^{\mathrm{e}}$ s.: secteurs H7/1977, couche 4; J2/1971, couche 2; J3/1971, couche 2; I $^{e r}$ s.: secteur L9-10/1981, couche 1. Lattes, IVe s.: us.25036, 25040, 27177, 27227, 27246, 123031 (Raux 1999, 463, fig. 13, $\mathrm{n}^{\circ}$ 758-762); III' s. : us.4473, 4636; II ${ }^{\mathrm{e}}$ s. : us.16004, 31010. Ensérune, dans des silos comblés au

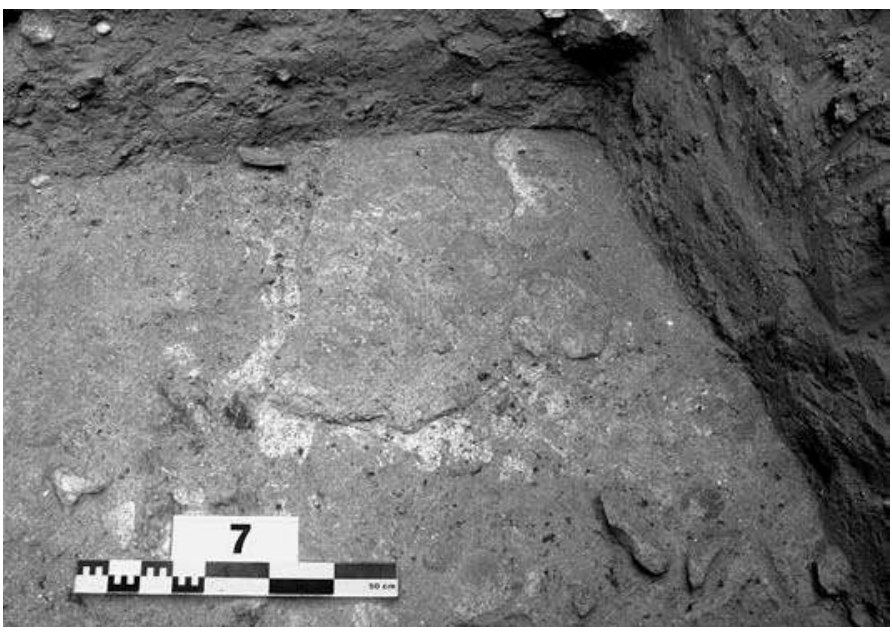

24 Le Cailar, sondage 1. Détail du foyer FY1018.

II s. (Gallet de Santerre 1980, 134). Notons qu'un second exemplaire figure au Cailar dans les ramassages de surface. Les fragments d'amphores et de vaisselle retrouvés dans la tranchée 1012, dont le remplissage est situé vers le milieu du $\mathrm{IV}^{\mathrm{e}}$ s. par la stratigraphie, couvrent apparemment, d'après leur typologie, une assez longue période dénotant un remploi de sédiments divers. Quelques tessons pourraient remonter à la fin du $\mathrm{V}^{\mathrm{e}} \mathrm{s}$. : c'est le cas au moins d'un fragment de cratère attique dont le décor (joueur de lyre) est relativement fin et maîtrisé (fig. $15, \mathrm{n}^{\circ} 2{ }^{2}{ }^{26}$. La répartition des bords d'amphore massaliète rappelle pour sa part celle observée ci-dessus dans les niveaux du premier quart du siècle. En regard, un bord de stemless attique à figures rouges présente un élément de palmette simplifiée plus proche du milieu du $\mathrm{IV}^{\mathrm{e}} \mathrm{s}$. (fig. $15, \mathrm{n}^{\circ} 5$ ).

\subsubsection{Niveaux postérieurs au milieu du $I V^{e} s . a v$. n. è.}

Une seule phase d'occupation postérieure au milieu du $\mathrm{IV}^{\mathrm{e}} \mathrm{s}$. est illustrée par des niveaux conservés en place. Il s'agit d'abord d'un sol de terre battue (us.1047), marqué au coin sud-ouest du sondage par un foyer lenticulaire aménagé (FY1048: fig. 23 et 28) composé d'une épaisse lentille de charbons, très noire, entourée par des tessons de dolium dessinant un demi-cercle. L'intérêt de ce foyer, implanté à l'aplomb de la tranchée d'épierrement 1012, est de prouver de manière indubitable que le mur MR1042 est alors détruit et épierré. Côté sud, le sol 1047 se trouve au niveau du sommet du bloc dressé de chant servant de piédroit à la porte PR1043 et passe par-dessus l'arasement du mur MR1002.

Une mince couche de sédimentation de couleur brun-gris (us.1003) recouvre le sol 1047 et témoigne de son fonctionnement; elle contient un lot réduit de tessons épars et relati- 

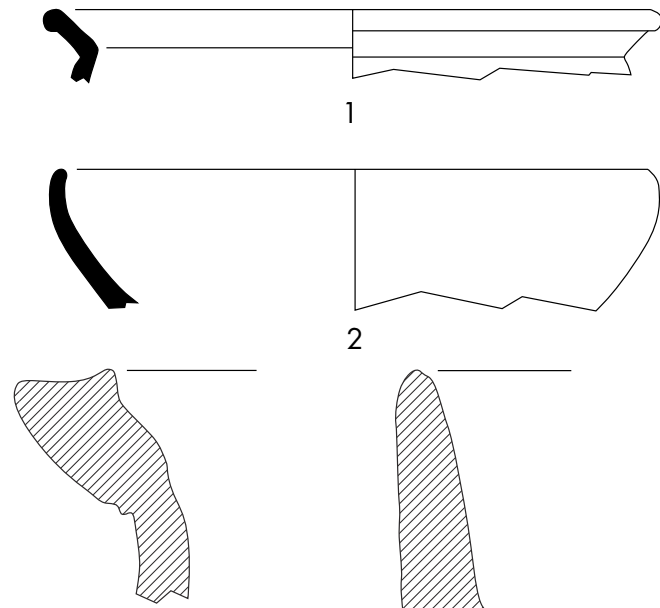

3
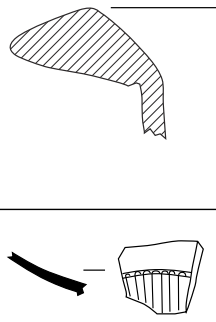

14
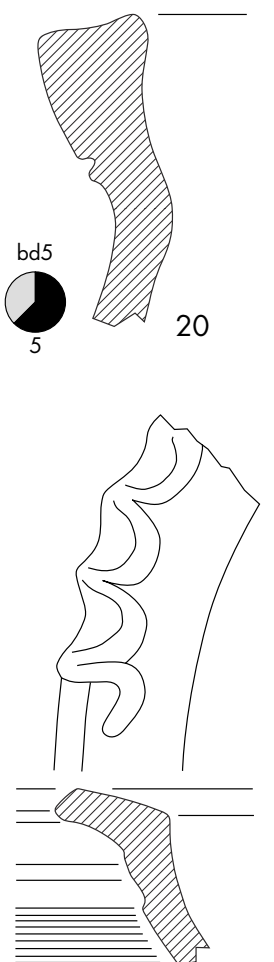

23
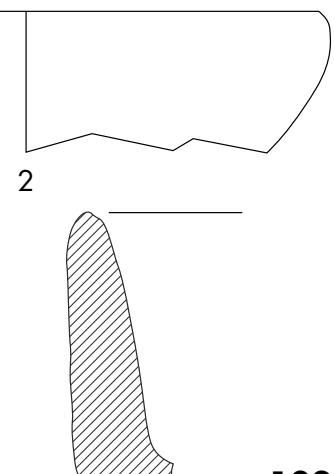

4

5
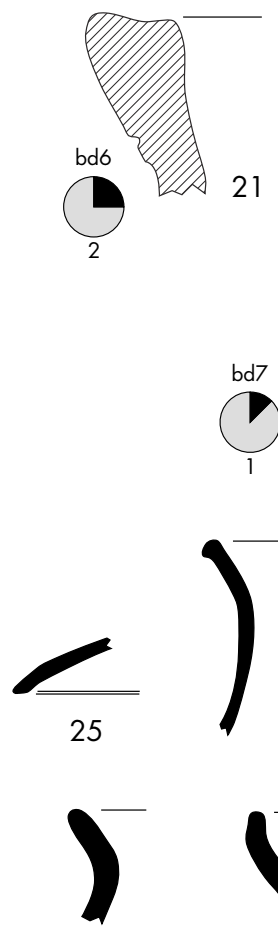

26

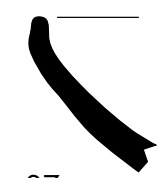

27
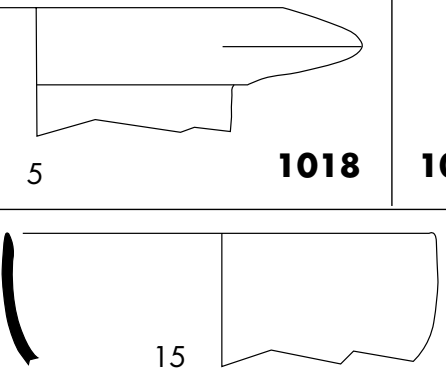

1017

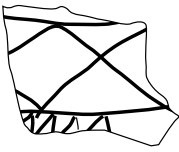

11

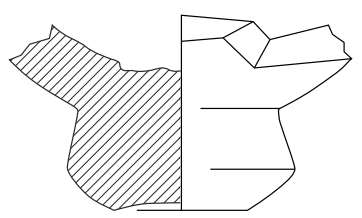

12
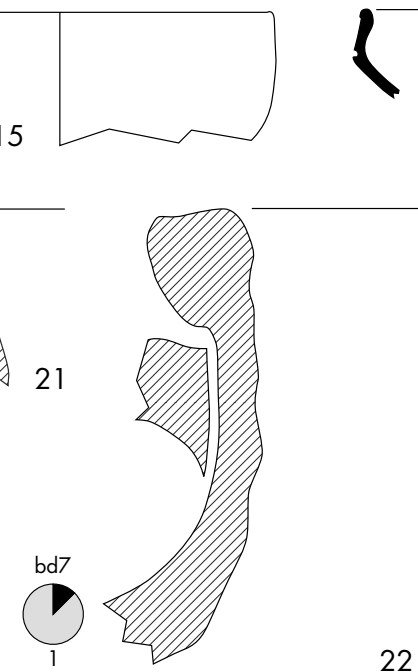

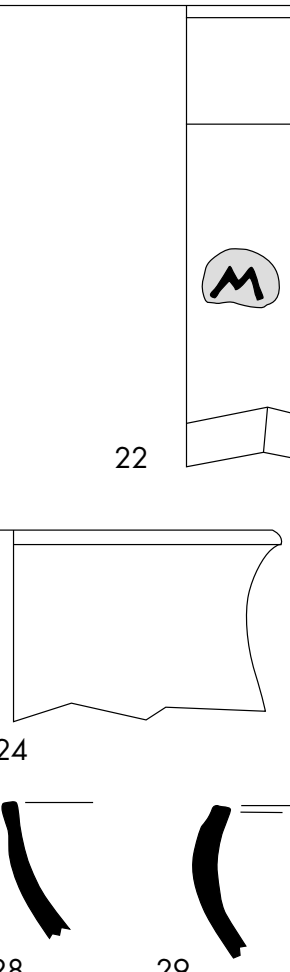

28
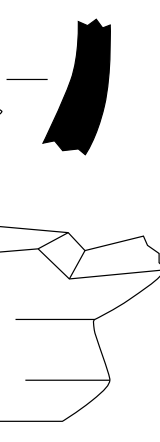

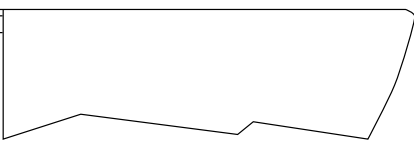

6
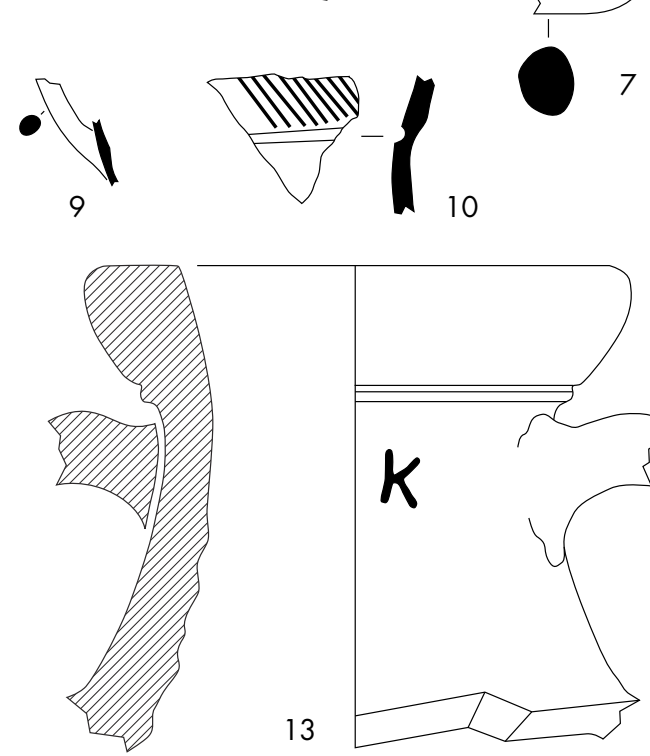

13
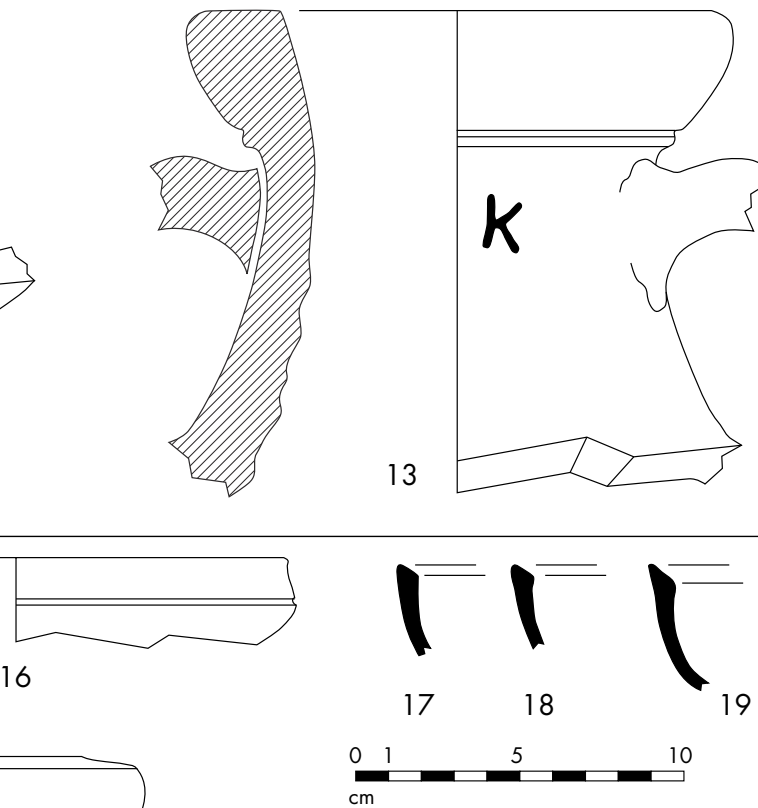

30

31

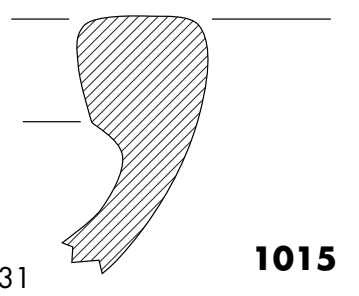

I 25 Le Cailar, sondage 1. Mobiliers céramiques significatifs des Us 1015, 1017, 1018 et 1022. 


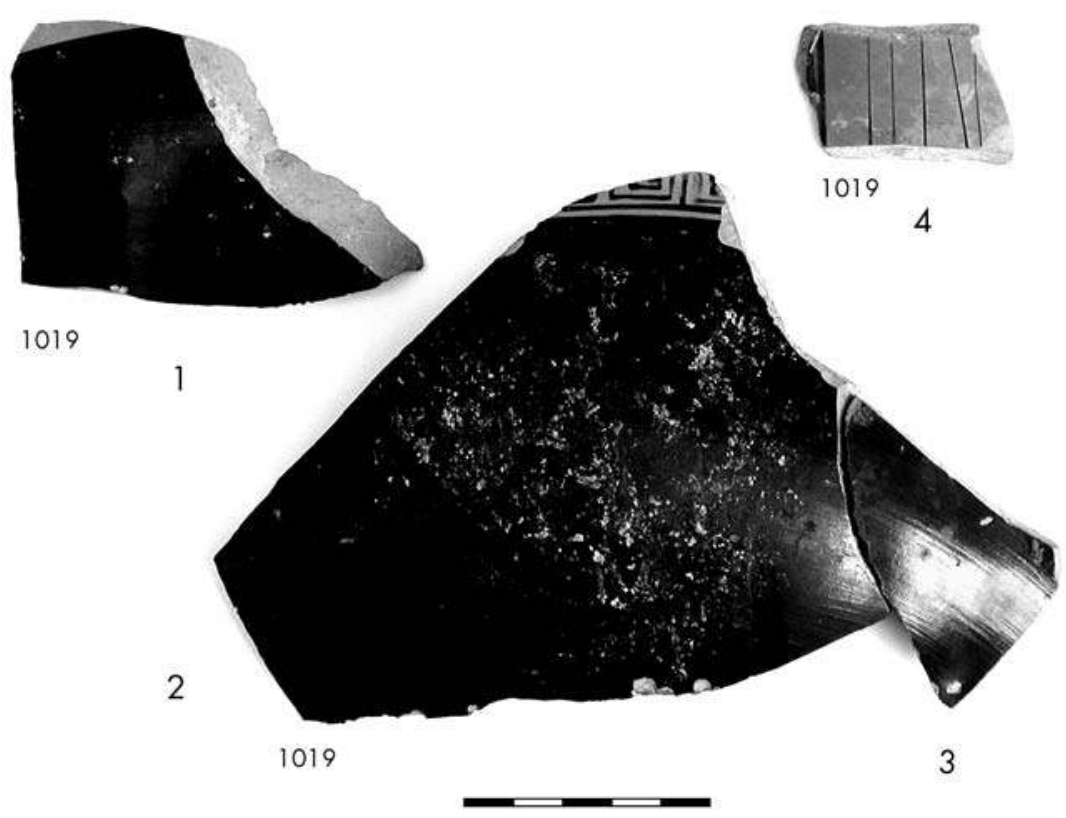

I 26 Le Cailar, sondage 1. Fragments de cratère en calice attique de I'Us 1019.

vement fragmentés. Son sommet a été certainement entamé par le creusement du caveau funéraire antérieur à l'ouverture de la fouille. Cette couche a livré le mobilier suivant:

- Inventaire: céramique: 101 fr.; 1 graffite lambda sur col d'amphore massaliète (fig. $27, \mathrm{n}^{\circ} 26$ ); faune: 3 os; fer: 1 pointe de clou (fig. 16 , $\mathrm{n}^{\circ}$ 9).

- Comptages : cér. à pâte claire peinte: 2 fr.; cér. attique: 1 fr.; cér. à pâte claire ancienne: 3 fr.; amphore massaliète: 44 fr.; amphore ibérique: 1 fr.; cér. non tournée type étang de Berre: 1 fr.; cér. non tournée régionale: 38 fr.; dolium: $11 \mathrm{fr}$.

- Typologie:

amphore massaliète: amphore A-MAS ind. : 2 anses.

cér. attique à figures rouges: kylix AT-FR ind.: 1 anse.

cér. à pâte claire peinte: coupe à une anse CL-MAS 410: 1 anse.

cér. à pâte claire ancienne: olpé CL-MAS 522: 1 bord (fig. 27, $\mathrm{n}^{\circ} 20$ ).

cér. non tournée type étang de Berre: urne CNT-BER U1: 1 fond.

cér. non tournée régionale: coupe CNT-LOR C1: 1 bord (fig. 27, $\mathrm{n}^{\circ} 25$ ); coupe CNT-LOR C2: 4 bords (fig. 27, $\mathrm{n}^{\circ} 24$ ); jatte CNT-LOR J1d: 1 bord (fig. $27, \mathrm{n}^{\circ} 23$ ); urne CNT-LOR U5 : 3 bords (fig. $27, \mathrm{n}^{\circ} 21$, 22); urne CNT-LOR ind.: 1 décor, 1 fond.

dolium: jarre DOLIUM ind.: 1 décor.

- Commentaire: Ce lot réduit de documents offre peu d'éléments de datation fine. Son attribution à une phase postérieure au milieu du $\mathrm{IV}^{\mathrm{e}} \mathrm{s}$. repose principalement sur des arguments stratigraphiques, la présence d'un fragment d'attique à figures rouges et l'aspect général du mobilier interdisant par ailleurs de descendre plus bas que la fin du IV $\mathrm{IV}^{\mathrm{e}} \mathrm{s}$. - ce que confirment les autres sortes de vases, tous de types fréquents au $\mathrm{IV}^{\mathrm{e}} \mathrm{s}$. La caractéristique la plus originale de cet ensemble est incontestablement l'abondance de la céramique non tournée régionale, nettement plus nombreuse que dans les couches plus anciennes.
Les niveaux postérieurs, excavés, ont été seulement observés en coupe, principalement sur la berme sud du sondage, moins perturbée que les autres par les tombes modernes (fig. 9). On retiendra les strates les plus évidentes, à savoir successivement:

- au-dessus de 1003, une épaisse couche de terre brun clair peu différenciée (us.1034) correspondant sans doute à une succession de plusieurs phases de remblaiement et de sols d'occupation dont pourraient témoigner des traces de cendre observables à différentes hauteurs;

- une sédimentation de sol de couleur brungris (us.1033), plus fortement anthropisée (nombreux petits charbons de bois), visible non seulement au sud, mais également dans les coupes nord et ouest du sondage;

- un sol cendreux de couleur gris foncé, avec traces de foyers lenticulaires (us.1010);

- une couche d'argile jaune contenant de multiples petits galets (us.1009) constituant un apport homogène; des traces de cendres et de charbons de bois au sommet de ce remblai permettent d'identifier une couche préparatoire à l'établissement d'un sol construit ${ }^{27}$;

- une couche de terre brun-jaune avec fragments d'adobes et quelques charbons de bois (us.1008) correspondant probablement à une réfection avec exhaussement du sol; cette couche a livré quelques tessons (amphore massaliète, céramique non tournée, bord et fond d'une coupe $27 \mathrm{ab}$ en céramique campanienne A ancienne) qui permettent d'en attribuer la formation à la fin du $\mathrm{III}^{\mathrm{e}}$ ou au début du $\mathrm{II}^{\mathrm{e}} \mathrm{s}$. av. n. è.; - une nouvelle couche d'argile jaune clair de 9 à $10 \mathrm{~cm}$ d'épaisseur (us.1007) contenant de multiples galets non calibrés (1 à $10 \mathrm{~cm}$ de diamètre) et constituant probablement comme 1009 un radier de sol construit;

- une épaisse strate de terre hétérogène (us.1006) interprétable comme une couche arable, remaniée par des travaux agricoles antérieurement à l'établissement du cimetière ;

- une profonde fosse remplie de terre meuble, au coin sud-est du sondage, correspondant à une tombe moderne (SP1005) creusée à partir du sommet de 1006 ou de plus haut;

- enfin, dans les 50 centimètres supérieurs de la coupe, un lit de terre meuble contenant diverses inclusions (graviers, ossements), qui paraît constituer un remblai moderne lié à un réaménagement du cimetière (us.1004) ${ }^{28}$. 

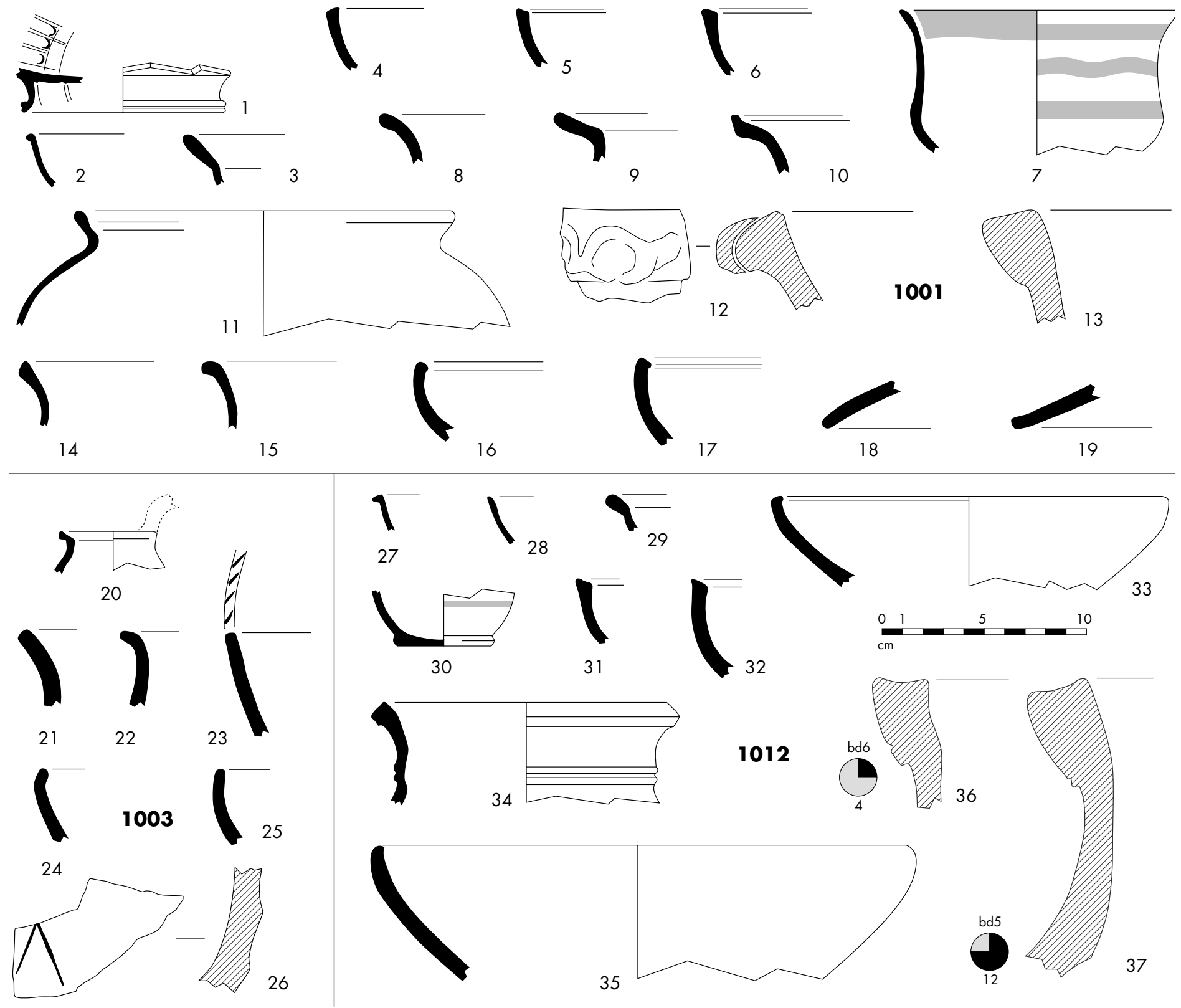

【27 Le Cailar, sondage 1. Mobiliers céramiques significatifs des Us 1001, 1003 et 1012.

\subsection{VESTIGES LAPIDAIRES (Jean-Claude Bessac)}

\subsubsection{Le matériau}

Toutes les pierres taillées examinées sont constituées d'un calcaire coquillier assez fin et de couleur jaune pâle à gris clair, correspondant aux indices M90 ou M91 du code des couleurs des sols de A. Cailleux. L'élément mouluré présente une teinte dominante jaune rouge correspondant à l'indice M45 du même code. Bien que fortement prédomi- nante sur le fragment, cette teinte n'est pas homogène et un quart de la pierre présente la même couleur jaune pâle à gris clair, identifiée sur les autres éléments. L'hypothèse d'une acquisition de la teinte rougeâtre à la suite d'un fort échauffement de l'élément mouluré peut être proposée.

La composition et la structure de sédimentation des débris de coquillages sont très caractéristiques et se démarquent assez franchement de toutes celles des roches des grands bassins carriers de la région (Castries, Pondres, Aubais, Sommières, Beaucaire, Sernhac, Vers). Un seul petit groupe d'exploitations, aujourd'hui fermé, a fourni par le passé une 


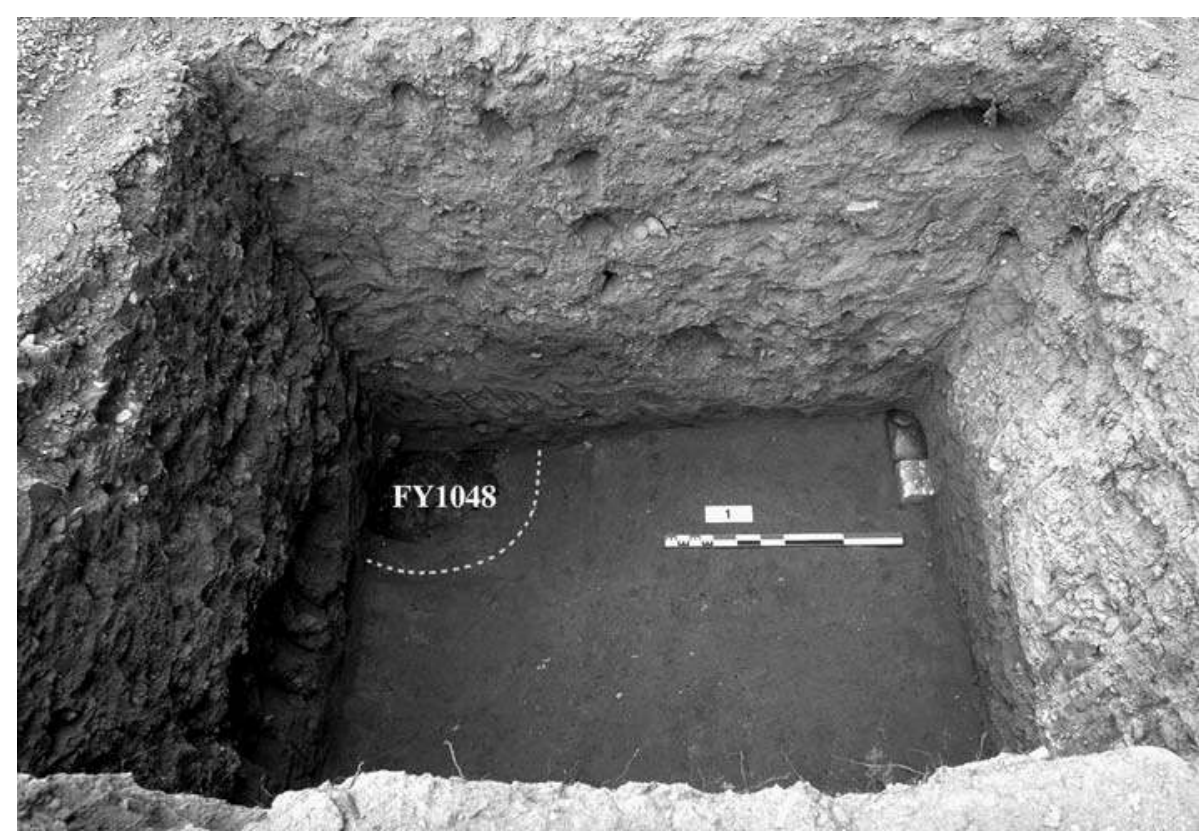

【28 Le Cailar, sondage 1. Vue du sol 1047 et du foyer FY1048. linéaire, que l'on peut assimiler à celles produites par un outil traditionnel: la polka. Cette dernière est pourvue d'un manche et sa partie métallique comporte deux tranchants disposés à $90^{\circ}$ l'un par rapport à l'autre. La grande majorité des impacts révèle essentiellement l'usage du tranchant perpendiculaire au manche de l'outil, mais il est également possible que les traces du second tranchant soient parfois mêlées à celles du premier sans que l'on puisse les identifier sûrement. Les impacts relevés sur le bloc inférieur révèlent un tranchant large de $8 \mathrm{~cm}$ et présentant une légère courbure dont la flèche mesure environ $0,1 \mathrm{~cm}$. Le bloc supérieur, employé de chant, porte des traces d'un tranchant d'outil similaire mais mesurant seulement $7 \mathrm{~cm}$ de large. L'orientation de ces impacts révèle deux positions de percussions, l'une très oblique, presque parallèle à la face en cours de taille et l'autre presque perpendiculaire et marquant assez profondément la pierre de coups très serrés. Cette dernière pratique concerne plutôt les chants des pierres que les grandes faces constituées par les lits d'attente et de pose.

Un ciseau droit de $4 \mathrm{~cm}$ de large semble avoir été utilisé pour la taille du fragment mouluré. D'autres ciseaux comparables, mais plus étroits, ont probablement été utilisés, en particulier pour tailler les chanfreins et pour affiner le travail des outils à percussion lancée sur les trois autres blocs, toutefois, il est difficile d'isoler leurs traces pour proposer des mesures.

Des traces de sciage ont été identifiées sur la bande d'anathyrose d'un joint montant du bloc supérieur remployé de chant. La largeur très réduite de cette bande, 0,5 à $1,5 \mathrm{~cm}$ environ, et le faible creux d'anathyrose, approximativement $0,2 \mathrm{~cm}$, prouvent l'usage d'une scie à joint constituée d'une lame très courte (moins de $10 \mathrm{~cm}$ ) et de faible épaisseur (moins de 0,2 cm). Dans l'état actuel de la recherche, ces traces constituent le plus ancien témoignage de l'emploi d'un tel outil en Occident.

Certaines faces des blocs, notamment les lits d'attente, paraissent égrisées. Il peut s'agir d'un égrisage d'assemblage consistant à déplacer à plusieurs reprises le bloc supérieur sur celui de dessous, de façon à ce qu'ils s'usent mutuellement. Mais cette opération peut être aussi pratiquée à l'aide d'une pierre abrasive telle que le grès. C'est la solution qui semble avoir été adoptée pour la régularisation de la surface des moulures.

Au-delà de ces quatre outils de façonnage, la forme de ces blocs atteste aussi l'emploi d'au moins deux instruments de
Quatre types de traces ont été identifiés. Les plus communes résultent d'un outil à percussion lancée transversale 
tracé: l'équerre et la règle, cette dernière étant très probablement graduée. Même si certains angles varient de quelques degrés par rapport à l'angle droit, d'autres sont suffisamment précis pour attester l'emploi de l'équerre. Les pierres étant relativement courtes, il est possible que les équerres aient fait aussi office de règle, mais il faut alors supposer qu'elles comportaient des repères, sinon des graduations correspondant à des unités de mesure bien déterminées.

\subsubsection{Description technique des blocs}

Cinq éléments de pierre de taille ont été mis au jour dont quatre seront étudiés ici, deux entiers et deux fragmentaires, dont un mouluré. Les deux premiers étaient remployés comme encadrement de porte dans un mur dont la construction remonte aux alentours de 400, et sont donc datables au plus tard du $\mathrm{V}^{\mathrm{e}} \mathrm{s}$. av. n. è. Le plus bas était placé à plat (bloc $\mathrm{n}^{\circ} 1$ ) et supportait le second (bloc $\mathrm{n}^{\circ} 2$ ), posé de chant (fig. 29).

\section{Le bloc inférieur $n^{\circ} 1$ (us.1002)}

Considéré à plat, le premier mesure $51,7 \mathrm{~cm}$ de long, $40 \mathrm{~cm}$ de large et 13,2 à 14,4 cm d'épaisseur pris dans ses lits de carrière. Dans sa position initiale, avant remploi, ses grandes faces constituaient le lit de pose et le lit d'attente. La plus longue des faces étroites qui constitue le chant de la pierre, comporte un chanfrein de 0,8 à $1,1 \mathrm{~cm}$, incliné d'environ $30^{\circ}$ et disposé en $\mathrm{L}$ sur l'arête sommitale et sur son retour vertical. Bien que cette face ait fait office de parement, sa taille à l'aide d'une polka, munie d'un tranchant de $8 \mathrm{~cm}$ de large, a laissé un creux central d'environ $0,4 \mathrm{~cm}$ de flèche. Ce même creux de façonnage est identifiable sur les quatre faces latérales mais avec un peu moins d'ampleur, environ $0,2 \mathrm{~cm}$ de flèche. La face chanfreinée constitue très vraisemblablement le parement initial de ce bloc.

Par rapport à cette position du parement, la face latérale droite pourrait constituer un retour partiel d'angle, au moins sur une dizaine de centimètres. Cette face semble légèrement égrisée et les traces de pose de la pierre supérieure permettent de penser qu'elle a servi de joint montant à l'arrière, sur environ une trentaine de centimètres.

Le lit d'attente est bien taillé sur une largeur approximative de $12 \mathrm{~cm}$. Au-delà, vers l'arrière du bloc, apparaît un léger démaigrissement qui forme un ressaut d'environ 1 à $1,2 \mathrm{~cm}$. Cet aménagement a été taillé pour recevoir un bloc de chant qui devait également reposer sur la pierre suivante contiguë au côté droit de celle posée à plat.

Le lit de pose de la pierre inférieure est caractérisé par une très grande fraîcheur des traces de l'outil à percussion lancée qui a servi à le tailler (polka). L'absence de traces d'abrasion plaide en faveur d'une pose de cette face directement sur un matériau meuble, certainement le sol de terre.

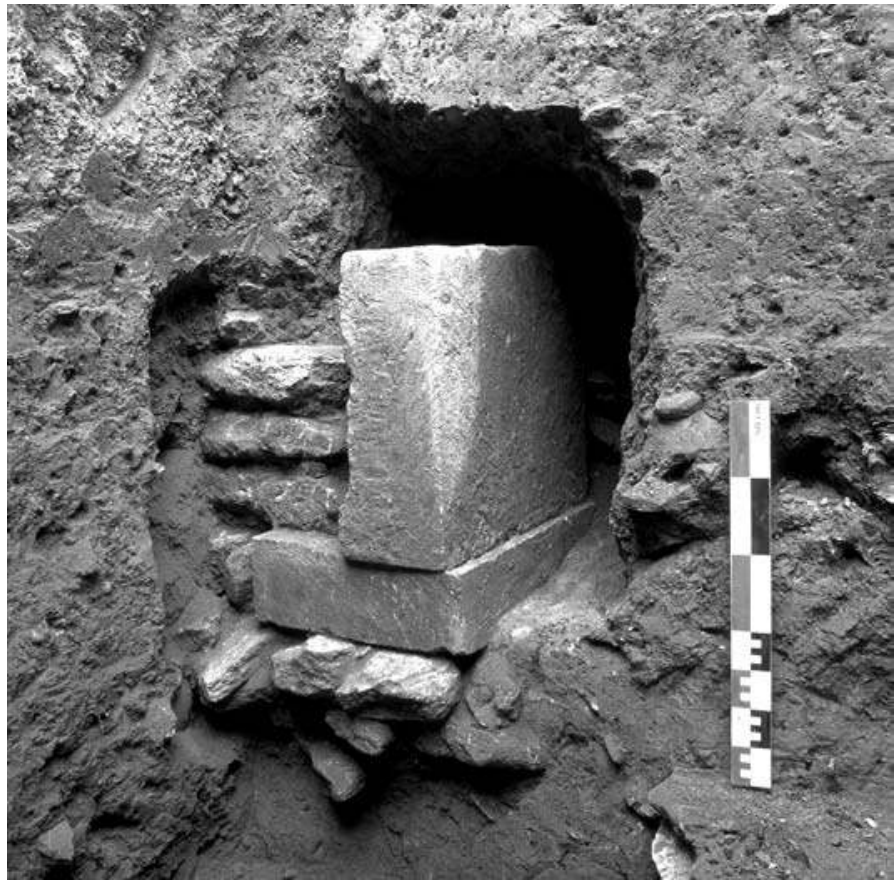

I 29 Le Cailar, sondage 1. Détail des blocs ouvragés $n^{\circ} 1$ et 2 réemployés dans le mur MR1002 pour bâtir le piédroit de la porte PR1043.

\section{Le bloc supérieur $n^{\circ} 2$ (us.1002)}

Placé dans ses lits de carrière, ce bloc mesure 51,5 à $52,5 \mathrm{~cm}$ de long, $46,7 \mathrm{~cm}$ de large et 18 à $18,5 \mathrm{~cm}$ de haut. Il s'agit d'un bloc inclus entre deux autres dans son emploi initial. Comme le précédent, ses grandes faces constituaient ses lits de pose et d'attente et il comporte aussi un parement limité en haut par un chanfrein. Toutefois, ce dernier, large d'environ $1 \mathrm{~cm}$, diffère en deux points de celui de la pierre précédente, d'une part, il ne se retourne pas vers le bas, d'autre part, son inclinaison est plus prononcée et forme un angle d'environ $15^{\circ}$ avec la verticale. Il s'agit donc vraisemblablement d'une pierre de fonction architectonique, assez proche de la précédente. Cependant, elle n'était pas contiguë à cette dernière et elle appartenait peut-être à une autre construction. Son joint montant gauche comporte un cadre d'anathyrose réduit à deux bandes, l'une au sommet et l'autre en retour, au contact du parement. La largeur de cette bande est irrégulière car définie par les aléas du sciage d'assemblage des blocs, au moment de leur mise en œuvre. Le joint montant droit est très bien taillé à $90^{\circ}$, à l'emplacement de son arête supérieure et de celle contiguë au parement. En revanche, vers le lit d'attente, la face est franchement voilée. On peut en déduire que le contact à joint vif n'était recherché avec la pierre voisine, que sur le parement et au niveau du lit d'attente.

En dehors des traces de la scie à joint et de quelques vestiges d'égrisage, ce bloc comporte des impacts d'un outil à 
percussion lancée linéaire transversale, muni d'un tranchant de $7 \mathrm{~cm}$ de large, certainement une polka.

\section{Fragment de bloc isolé $n^{\circ} 3$ (us.1025)}

Il ne subsiste qu'un angle de ce bloc dont seule la hauteur de $15 \mathrm{~cm}$ est complète. Sa longueur conservée est de $25 \mathrm{~cm}$ et sa largeur de $14 \mathrm{~cm}$. Il forme un angle bien droit en tous sens. Son lit d'attente est bien régularisé avec un ciseau de $4 \mathrm{~cm}$ de large et il en est de même pour ses faces latérales. En contrepartie, son lit de pose n'est taillé que très sommairement avec un outil non identifiable en raison de la surface très réduite conservée à ce niveau du bloc. Il pourrait s'agir d'un état brut d'extraction ou d'équarrissement en carrière. Le contexte de découverte (us.1025) est datable du dernier quart du $\mathrm{V}^{\mathrm{e}} \mathrm{s}$.

\section{Fragment de bloc mouluré $n^{\circ} 4$ (us.1019)}

Ce fragment (fig. 17) provenant d'un niveau du premier quart du IVe s. av. n. è. (us.1019) est incomplet en tous sens et seules les dimensions conservées sont mesurables: longueur $21,5 \mathrm{~cm}$, largeur 13,2 cm, hauteur $9,7 \mathrm{~cm}$. Il comporte une face moulurée comprenant successivement, de bas en haut: un listel de $1,5 \mathrm{~cm}$, un chanfrein renversé à $45^{\circ}$ de $1 \mathrm{~cm}$, une sorte de tore renversé très angulaire, que l'on peut aussi interpréter comme un chanfrein droit se raccordant à un filet horizontal par l'intermédiaire d'une courbe convexe, le tout d'une hauteur de $3,2 \mathrm{~cm}$ et, pour finir, l'amorce d'un nouveau chanfrein droit conservé sur une hauteur de 3,6 cm.

Le lit de pose est parfaitement plan et taillé au ciseau droit de $4 \mathrm{~cm}$ de large. Un égrisage périmétral précise les arêtes sur une largeur de 1 à $2 \mathrm{~cm}$, selon les endroits. Le joint montant droit, le seul en partie conservé, présente une qualité de taille équivalente réalisée avec le même outil. Ce même ciseau a servi à la taille des moulures, mais celles-ci ont été ensuite très soigneusement égrisées, si bien que les impacts d'outil n'apparaissent plus que dans les fonds inaccessibles à l'abrasif.

\subsubsection{Commentaires sur le matériel lapidaire du Cailar}

En dépit du nombre réduit d'éléments recueillis du fait de la très faible surface fouillée, on peut affirmer que les quatre pierres taillées découvertes au Cailar appartiennent à un ou plusieurs monuments soigneusement appareillés. Ce ou ces monuments comprenaient des pierres disposées en orthostate et un décor mouluré. Ce dernier témoigne en faveur d'un très grand soin d'exécution et d'une expérience professionnelle tout à fait inhabituelle dans la région avant la fin de l'époque hellénistique de la part des artisans qui ont réalisé cette pièce. Outre la précision constatée dans la réalisation du décor et de la taille, deux faits techniques particulièrement importants sont à signaler: l'emploi de la scie à joint et l'usage d'une mesure très proche de la coudée samienne de $52,5 \mathrm{~cm}$, en vigueur en divers points du monde grec, notamment à Marseille.

Dans la mesure où l'on tient compte qu'il s'agit là de remplois dans des contextes archéologiques datés de la fin du $\mathrm{V}^{\mathrm{e}}$ ou du début du IVe siècle avant notre ère, on peut affirmer qu'il s'agit des plus anciens témoignages connus en Occident dans ce domaine technique et métrologique.

Ces fragments lapidaires attestent aussi une activité extractive très ancienne organisée dans la région du village actuel de Mus et non une simple collecte de roches erratiques. Soulignons que cette pierre de taille se trouve à quelques mètres au-dessous de la surface du sol et exige une extraction en puits, technique tout à fait inhabituelle en Gaule méditerranéenne, quelle que soit l'époque considérée. Une activité extractive aussi précoce, destinée à une taille appareillée, remet aussi à l'ordre du jour le problème posé par la tour hellénistique de Mauressip à Saint-Cômes en Vaunage, où au moins quatre catégories différentes de pierre sont attestées, dont certaines déjà en remploi. Le site du Cailar, dont la proportion de céramique importée dépasse tout ce que l'on connaît sur la côte du Languedoc oriental, ne constituerait-il pas aussi un point d'entrée maritime majeur pour les techniques de construction monumentale dans l'arrière pays, vers la plaine de Vaunage et plus loin, vers Nîmes? En faveur de cette hypothèse, rappelons que le linteau sculpté protohistorique de Nages est vraisemblablement réalisé en pierre de Mus et que certains monuments antiques de Nîmes semblent utiliser cette même roche.

\subsection{LA FAUNE (Armelle Gardeisen)}

Il est possible de fournir une première ébauche du spectre faunique associé aux ensembles stratifiés du sondage $1 \mathrm{du}$ Cailar. Pour cela, 16 unités stratigraphiques ont été sélectionnées de manière à présenter une évolution de la faune consommée sur le site. Le nombre réduit de restes disponibles (566 os ou fragments d'os) a conduit cependant à regrouper l'ensemble en deux phases chronologiques, l'une rassemblant les niveaux de la deuxième moitié du $\mathrm{V}^{\mathrm{e}} \mathrm{s}$. av. n. è., l'autre la première moitié $d u \mathrm{IV}^{\mathrm{e}} \mathrm{s}$. La répartition des ossements et dents, attribués essentiellement à des animaux domestiques, est présentée sous la forme de deux tableaux (fig. 30). On devra tenir compte d'un léger déséquilibre quantitatif entre les populations illustrant les deux phases. La plus récente est la plus riche et de fait la plus caractéristique en terme d'exploitation animale à caractère alimentaire: les ossements porteurs de stigmates de découpe y sont en effet proportionnellement plus nombreux.

Cette analyse reposant sur un effectif encore réduit ne peut permettre qu'une approche préliminaire de la faune du site. 


\begin{tabular}{|l|c|c|c|c|c|c|c|c|c|c|}
\hline $\mathbf{- 4 5 0 / - 4 0 0}$ & NRD & \%NRD & NMI TJ & NMI J & NMI JA & NMI A & NMI Tot & NR brülés & NR découpés & NR rognés \\
\hline Lapin & 1 & 0,9 & & & & 1 & 1 & & & \\
\hline Cerf & 1 & 0,9 & & & & 1 & 1 & & & \\
\hline Sanglier & & & & & & & & & & \\
\hline Chien & 3 & 0,8 & & & & 2 & 2 & & & \\
\hline Bœuf & 22 & 20,4 & & & & 2 & 2 & & 6 & 4 \\
\hline Mouton-Chèvre & 56 & 51,9 & 4 & 4 & 2 & 5 & 15 & & 2 & \\
\hline Porc & 19 & 17,6 & & 2 & 1 & 2 & 5 & & 2 & \\
\hline Oiseaux & 7 & 6,5 & & & & & & & & \\
\hline Tortue & & & & & & & & & & \\
\hline Total Déterminés & 108 & 65,5 & & & & & & & & \\
\hline NR Indéterminés & 57 & 34,5 & & & & & & & $\mathbf{1 6}$ & $\mathbf{6}$ \\
\hline TOTAUX & $\mathbf{1 6 5}$ & & $\mathbf{4}$ & $\mathbf{6}$ & $\mathbf{3}$ & $\mathbf{1 3}$ & $\mathbf{2 6}$ & & & \\
\hline
\end{tabular}

\begin{tabular}{|l|c|c|c|c|c|c|c|c|c|c|}
\hline $\mathbf{- 4 0 0 / - 3 5 0}$ & NRD & \%NRD & NMI TJ & NMI J & NMI JA & NMI A & NMI Tot & NR brúlés & NR découpés & NR rognés \\
\hline Lapin & 4 & 2 & & & 1 & 3 & 4 & & & \\
\hline Cerf & 4 & 2 & & & & 1 & 1 & & & \\
\hline Sanglier & 1 & 0,5 & & & 1 & & 1 & & & \\
\hline Chien & 5 & 2,5 & & 1 & & 2 & 3 & & 1 & \\
\hline Boeuf & 70 & 35,5 & & 2 & 1 & 5 & 8 & 1 & 22 & 5 \\
\hline Mouton-Chèvre & 62 & 31,5 & 4 & 3 & 1 & 4 & 12 & 1 & 12 & 3 \\
\hline Ovis & 3 & 1,5 & & & & 1 & 1 & & & 7 \\
\hline Porc & 37 & 18,8 & 2 & 3 & 1 & 6 & 12 & & & 6 \\
\hline Oiseaux & 8 & 4,1 & & & & & & & & \\
\hline Tortue & 3 & 1,5 & & & & 1 & 1 & & & \\
\hline Total Déterminés & 197 & 49,1 & & & & & & & & \\
\hline NR Indéterminés & 204 & 50,9 & & & & & & & & $\mathbf{4 2}$ \\
\hline TOTAUX & $\mathbf{4 0 1}$ & & $\mathbf{6}$ & $\mathbf{9}$ & $\mathbf{5}$ & $\mathbf{2 3}$ & $\mathbf{4 3}$ & $\mathbf{2}$ & $\mathbf{4 2}$ \\
\hline
\end{tabular}

Abréviations : NRD : nombre de restes déterminés. NMI : nombre miminum d'individus.

$\mathrm{TJ}$ : très jeune. $\mathrm{J}$ : jeune. JA : jeune adulte. $\mathrm{A}$ : adulte. Tot : total.

I 30 Répartition de la faune du sondage 1 du Cailar en nombre de restes et en individus dans la deuxième moitié du Ve $\mathrm{s}$. (A) et dans la première moitié du IVe s. av. n. è. (B).

On se contentera donc de relever la dominance très nette de la trilogie domestique classique (bovins, ovins-caprins, porcins). À celle-ci s'ajoutent quelques gibiers comme le lapin et de manière plus anecdotique le cerf. La présence du sanglier reste à confirmer, le seul ossement attribuable à cet animal étant un fragment de mandibule dont la robustesse et la compacité évoquent un individu sauvage, par opposition à la gracilité des porcs au cours de l'âge du Fer. On remarquera aussi la présence discrète mais régulière du chien, de taille moyenne à grande, qui a été manifestement consommé: un radius porte la trace d'un tranché de découpe oblique dans le tiers proximal de sa diaphyse, face caudale (us.1001).

Les oiseaux, indéterminés ici du point de vue spécifique, semblent avoir constitué un gibier exploité de façon sporadique; les excellentes conditions de conservation ne sauraient justifier une perte significative de restes osseux d'oi- seaux. En effet, les ossements sont bien minéralisés et la fragmentation post-dépositionnelle est peu importante; parallèlement, les interventions de charognards ou de petits carnivores sont rares.

Le porc apparaît comme un élément stable dans l'approvisionnement, alors que les grands et petits ruminants semblent davantage sujets à des variations. Ce phénomène a déjà été décrit pour les ovins-caprins et les porcins au cours des trois derniers siècles avant le changement d'ère sur le site de Lattes, situé comme le Cailar en zone littorale (Colomer 1992). Il se pourrait que, dans cette zone, on ait très tôt privilégié l'exploitation des bovins alors que l'arrière-pays était davantage orienté vers l'élevage des petits ruminants (Gardeisen 1999). La spécificité bovine de la plaine littorale semble installée depuis la fin du Néolithique et perdure jusqu'aux alentours de l'an mil (Gardeisen 1993; Forest, à paraître). 


\begin{tabular}{|c|c|c|c|c|c|c|c|c|c|c|c|c|}
\hline \multirow{3}{*}{ Nombre de restes } & \multicolumn{5}{|c|}{ Collecte manuelle } & \multicolumn{6}{|c|}{ Prélèvement } & \multirow{3}{*}{ Tota } \\
\hline & \multirow{2}{*}{ US 1001} & \multirow{2}{*}{ US 1012} & \multirow{2}{*}{ US 1015} & \multirow{2}{*}{ US 1017} & \multirow{2}{*}{ US 1031} & \multicolumn{2}{|c|}{ US 1022 (1 litre) } & \multirow{2}{*}{\begin{tabular}{|l} 
US 1023 \\
$>4 \mathrm{~mm}$
\end{tabular}} & \multirow{2}{*}{$\begin{array}{l}\text { (11 litres) } \\
>1 \mathrm{~mm}\end{array}$} & \multicolumn{2}{|c|}{ US 1025 (20 litres) } & \\
\hline & & & & & & $>4 \mathrm{~mm}$ & $>1 \mathrm{~mm}$ & & & $>4 \mathrm{~mm}$ & $>1 \mathrm{~mm}$ & \\
\hline \multicolumn{13}{|l|}{ Os de la tête } \\
\hline operculaire & 1 & & & & & & & & & 2 & & 3 \\
\hline articulaire & & & & & & & & & & & 1 & 1 \\
\hline maxillaire & & & & & 1 & & & & & & & 1 \\
\hline cleithrum & & & 1 & & & & & & & & 1 & 2 \\
\hline épihyale & & & & & & & & & & & 2 & 2 \\
\hline hyomandibulaire & & 1 & & & & & & & & & & 1 \\
\hline dent mola-réniforme & & & & & & & & 1 & & & & 1 \\
\hline dent molariforme & & & & & & & & & 2 & & 7 & 9 \\
\hline dent caniniforme & & & & & & & & & & 1 & & 1 \\
\hline prémaxillaire & & & & 1 & & & & & & & & 1 \\
\hline \multicolumn{13}{|l|}{ Rachis } \\
\hline vertèbre thoracique & & & & & & & & 1 & 2 & 3 & 3 & 9 \\
\hline vertèbre caudale & & & & & & & 1 & & 1 & 6 & 6 & 14 \\
\hline complexe urophore & & & & & & & & & 1 & & & \\
\hline NRT & $\mathbf{1}$ & $\mathbf{1}$ & 1 & $\mathbf{1}$ & 1 & 0 & 1 & 2 & 6 & 12 & 20 & 46 \\
\hline Arête & & & & & & & & 1 & & 4 & 26 & 31 \\
\hline Lépidotriche & 22 & & & & & & 1 & & 13 & 1 & 11 & 48 \\
\hline Ecaille & & & & & & & 10 & 6 & 33 & 120 & 150 & 319 \\
\hline NR & 23 & $\mathbf{1}$ & $\mathbf{1}$ & $\mathbf{1}$ & 1 & 0 & 12 & 9 & 52 & 137 & 207 & 444 \\
\hline NMI & 1 & 1 & 1 & 1 & 1 & \multicolumn{2}{|c|}{2} & \multicolumn{2}{|c|}{3} & \multicolumn{2}{|r|}{9} & 17 \\
\hline Nombre de taxons & 1 & 1 & 1 & 1 & 1 & \multicolumn{2}{|c|}{2} & \multicolumn{2}{|c|}{3} & \multicolumn{2}{|c|}{5} & 5 \\
\hline
\end{tabular}

131 Le Cailar, sondage 1. Nombre de restes d'ichtyofaune déterminés au niveau taxonomique (NRT: famille, genre ou espèce) par pièce anatomique et par unité stratigraphique.

La prédation semble constituer une activité de moindre rapport mais les échantillons sont encore numériquement trop faibles pour tirer de véritables conclusions de ces résultats. Toutefois, la tendance régionale montre une chasse bien plus active qu'au Cailar sur les oppidums du Languedoc oriental à la même époque: environ $20 \%$ des individus exploités, contre $7 \%$ et $14 \%$ respectivement au cours des deux phases d'occupation du site (Colomer 1992).

Ici, les taux sont modifiés par une augmentation nette des restes de bovins entre les deux phases. À cela s'ajoute le fait que le tiers de ceux-ci est immature: deux juvéniles et un jeune adulte sur un total de huit individus. Les classes d'âge d'abattage observées pour les principales espèces domestiques témoignent d'une exploitation orientée vers l'acquisition de viande: les taux de juvéniles y sont assez importants, approximativement proches de la moitié de la population identifiée (fig. 30).

Les marques de découpe des carcasses sont d'autant plus nombreuses que le format de l'animal est important: ainsi, les taux d'ossements porteurs de traces de découpe à vocation alimentaire sont plus importants chez les bovins. Les observations sont particulièrement fréquentes sur les corps de côtes (toutes espèces confondues) qui ont fait l'objet d'une découpe en portions traduite par des doubles tranchés transverses effectués par la face interne de l'os de façon à déterminer des parts de viandes comprises entre 95 et $130 \mathrm{~mm}$ de longueur. Globalement, l'essentiel des marques a été attribué à des actions de dépeçage ou encore de mise en pièce; parmi ces exemples, on relève quelques rares actions de désarticulation. En revanche, il n'a pas été observé de traces du dépouillage ou du débitage primaire des carcasses. Les assemblages correspondent aux reliefs d'une consommation de type domestique, la viande étant introduite dans la maison sous forme de quartiers déjà découpés.

\subsection{L'ICHTYOFAUNE (Gaël Piqués)}

La localisation du site du Cailar au confluent du Rhôny et du Vistre, suggérait la possibilité d'une exploitation des ressources piscicoles, confirmée par la découverte de restes de poissons au cours de la fouille. Des prélèvements ont alors été effectués afin d'évaluer les potentialités du site en données ichtyofauniques et de dresser un premier bilan sur la nature des espèces consommées.

\subsubsection{Matériel et méthode d'étude}

L'essentiel du matériel ichtyofaunique étudié provient des prélèvements tamisés à l'eau à partir d'une colonne de tamis de 4,1 et $0,5 \mathrm{~mm}$. Ces prélèvements, effectués dans des couches de remblai et d'occupation fournissent un échantillon d'une quarantaine de restes dont la famille, le genre ou l'espèce a pu être déterminé (fig. 31). À cela s'ajoutent des écailles, des lépidotriches (rayons osseux des nageoires) et des arêtes indéterminées.

En raison d'un échantillonnage encore restreint, l'étude du matériel ne peut être pour le moment que qualitative. L'analyse des os passe par l'enregistrement d'un certain nombre de données qui demanderont à être enrichies par l'apport de nouveaux prélèvements afin d'envisager une étude quanti- 


\begin{tabular}{|c|c|c|c|c|c|c|c|c|c|c|c|}
\hline \multirow[b]{2}{*}{ US } & \multirow[b]{2}{*}{ Taxon } & \multirow[b]{2}{*}{ Nom commun } & \multirow[b]{2}{*}{ Os } & \multirow[b]{2}{*}{ NR } & \multirow[b]{2}{*}{ NMI } & \multicolumn{4}{|c|}{ Mesures (mm.) } & \multirow[b]{2}{*}{ Lt $(\mathbf{c m})}$. & \multirow[b]{2}{*}{ Pds (g.) } \\
\hline & & & & & & M1 & M2 & M3 & M4 & & \\
\hline \multirow[t]{2}{*}{1001} & indéterminé & & fr. d'operculaire (G) & 1 & & & & & & & \\
\hline & & & lépidotriche & 22 & & & & & & & \\
\hline 1012 & Dicenthrarchus labrax & loup & hyomandibulaire & 1 & 1 & & 33,8 & 7,3 & & 46 & 1500 \\
\hline \multirow[t]{2}{*}{1015} & Dicenthrarchus labrax & loup & cleithrum (D) & 1 & 1 & & 7,5 & & & 42 & 800 \\
\hline & & & cleithrum $(G)$ & 1 & & & & & & & \\
\hline 1017 & Sparus aurata & daurade & prémaxillaire $(G)$ & 1 & 1 & & & 9.8 & 11.8 & 30 & 500 \\
\hline \multirow[t]{2}{*}{1022} & Anguilla anguilla & anguille & vertèbre caudale & 1 & 1 & & & & & & \\
\hline & indéterminé & & écaille & & 1 & & & & & & \\
\hline \multirow[t]{12}{*}{1023} & Sparus aurata & daurade & dent mola-réniforme & 1 & 1 & & & & & & \\
\hline & Anguilla anguilla & anguille & vertèbre thoracique & 1 & 1 & & & & & $<20$ & \\
\hline & Mugilidae & muge & 2ème vertèbre & 1 & & & & & & & \\
\hline & & & 3ème vertèbre & 1 & & & & & & & \\
\hline & & & 4ème vertèbre & 1 & 1 & & & & & $<16$ & \\
\hline & Mugilidae & muge & vertèbre caudale & 1 & 1 & & & & & & \\
\hline & Sparidae & famille des Sparidés & dent molariforme & 2 & & & & & & & \\
\hline & indéterminé & & complexe urophore & 1 & & & & & & & \\
\hline & & & fr. de vertèbre & 1 & & & & & & & \\
\hline & & & écaille & 39 & & & & & & & \\
\hline & & & lépidotriche & 13 & & & & & & & \\
\hline & & & axonoste & 1 & & & & & & & \\
\hline \multirow[t]{23}{*}{1025} & Dicenthrarchus labrax & loup & $13 / 15$ ème vertèbre & 1 & 1 & 8.7 & 8.2 & 10.5 & & 42 & 1000 \\
\hline & Sparus aurata & daurade & 13 ème vertèbre & 1 & 1 & 8.9 & 8.5 & 11,2 & & 42 & 1100 \\
\hline & Sparidae & famille des Sparidés & dent molariforme & 7 & & & & & & & \\
\hline & & & dent caniniforme & 1 & & & & & & & \\
\hline & Mugilidae & muge & 14/15ème vertèbre & 1 & 1 & 9 & & & & 50 & 1000 \\
\hline & Anguilla anguilla & anguille & $31 / 45$ ème vertèbre & 1 & 1 & 2.8 & 3.2 & 3.9 & & 44 & 170 \\
\hline & & & 14/20ème vertèbre & 1 & 1 & 2.7 & 2,96 & 3.8 & & 41 & 125 \\
\hline & & & vertèbre caudale & 3 & & & & & & & \\
\hline & & & articulaire (D) & 1 & & & & & & & \\
\hline & & & cleithrum (D) & & & & & & & & \\
\hline & & & épihyal $(G)$ & 1 & & & & & & & \\
\hline & & & épihyal (D) & 1 & & & & & & & \\
\hline & & & 14/20ème vertèbre & 1 & 1 & 1.5 & 1.6 & 2.3 & & 27 & 50 \\
\hline & & & vertèbre caudale & 2 & & & & & & & \\
\hline & & & vertèbre thoracique & 1 & 1 & & & & & $<20$ & \\
\hline & & & vertèbre caudale & 1 & & & & & & $<20$ & \\
\hline & Cyprinidae & famille des Cyprinidés & vertèbre thoracique & 1 & 1 & & & & & & \\
\hline & & & vertèbre thoracique & 1 & 1 & & & & & & \\
\hline & & & vertèbre caudale & 1 & 1 & & & & & & \\
\hline & indéterminé & & fr. d'operculaire & 2 & & & & & & & \\
\hline & & & axonoste & 30 & & & & & & & \\
\hline & & & lépidotriche & 12 & & & & & & & \\
\hline & & & écaille & 270 & & & & & & & \\
\hline 1031 & Sparus aurata & daurade & maxillaire $(G)$ & 1 & 1 & 37.1 & 11.1 & & & 39 & 900 \\
\hline
\end{tabular}

I 32 Le Cailar, sondage 1. Identification et quantification des données ichtyofauniques par unité stratigraphique.

tative ultérieure. Pour chaque unité stratigraphique, les données enregistrées sont: la détermination anatomique et spécifique des os, le nombre de reste (NR) et le nombre minimum d'individu (NMI) par taxons, et enfin les mesures des os pour reconstituer la longueur totale (LT) et le poids (Pds) du poisson (fig. 32).

Si l'on exclut les arêtes, les lépidotriches et les écailles, tous les os à l'exception d'un operculaire (us.1001) ont pu être déterminés au niveau anatomique et taxonomique (famille, genre ou espèce), en raison de leur très bon état de conservation. Ces déterminations ont été réalisées à partir d'une collection de comparaison composée d'une centaine d'espèces d'eau douce et marines originaires du sud de la France et de la Méditerranée.

Les vertèbres de Cyprinidés (chevaine, rotengle...) n'ont pu être déterminées au-delà de la famille: bien qu'il existe des critères morphologiques de détermination spécifique (Le Gall 1984), ceux-ci se sont avérés difficilement appli- 


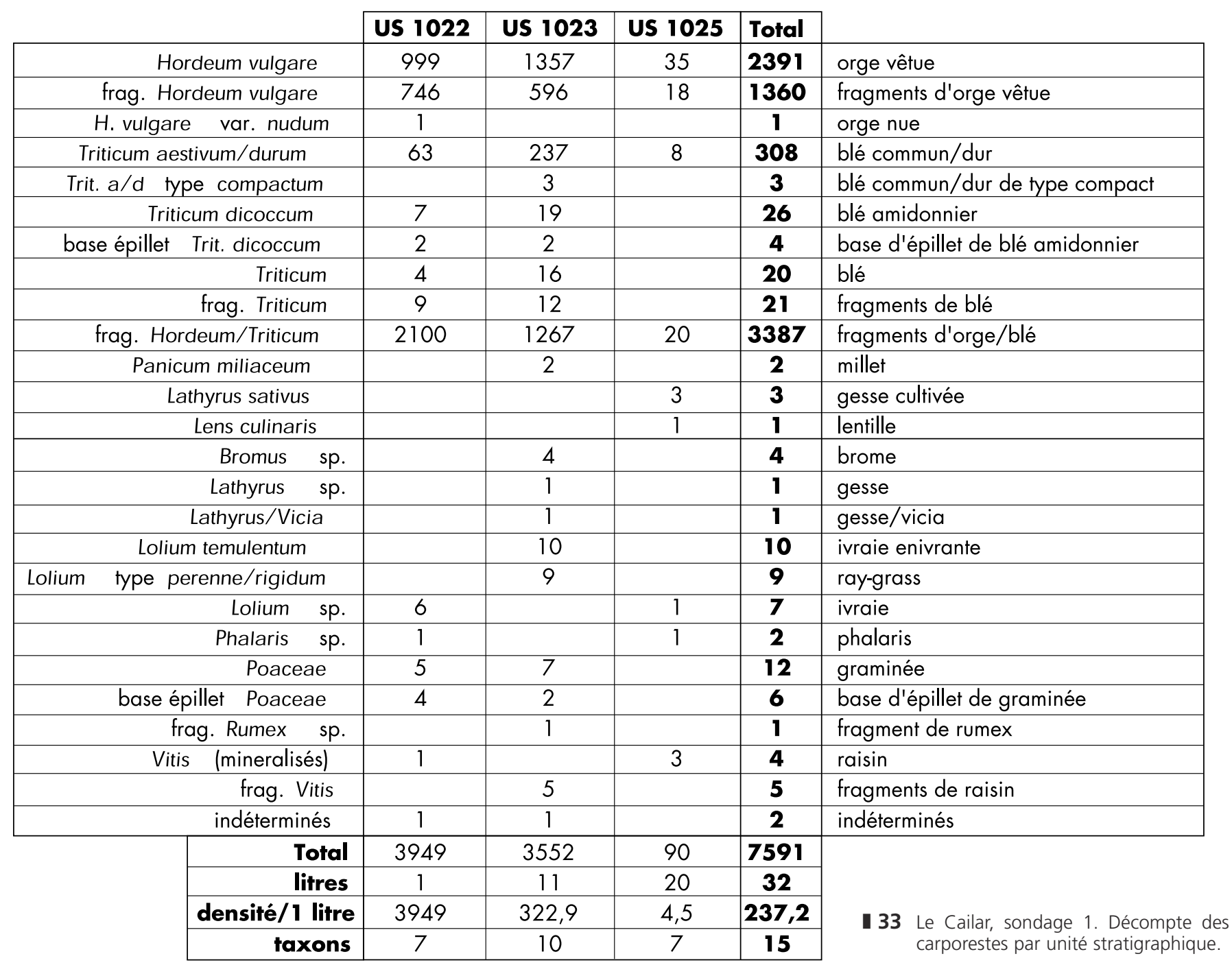

cables au matériel archéologique. Pour les Mugilidés, qui comptent en Languedoc trois genres (Mugil, Liza, Chelon), la diagnose spécifique des os est également délicate. Cette distinction est toutefois de faible intérêt car ces muges partagent approximativement le même biotope (Desse 1987).

Le nombre minimum d'individu (NMI) par unité stratigraphique est défini pour chaque taxon à partir du nombre de spécimens de taille différente d'après la mesure des os, après correction, dans le cas d'individus de même taille, par le dénombrement des os pairs. Quant à la taille et au poids des spécimens archéologiques, leur reconstitution est effectuée à l'aide des données métriques des fiches ostéologiques consacrées aux poissons ${ }^{29}$ éditées sous la direction de J. Desse et N. Desse-Berset. Celles utilisées ici portent sur: Dicentrarchus labrax (L.) (Sternberg 1992), Sparus aurata L. (Desse 1996), Anguilla anguilla L. (Piqués à paraître) et Liza Ramada (R.) (Desse 1987). Pour cette dernière espèce, les auteurs précisent que les mesures relevées sur le rachis de différentes espèces de Mugilidés ne semblent pas présenter de notables différences avec celles prises sur Liza ramada, et peuvent probablement être exploitées sur les mêmes abaques.

\subsubsection{Une activité de pêche tournée vers la lagune}

Les prélèvements effectués dans le sondage 1 du Cailar ont été répartis en deux phases, l'une concernant la deuxième moitié du $\mathrm{V}^{\mathrm{e}} \mathrm{s}$., l'autre la première moitié du $\mathrm{IV}^{\mathrm{e}} \mathrm{s}$. av. n. è. Dans chacune de ces phases figurent quatre espèces, qui sont: le loup (Dicentrarchus labrax (L.), la daurade (Sparus aurata L.) le muge (famille des Mugilidés) et l'anguille (Anguilla anguilla L). S'ajoutent dans la seconde phase des restes de Cyprinidés (us.1025).

La présence de poissons de fleuves et de rivières tels que les Cyprinidés témoigne de l'existence d'une exploitation des ressources du Vistre ou du Rhôny. 
La daurade, le loup, le muge et l'anguille, sont des espèces très abondantes dans les étangs littoraux; d'origine marine, elles colonisent ce milieu pour y effectuer leur croissance (Sternberg 1995, 69-74). Cependant, l'anguille peuple également la plupart des cours d'eau, de même que le muge et le loup peuvent séjourner en eau douce. Certains muges remontent les fleuves sur plus d'une centaine de kilomètres (Bauchot 1980), et dans le Rhône des loups sont encore pêchés jusqu'à Arles. Toutefois l'activité de pêche des habitants du Cailar au $\mathrm{V}^{\mathrm{e}}$ et $\mathrm{IV}^{\mathrm{e}} \mathrm{s}$. av. n. è. concernait aussi la lagune, comme l'indique la présence de daurades royales dont la répartition ne remonte pas au-delà des étangs lagunaires.

La répartition des espèces dépendant de contraintes hydrobiologique (taux d'oxygénation et température de l'eau, teneur en sel...), il est possible de caractériser le milieu de pêche à partir des associations d'espèces. Il faut noter que la présence de Cyprinidés n'implique pas forcément une eau totalement douce car des poissons appartenant à cette famille, comme le chevaine (Leuciscus cephalus), s'acclimatent aux eaux saumâtres. En ce sens, l'ichtyofaune apporte une contribution à la restitution autour du site d'un milieu deltaïque proche d'une lagune.

Pour le site du Cailar, les ressources de l'étang par rapport à celle d'un fleuve ou d'une rivière ne furent certainement pas seulement un appoint dans l'activité de pêche, mais semblent avoir constitué l'apport principal. Cette hypothèse repose sur le fait que l'effort de pêche en lagune est nettement plus rentable que dans un cours d'eau: les poissons capturés y sont en effet de taille plus conséquente. Or, pour les $V^{e}$ et $I V^{e} s$. av. n. è., la mesure des os indique des captures de loups, daurades et muges d'un poids supérieur à un kilogramme. Ces données métriques, comparables à celles d'autres sites côtiers protohistoriques du Languedoc (Sternberg 1995), témoignent des effets d'une pression de la pêche qui en s'accentuant au cours du temps a conduit à la diminution progressive de la taille moyenne des captures d'espèces comme la daurade royale (Desse 1993).

\section{6. ÉLEMENTS CARPOLOGIQUES (Natàlia Alonso Martínez)}

Les prélèvements archéobotaniques réalisés dans le sondage 1 du Cailar ont permis la récupération d'un nombre assez élevé de restes de semences et de fruits, principalement des céréales. Trois couches ont été échantillonnées: un dépotoir (us.1023) du dernier quart du $\mathrm{V}^{\mathrm{e}} \mathrm{s}$., un foyer (us.1022) du premier quart du $\mathrm{IV}^{\mathrm{e}} \mathrm{s}$. et un remplissage de tranchée antique (us.1025) contenant des mobiliers de la fin du $V^{e}$ et du début du $\mathrm{IV}^{\mathrm{e}} \mathrm{s}$. Malgré la faible surface fouillée, les résultats sont très significatifs, comme le montrent quelques chiffres: que ce soit le nombre de restes (7590), les 15 taxons identifiés - dont 8 cultivés -, ou encore la densité moyenne (237,2 restes par litre traité). La plus grande concentration correspond au foyer FY1022, qui a livré 3948 restes dans un seul litre de sédiment (fig. 33).

Parmi les taxons déterminés, l'orge vêtue (Hordeum vulgare) est de loin la céréale la mieux représentée, avec 2391 individus et 1360 fragments, soit $86,8 \%$ des individus de plantes cultivées, autant pour ce qui concerne la fin du $\mathrm{V}^{\mathrm{e}}$ siècle que le début du IVe (fig. 33 et 34). D'autres céréales ont été aussi récupérées mais en quantité moindre. La deuxième en nombre est le blé nu (Triticum aestivum/durum) assez abondant, avec 308 individus, soit $11,2 \%$, tandis que le pourcentage des autres céréales est très réduit: amidonnier (Triticum dicoccum: 0,94\%), blé nu de type compact (Triticum aestivum/durum type compactum: 0,1\%), millet (Panicum miliaceum: 0,07\%) et orge nue (Hordeum vulgare var. nudum: 0,04\%).

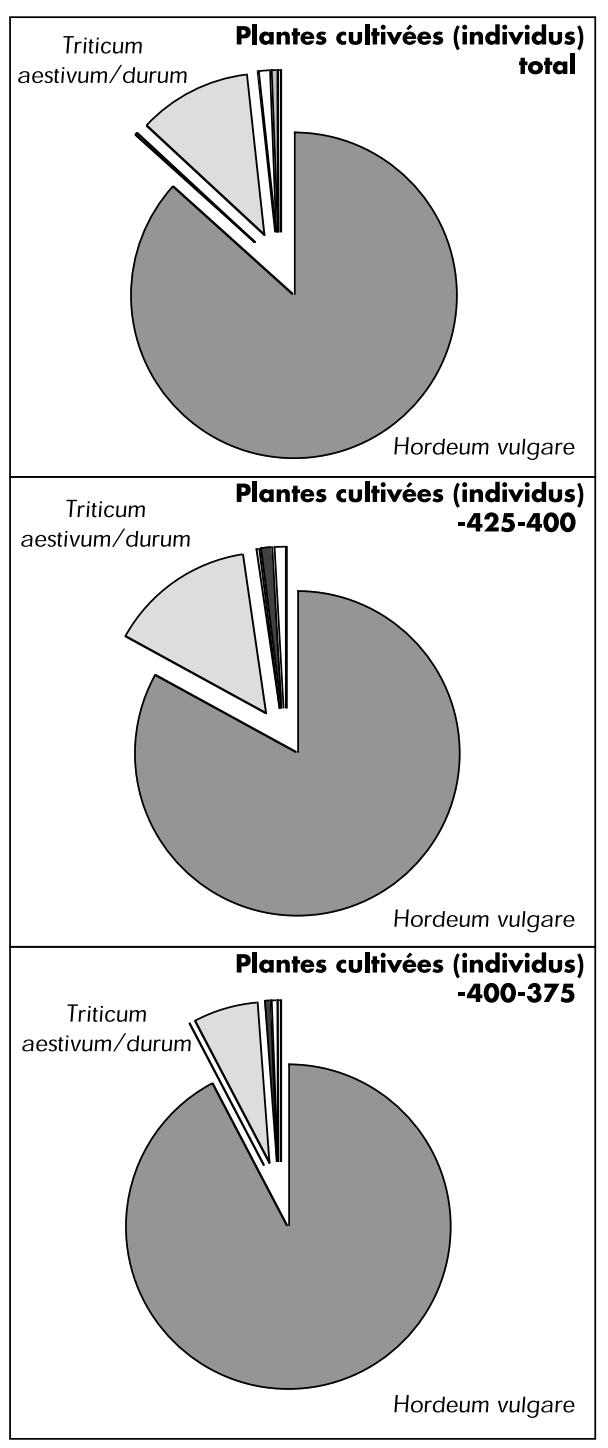

I 34 Le Cailar, sondage 1. Répartition des plantes cultivées par périodes. 
Seulement deux espèces cultivées autres que les céréales ont été identifiés: la lentille (Lens culinaris: 0,04\% des individus), et la gesse cultivée (Lathyrus sativus: 0,11\%).

Les plantes sauvages sont aussi présentes, avec 7 taxons déterminés, tous rares sauf le groupe des ivraies (Lolium sp., Lolium temulentum, ivraie enivrante et Lolium perenne/rigidum, ray-grass), légèrement plus représenté. Presque tous les taxons sauvages déterminés correspondent à des plantes synanthropiques, surtout des herbacées qui poussent comme mauvaises herbes ou rudérales sur les bords des chemins ou dans les lieux très fréquentés par les humains: le brome (Bromus sp.), le phalaris (Phalaris sp.), le rumex (Rumex sp.) ainsi que les ivraies. Compte tenu du registre archéobotanique présent dans les prélèvements étudiés, on peut considérer qu'il s'agit de plantes accompagnant la culture et la récolte des céréales.

Une autre espèce, avec seulement 3 exemplaires minéralisés et 5 fragments, est le raisin. Son très mauvais état de conservation et sa fragmentation ne permettent pas discerner s'il s'agit de raisin cultivé ou non.

La faible présence des restes correspondant à des sous-produits de la cueillette, principalement les segments de rachis, de glumelles, les bases d'épillet, et la quantité de mauvaises herbes indiquent qu'il s'agit d'un grain assez propre, préparé pour l'alimentation humaine. La carbonisation s'est produite probablement accidentellement alors que le grain était déjà propre.

Pour ce qui concerne le foyer FY1022, il ne semble pas s'agir d'une structure de transformation des orges, mais plutôt d'un foyer domestique où ont brûlé les céréales avant leur consommation. Dans le premier cas, la présence des sous-produits aurait été beaucoup plus importante. La même remarque est possible pour le prélèvement du dépotoir 1023 où le type de restes est similaire et pourrait correspondre au nettoyage de foyers. Le comblement de la tranchée 1025 donne des résultats plus pauvres où l'on note seulement la présence d'orges et la récupération de gesses et de lentilles.

La prépondérance de l'orge vêtue au Cailar confirme l'importance de cette culture à partir de l'âge du Bronze dans le Midi. Des grands amas d'orges sont en effet connus au premier âge du Fer à Lattes Port-Ariane (Alonso et al., inédit) et au Lycée Technique de Montpellier (Erroux 1966), et au début du deuxième âge du Fer ( $\mathrm{V}^{\mathrm{e}}$-début $\mathrm{IV}^{\mathrm{e}} \mathrm{s}$.) dans la ville de Lattara (Alonso, inédit).

Le blé nu représente ici en importance la deuxième céréale récoltée, bien que loin derrière l'orge, et surpasse l'amidonnier. L'orge vêtue et l'amidonnier sont les céréales les mieux attestées sur les sites de l'âge du Bronze comme La Fangade (Sète), Port-Vielh (Vendres) (Bouby 1999) ou Lattes Port-Ariane (Alonso et al., inédit). C'est pendant à l'âge du Fer, surtout à partir du IV ${ }^{\text {e }}$ siècle, que la culture du blé nu prend une importance majeure, comme on a pu le constater à Lattes, autant sur le site de Saint-Sauveur (Buxó 1999, 533-534) qu'à Port-Ariane (Alonso et al., inédit).

\section{Conclusion}

$\mathrm{S}$ ur la base des données actuellement acquises sur le gisement du Cailar, on peut tenter d'une part de caractériser ce site, et d'autre part de le positionner dans le cadre régional du Languedoc oriental.

Le premier apport des découvertes et recherches récentes concerne la chronologie. Il faut reconnaître que le début de l'occupation est encore mal situé dans le temps. Le sondage 1 a démontré que l'origine remontait au-delà du milieu du $\mathrm{V}^{\mathrm{e}} \mathrm{s}$., tandis que les tessons trouvés en prospection suggèrent une date autour de 500 av. n. è. Cependant, dans le cimetière, les niveaux primitifs de l'habitat sont à une profondeur telle par rapport au sol moderne - plus de 3,5 $\mathrm{m}-$ qu'il serait hasardeux de présumer de leur datation à partir des seuls documents trouvés en surface ou dans les creusements de caveaux qui ne descendent guère que jusqu'à $2 \mathrm{~m}$. Relevons par exemple qu'un tesson de bucchero nero est inclus au remplissage de la tranchée d'épierrement 1015 du sondage 1 et pourrait témoigner d'une occupation antérieure à la fin $\mathrm{du} \mathrm{VI}^{\mathrm{e}} \mathrm{s}$.

Les données de prospection indiquent une présence humaine apparemment continue à partir du $\mathrm{V}^{\mathrm{e}} \mathrm{s}$. av. n. è. jusqu'à l'époque romaine, assurément jusqu'au HautEmpire, probablement jusqu'à l'orée du $\mathrm{IV}^{\mathrm{e}} \mathrm{s}$. de n. è., puis du $I^{\mathrm{e}}$ au $\mathrm{XV}^{\mathrm{e}}$ s., l'Antiquité tardive n'étant pour l'heure pas réellement documentée.

L'analyse globale de la stratigraphie du sondage 1 confirme la continuité de l'occupation de l'âge du Fer, au moins du $\mathrm{V}^{\mathrm{e}} \mathrm{au} \mathrm{II}^{\mathrm{e}} \mathrm{s}$. av. n. è. Le rythme de la sédimentation est, pour cette période, d'environ $1 \mathrm{~m}$ par siècle: 1,25 $\mathrm{m}$ d'épaisseur pour quelque 125 ans dans la partie conservée en place (us.1003 à 1035), $85 \mathrm{~cm}$ ensuite pour une période allant de la fin du IVe à la fin du III ${ }^{\mathrm{e}}$ s. av. n. è. (us.1034 à 1008). Cet exhaussement, lié en partie à l'utilisation des ruines de murs en adobes comme remblai, est nettement plus rapide au cours de l'âge du Fer qu'aux périodes ultérieures. Sur ce point, la comparaison avec d'autres gisements similaires de la plaine littorale n'est pas inintéressante: le rythme de la sédimentation anthropique relevé au Cailar est en effet tout à fait comparable à celui de Lattes, où l'on observe également intra muros un exhaussement moyen d'un mètre par siècle; il est par contre beaucoup plus fort qu'à Espeyran, où cette sédimentation n'est que de $25 \mathrm{~cm}$ par siècle. Une telle différence est probablement liée aux risques locaux d'inondation ou de remontée de la nappe phréatique, qui devaient être plus sensibles au Cailar et à Lattes qu'à 
Espeyran, où l'habitat est construit sur une langue de galets des Costières assez élevée et bien drainée.

Il est plus difficile de déterminer la taille de l'agglomération aux différentes périodes. Pour ce qui est de la Protohistoire, on relève la présence de tessons d'amphores de Marseille dans l'ensemble des terrains prospectés autour du cimetière, sur une surface minimale de 2 hectares. La prise en compte des points particuliers de la topographie (tracés anciens des cours d'eau, courbes de niveau, anomalies dans le plan cadastral et urbain) incite à étendre ce périmètre à l'extrémité sud du village actuel, en incluant les environs du Temple près duquel fut recueilli l'un des chenets publiés naguère, soit une surface possible de 4 à 5 ha sur laquelle il est raisonnable de supposer l'existence d'un habitat à la fois groupé et durable ${ }^{30}$. Une telle estimation reste en l'état des données la plus probable. Inclure le boulevard Gambetta où fut trouvé un second chenet (parcelle cadastrale 139) conduirait à doubler cette superficie en englobant la majeure partie du vieux village, mais cette option maximale, reposant sur un document unique et isolé de tout contexte, demeure assez hypothétique.

Le Cailar continua-t-il à former à l'époque romaine une agglomération importante, comme on l'a parfois supposé, en proposant notamment de l'identifier avec la "Virinn(ae)" de l'inscription géographique de Nimes ${ }^{31}$ ? Cela reste discuté, car l'analyse du peuplement de la zone n'exclut pas à cette époque un éclatement de l'habitat en plusieurs établissements de moindre dimension: ce que pourrait éventuellement refléter la modestie des témoins gallo-romains sur le site du Castellas (Raynaud à paraître).

Le sondage 1 apporte des informations précises et abondantes sur les $V^{e}$ et $I V^{e} s$. av. n. è., qui permettent, pour cette période du moins, d'insérer le gisement dans un contexte régional plus large. La fouille, bien que de surface extrêmement réduite, confirme l'existence d'un habitat construit en dur dès avant le milieu du $\mathrm{V}^{\mathrm{e}} \mathrm{s}$. et sa pérennité sur plusieurs générations. On soulignera la précocité de l'emploi de la pierre et de la brique pour construire les murs: dans la Vaunage proche ${ }^{32}$, la construction en pierre n'est attestée qu'à partir de la fin du $\mathrm{V}^{\mathrm{e}} \mathrm{s}$. et la brique apparemment inusitée ${ }^{33}$. Plus précoce encore, relativement aux données régionales, est la présence de la pierre taillée, illustrée ici par plusieurs blocs montrant l'application de techniques parfaitement maîtrisées. Ces éléments travaillés, hors d'usage ou en remploi - dont l'élaboration est donc plus ancienne encore - ont été retrouvés dans des couches du troisième quart du $\mathrm{V}^{\mathrm{e}} \mathrm{s}$. (us.1032), de la fin du $\mathrm{V}^{\mathrm{e}}$ ou du début du $\mathrm{IV}^{\mathrm{e}} \mathrm{s}$. (us.1019, 1025), et dans un mur construit vers 400 (us.1002). Les caractères techniques et la qualité de la taille témoignent assurément d'apports exogènes, dont l'origine méditerranéenne est indubitable.

Le faciès céramique reflète également une large ouverture au monde méditerranéen, à la fois qualitativement et quan-

\begin{tabular}{|c|c|}
\hline tournée fine: 290 (5.87\%) & $\begin{array}{l}\text { attique: } 57(4.96 \%) \\
\text { pseudo-at: } 28(2.44 \%) \\
\text { cl.-peinte: } 183(15.93 \%) \\
\text { autres grises: } 3(0.26 \%) \\
\text { gris mono: } 16(1.39 \%) \\
\text { ib-lang: } 1(0.09 \%) \\
\text { ital-vn: } 1(0.09 \%) \\
\text { bucchero: } 1(0.09 \%)\end{array}$ \\
\hline tournée commune: 354 (7.17\%) & $\begin{array}{l}\text { pâte-cl.: } 246(21.41 \%) \\
\text { mort-m: } 9(0.78 \%) \\
\text { cct-lor: } 97(8.44 \%) \\
\text { com-itagr: } 2(0.17 \%)\end{array}$ \\
\hline non tournée: 505 (10.22\%) & $\begin{array}{l}\text { CNT-Ber: } 29 \text { (2.52\%) } \\
\text { CNT-Lor: } 476(41.43 \%)\end{array}$ \\
\hline \multicolumn{2}{|l|}{ TOTAL VAISSELLE: 1149 (23.26\%) } \\
\hline amphores: 3455 (69.95\%) & $\begin{array}{l}\text { a-mas: } 3425(99.13 \%) \\
\text { a-gre: } 7(0.2 \%) \\
\text { a-ibé: } 8(0.23 \%) \\
\text { a-etr: } 11(0.32 \%) \\
\text { a-mgr: } 1(0.03 \%) \\
\text { a-autres: } 2(0.06 \%) \\
\text { a-pun: } 1(0.03 \%)\end{array}$ \\
\hline \multicolumn{2}{|l|}{ dolium: 335 (6.78\%) } \\
\hline TOTAL : 4939 fragments & \\
\hline
\end{tabular}

I 35 Le Cailar, sondage 1. Décompte et proportions moyennes des différentes catégories de céramiques pour la période 450-350 av. n. è.

titativement, ainsi que le montrera la comparaison avec quelques sites du Languedoc oriental où des informations chiffrées sont disponibles pour l'époque concernée. Nous limiterons ces comparaisons au siècle 450-350 pour lequel le sondage 1 du Cailar a fourni une base statistique suffisante (4939 fragments de vases) (fig. 35) ${ }^{34}$.

La céramique attique (fig. 15 et fig. 26) est en ce sens signifiante, d'abord par son abondance: dans la deuxième moitié du $\mathrm{V}^{\mathrm{e}}$ siècle, elle est plus fréquente que partout ailleurs dans la région considérée (fig. $36, \mathrm{n}^{\circ} 3$ ), tandis qu'elle rejoint au $\mathrm{IV}^{\mathrm{e}}$ siècle les taux observés dans les établissements littoraux (Lattes et Espeyran), où elle reste cinq à dix fois plus courante que dans l'hinterland (voir sur ce point Py 1999, 655-656); ensuite par sa qualité: les vases figurés sont relativement nombreux et comprennent plusieurs pièces de grande taille (cratère en calice notamment).

D'autres céramiques tournées sont également bien représentées, notamment la céramique pseudo-attique, surtout au $\mathrm{IV}^{\mathrm{e}} \mathrm{s}$. (avec deux tessons décorés de rehauts peints), la céramique à pâte claire peinte et non peinte de Marseille et de la basse vallée du Rhône (37 \% de la vaisselle en moyenne) 

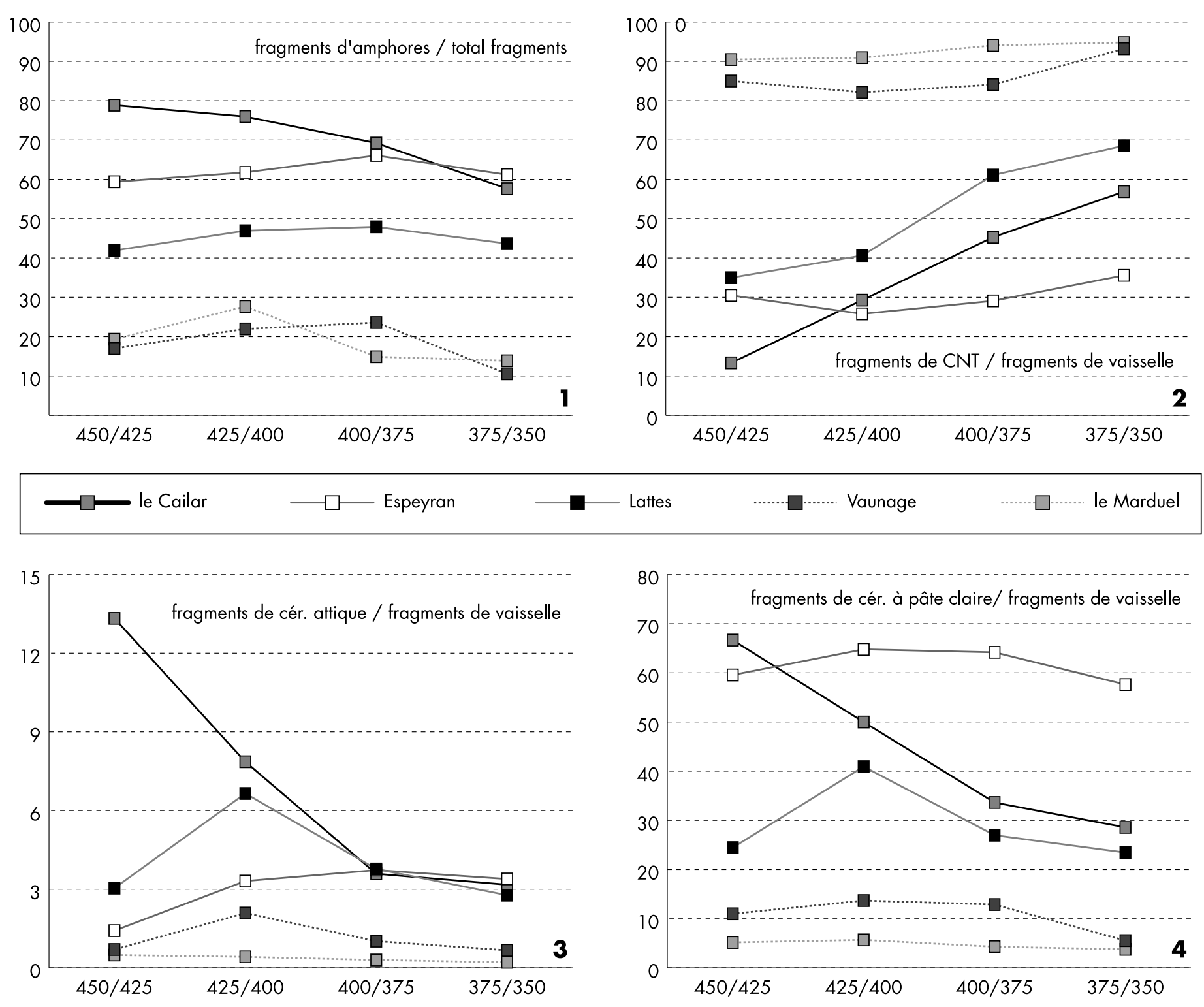

136 Évolution des proportions d'amphore, de céramique non tournée, de céramique attique et de céramique à pâte claire entre 450 et 350 av. n. è. au Cailar et sur les sites environnants.

(fig. 36, $\mathrm{n}^{\circ} 4$ ), ou encore la céramique commune tournée $(8 \%)$. Par contre, les proportions de céramique non tournée s'avèrent relativement faibles, avec en moyenne $10 \%$ du total des tessons découverts et $41 \%$ de la vaisselle. Cette rareté est surtout patente au troisième quart du $\mathrm{V}^{\mathrm{e}} \mathrm{s}$., où le pourcentage atteint seulement $13 \%$ de la vaisselle (fig. 36, $\mathrm{n}^{\circ} 2$ ), soit un taux huit fois moindre que sur les sites indigènes de l'hinterland (80 à $95 \%)$, moitié moindre qu'à Lattes $(35 \%)$ et à Espeyran (30\%), à peu près équivalent à ce que l'on observe à Agde (9 à $19 \%$ : Garcia 1995) et à peine supérieur aux proportions de Marseille (de 3 à $10 \%$ : Gantès 1992).

Mais c'est surtout l'énormité du volume des apports amphoriques, principalement massaliètes, qui ressort des comptages: avec près de 3500 fragments constituant $70 \%$ des trouvailles, les amphores dominent largement le mobilier et dénotent une forte activité marchande ainsi qu'une forte consommation de vin sur le site même ${ }^{35}$. La différence sur ce point est particulièrement nette avec les oppidums de la Vaunage ou du Marduel (fig. 36, $\mathrm{n}^{\circ} 1$ ), où les fragments d'amphores ne constituent jamais plus de 20 à $30 \%$ des découvertes. La comparaison avec les comptoirs fluvio-lagunaires voisins place même le Cailar loin devant Lattes (40 à $50 \%$ d'amphores), nettement devant Espeyran au $\mathrm{V}^{\mathrm{e}} \mathrm{s}$. $(60 \%)$ et à égalité au IV s. (60-70\%).

L'analyse détaillée des courbes par quart de siècle révèle une tendance générale caractérisée par un tassement progressif des échanges entre le milieu du $\mathrm{V}^{\mathrm{e}} \mathrm{s}$. et le milieu du 
$\mathrm{IV}^{\mathrm{e}}$ s., concernant aussi bien les amphores (fig. $36, \mathrm{n}^{\circ} 1$ ) que les vases fins (fig. $36, n^{\circ} 3$ et 4 ), et en regard une croissance des proportions des vases non tournés régionaux (fig. 36, n $\left.{ }^{\circ} 2\right)^{36}$. Dans la zone côtière, cette évolution est plus sensible à Lattes et au Cailar qu'à Espeyran, dont les données paraissent plus stables. Bien que se plaçant à un autre niveau, cet affaiblissement graduel des taux d'importation dans la stratigraphie du sondage 1 du Cailar correspond assez bien au phénomène de crise mis en évidence aux $\mathrm{IV}^{\mathrm{e}}-\mathrm{II}^{\mathrm{e}}$ s. sur les sites indigènes de la région nimoise (Py 1990, 160-162 et 182-196). Tout en notant cette convergence, il convient néanmoins de rester prudent dans son interprétation, en attendant que de nouvelles recherches sur le site élargissent la base documentaire.

Globalement cependant, le faciès du mobilier recueilli, auquel s'ajoutent certains aspects de l'architecture (notamment la taille de pierre), ne laisse guère de doute sur la nature de ce gisement, qui trouve sa place aux côtés d'autres comptoirs fluvio-lagunaires du Languedoc oriental. L'énorme quantité d'amphores présente au Cailar indique bien que ce site, établi au débouché d'un fleuve navigable et à proximité d'un vaste étang littoral ouvert sur la mer par de multiples graus (le Stagnum Volcarum de Pline), a servi de débarcadère pour les marchands méditer- ranéens, au même titre qu'Espeyran au bord du Petit-Rhône (Barruol 1978) et que Lattes au bord du Lez (Py 1993a) ${ }^{37}$. Comme sur ces sites, le poids de Marseille aux $\mathrm{V}^{\mathrm{e}}$ et $\mathrm{IV}^{\mathrm{e}}$ siècles avant notre ère est écrasant, et se pose la question du rôle que purent jouer les Grecs dans l'établissement et la gestion d'un tel emporion, dont le statut doit a priori être considéré comme indigène, par défaut tout autant que par précaution ${ }^{38}$. Quelles relations, par ailleurs, doit-on supposer entre cette agglomération littorale et les oppidums de l'intérieur, proches et reliés à elle par des axes de circulation évidents: la vallée du Rhôny vers la Vaunage, la vallée du Vistre vers Nimes, la vallée du Vidourle vers Ambrussum et au-delà vers Villevieille et Gailhan?

On le voit aujourd'hui, avec la découverte de ce site nouveau et apparemment important, c'est un système plus complet et certainement plus complexe qu'on ne le pensait qui se révèle sur la façade du Languedoc oriental, en relation avec le développement - et les aléas - du commerce méditerranéen. Il semble évident que seule une meilleure connaissance de chaque composante de ce système, reposant sur la programmation de fouilles nouvelles, permettra d'en connaître la nature réelle, le fonctionnement et l'évolution au cours de l'âge du Fer.

\section{Notes de commentaire}

* M. PY: UMR 154 du CNRS, Lattes.

R. Roure: Allocataire de recherche à l'Université Paul-Valéry, Montpellier. N. Alonso Martinez: Unité d'Archéologie, de Préhistoire et d'Histoire antique de l'Université de Lerida, Espagne.

J.-C. BESSAC: UMR 154 du CNRS, Lattes.

A. GARDEISEN : UMR 154 du CNRS, Lattes.

G. PIQUES : chercheur associé à l'UMR 154 du CNRS, Lattes.

1 En 1801, le Vistre est encore considéré comme rivière navigable (Pasquier 1993,197).

2 Duchesne, Franc. Script. I, p. 850 (cité par Germer-Durand, 1868, 52).

3 Le château, avec ses archives, a brûlé en 1383, et le bâtiment édifié ensuite fut détruit en 1629 .

4 Soit les parcelles 399 et 400 (section H).

5 Parcelle cadastrale 397.

6 Sur ce type de bord à méplat incliné vers l'intérieur et lèvre moulurée, attesté entre la fin du IVe et le milieu du II e s., cf. Py 2001, 202-203.

7 Variante A-AFR TrA-bd1 de Py 2001, 253-254, à lèvre assez haute, attestée entre 150 et 50 av. n. è.

8 L'association d'un décor externe figuré et interne estampé n'est pas très courante, mais cependant attestée sur plusieurs formes ouvertes, comme ici sur la coupe-skyphos (cf. Journal of Hellenic Studies, 64, 1944, 67-77) ou ailleurs sur des stemless (cf. Journal of Hellenic Studies, 56,1936, 205-215).

9 Variante CAMP-A 23-bd1: cf. Py 2001, 449, n 2262-2267.

10 L'identification des céramiques antiques et médiévales trouvées au Cailar a bénéficié du concours éclairé de Claude Raynaud, que nous tenons à remercier vivement pour son aide.

11 Catégorie absente de Dicocer[1], importée de la région Saône-Rhône aux $\mathrm{V}^{\mathrm{e}}-\mathrm{VI}^{\mathrm{e}} \mathrm{s}$. de notre ère.
12 Sur les catégories et les formes des céramiques régionales de cette époque et de la suivante, voir principalement Leenhardt 1993, 111-228 (typologie CATHMA).

13 Sur cette production, cf. Bonhoure 1992

14 Voir la typologie de Leenhardt 1995, 63.

15 Une butte de terre nettement perceptible au nord-est de la parcelle 400 (fig. 5) correspond sans doute aux ruines de ce château, dont les murs étaient encore visibles au XIX ${ }^{\mathrm{e}}$ siècle aux alentours des actuelles arènes.

16 Le point zéro du chantier, établi à l'angle sud-est du monument aux morts (fig. 7), a été coté à $+5,30 \mathrm{~m}$ NGF par rapport à la borne IGN située à la base du piédroit de la porte du cimetière (altitude $4 \mathrm{~m}$ ). L'échelle des profondeurs NGF est indiquée sur le côté droit des stratigraphies illustrées ci-après (fig. 9 et 11).

17 Nous tenons à remercier vivement Claude Raynaud qui nous a rapidement alertés de cette découverte, et les membres de son équipe qui ont ensuite participé activement à la fouille et au traitement du mobilier, à savoir Pascal Rey, Olivier Calériza et Claude Vidal. Nos remerciements vont également à M. Berger-Lefranc, alors Maire du Cailar, pour son autorisation immédiate, et à M. André Blanc, chef du service technique de la Mairie, qui a mis à notre disposition tous les moyens nécessaires à la réalisation de la fouille.

18 Le sondage 1 a été mené par une petite équipe comprenant, outre les signataires de cet article et les personnes citées ci-dessus, Stéphanie Raux, Gael Piqués et Denis Lebeaupin. Nous remercions également Xavier Gutherz et Christophe Pellecuer, conservateurs au Service régional de l'Archéologie, pour l'autorisation réglementaire et le suivi du dossier.

19 Aucun financement n'a pu être alloué à cette opération de sondage urgent, type d'intervention pour lequel le Ministère de la Culture ne met apparemment plus guère de crédits à la disposition des services régionaux.

20 Les mobiliers trouvés au Cailar, aussi bien en surface qu'en stratigraphie, sont conservés à Nimes, au dépôt du Centre Archéologique du Gard. 
21 Sur ces blocs, voir ci-après l'annexe technique de Jean-Claude Bessac au $\S 2.3$.

22 Ajouter lors des fouilles de Lattes en 2001 deux anses dans les us 50316 et 50323.

23 Voir les contextes fournis par Py 2001, 210 et 218, note 18.

24 L'apparition du type bd7 vers 400 est notamment confirmée par un exemplaire de Lattes portant une estampille $\mathrm{T}$ en creux sans cartouche, datable aux environs de 399 av. n. è. (Py 2001, n 830).

25 Sur les rares importations italiennes du $\mathrm{IV}^{\mathrm{e}} \mathrm{s}$. à décor de rehaut blanc en Gaule du sud, de provenance étrusque ou autre, cf. Jolivet 1980; Py 2001, 1143-1148.

26 À propos du motif de la lyre représenté sur ce tesson, Ludi Chazalon nous communique les remarques suivantes: «Ce qui semble caractéristique, c'est la façon de rendre les "kollopes" (clefs de l'instrument). Habituellement toute la zone est réservée et les clefs sont dessinées à l'intérieur en vernis noir ou délayé, ou bien il n'y a pas de clef mais un "joug rotatif". Sur le tesson du Cailar, ce sont les clefs qui sont réservées, et non pas tout un espace à l'intérieur duquel elles seraient peintes. Ce cas de figure est assez rare: il se rencontre par exemple sur une petite œnochoé de 420-410 conservée en Allemagne, attique, d'un peintre qualifié de "peut-être béotien" par Simon 1997. Malgré cette connivence dans la façon de représenter les kollopes, le peintre du Cailar semble plus maître de son trait, notamment dans le rendu du bras de la lyre (lignes de contour fermes). Peut-être appartient-il au même cercle, peut-être a-t-il influencé le peintre de l'œnochoé... Concernant les kollopes, on citera deux autres lyres (Moore 1997, $n^{\circ} 656$ et $n^{\circ} 1638$ ) avec cette particularité, mais le reste du dessin est plus maniéré. Le n ${ }^{\circ} 656$ est dit "dans la manière du peintre de Meidias", vers 410-400, mais la monographie sur ce peintre ne donne rien d'approchant si l'on ne se base que sur la lyre. Même chose pour une lyre du peintre de Schuvalov (Paquette 1984, 154, L7 : œnochoé Bâle, Galerie André Emmerich n 20, vers 420) représentée avec des kollopes réservés mais soulignés d'une ligne de contour noire. Curiosité iconographique: sur le fragment du Cailar, la main droite tenant le plectre est particulièrement haut sur la lyre. D'habitude quand on joue de la lyre, la main gauche est montrée ouverte, doigts sur les cordes et la main droite avec le plectre au niveau de la caisse».

27 Les radiers de sols constitués d'une couche de galets enrobés d'argile jaune ou brun-rougeâtre, le plus souvent d'origine naturelle (sédiments villafranchiens), sont fréquents dans les habitats littoraux du Languedoc oriental, notamment à partir du $\mathrm{III}^{\mathrm{e}} \mathrm{s}$. av. n. è., comme en témoignent les exemples observés à Lattes (par exemple zone 1, secteur 4, vers 200-175 : Roux 1990, 39; zone 4-nord, secteur 1, vers 150-125: Py 1990a, 213; zone 20, secteur 2, vers 250-175: Py 1996, 217; zone 31, secteur 4, vers 100-75; zone 35, secteur 8, vers 150-125...) et à Espeyran (Barruol 1978, 67, fig. 35).

28 La partie orientale du cimetière actuel a été créée en 1838-1839; elle a été surélevée trente ans plus tard. La partie ouest, de l'autre côté de l'allée centrale, a été ajoutée en 1882 (Pasquier 1993, 356).

29 La méthode repose sur le principe d'appariement de mesures effectuées sur les pièces archéologiques avec des mesures effectuées sur les os de spéci- mens actuels dont la longueur totale (LT) et le poids (Pds) sont connus (Casteel 1976).

30 La butte ainsi circonscrite, mesurant approximativement $250 \mathrm{~m}$ de diamètre, est bordée à l'ouest et au sud par le fossé pérennisant le lit fossile du Rhôny, au nord par la rue Bernard Lazare et à l'est par le boulevard Louis-Blanc, proche de l'ancien cours du Vistre.

31 Germer-Durand 1868; 1893, 41-45; Blanchet 1941, 115-116; Fiches 1996, 304.

32 La plaine de Vaunage, entourée de cinq oppidums du Bronze final et des âges du Fer, n'est distante du Cailar que d'une douzaine de kilomètres à vol d'oiseau.

33 Py 1990, 86 et 638 sqq.

34 Pour la même période, on raisonne sur 135907 fragments de vases à Lattes, 4844 fr. à Espeyran, 9785 fr. en Vaunage et 34909 fr. au Marduel.

35 Si tant est que ce vin n'ait pas été transvasé dans d'autres types de conteneurs pour une redistribution vers l'intérieur du pays, ce qui a été parfois envisagé (par exemple Garcia 1990, 116) mais reste peu probable (discussion dans Py 1999, 654-658).

36 Croissance plus forte encore au Cailar après le milieu du $\mathrm{IV}^{\mathrm{e}} \mathrm{s}$., si l'on tient compte du mobilier de la couche 1003 du sondage 1 où la céramique non tournée constitue $86 \%$ des fragments de vaisselle; néanmoins l'effectif de cet échantillon, seul représentant de la période, est trop réduit (101 fr.) pour que l'on retienne définitivement cette indication.

37 Rappelons que ces sites languedociens livrent des taux plus élevés d'amphores que des villes grecques comme Olbia ou Marseille, et nettement plus qu'Arles dont le statut n'est pas encore clairement défini (17\% seulement du total des découvertes: Arcelin 1995, 334). Cette modeste place des apports amphoriques, et la présence désormais attestée de deux comptoirs au pied de la Costière (Espeyran et le Cailar), n'incitent guère à voir dans Arles un "vecteur marchand et culturel... vers les Costières du Gard", comme le suppose Patrice Arcelin, ibid., 337.

38 En l'absence de textes ou d'inscriptions explicites, susceptibles de fonder une opinion contraire, il est en effet difficile d'envisager, pour l'heure, une autre hypothèse que celle d'un comptoir indigène largement ouvert aux agents méditerranéens. On sait la difficulté persistante de reconnaître une implantation coloniale ou commerciale étrangère à partir des seuls documents archéologiques: les cas d'Espeyran, dont l'identification avec Rhodanousia a été successivement proposée (Barruol 1978) et mise en doute (Bats 1988; résumé du débat dans Py 1990, 112-113), de La Monédière, pensé comme un habitat grec (Nickels 1976; 1983) ou traditionnel (Dedet 1990), et encore de Béziers, "ville grecque oubliée" pour les uns (Ugolini 1991) et cité ibéro-languedocienne pour d'autres (Py 1993), montrent assez combien l'identification des fondations et même des présences étrangères est délicate et sujette à controverses depuis que quelques tessons attiques ne suffisent plus à définir les "stations grecques du Rhône aux Pyrénées" (Coulouma 1948).

\section{Références bibliographiques}

Arcelin 1995 : ARCELIN (P.) - Arles protohistorique, centre d'échanges économiques et culturels. In: Sur les pas des Grecs en Occident, Études Massaliètes 4, 1995, pp. 325-338.

Arcelin 2000 : ARCELIN (P.), ROUILLARD (P.) - Premier aperçu sur la composition de la céramique attique d'Arles (Bouches-du-Rhône) au IV ${ }^{e} \mathrm{~s}$. av. J.-C. In : La céramique attique du IVe s. en Méditerranée occidentale, Actes du colloque d'Arles, Naples, 2000, pp. 159-165.

Barra 1989 : BARRA BAGNASCO (M.) - Locri Epizefiri III, cultura materiale e vita quotidiana. Studi e materiali di archeologia, 2, Firenze, 1989.

Barra 1992 : BARRA BAGNASCO (M.) - Le anfore. In : Locri Epizefiri IV, lo scavo di Marasà Sud, il sacello tardo-arcaico e la "casa dei leoni". Studi e materiali di archeologia, 4, Firenze, 1992, pp. 205-239.
Barra 1995 : BARRA BAGNASCO (M.) - Anfore locresi : documenti a favore di una produzione locale tra VI e IV sec. a. C. In : Estudis sobre la ceràmica antigua, Barcelone, 1995, pp. 71-81.

Barruol 1978 : BARRUOL (G.), PY (M.) - Recherches récentes sur la ville antique d'Espeyran à Saint-Gilles-du-Gard. RANarb, 11, 1978, pp. 19-100.

Bats 1988 : BATS (M.) - Vaisselle et alimentation à Olbia de Provence (v. 350v. 50 av. J.-C.), modèles culturels et catégories céramiques. Paris, CNRS, 1988 (suppl. à la RANarb, 18).

Bats 1993 : BATS (M.) - Céramique à pâte claire massaliète et de tradition massaliète. In : Dicocer[1], Dictionnaire des céramiques antiques (VII ${ }^{e} s$. av. n. è.-VII e s. de n. è.) en Méditerranée nord-occidentale (Provence, Languedoc, Ampurdan). Lattara 6, 1993, pp. 206-221. 
Bauchot 1980 : BAUCHOT (M.-L.), PRAS (A.) - Guide des poissons marins d'Europe. Paris, 1980.

Blanchet 1941 : BLANCHET (A.), LOUIS (M.) - Forma Orbis Romani, Carte archéologique de la Gaule romaine, département du Gard. Paris, 1941.

Bonhoure 1992 : BONHOURE (I.) - La production de poteries grises au XII siècle à Saint-Victor-des-Oules, Gard. Étude du four 91A. Archéologie du Midi Médiéval, 10, 1992, pp. 205-228.

Bouby 1999 : BOUBY (L.), LEROY (F.), CAROZZA (L.) - Food plants from late Bronze Age lagoon sites in Languedoc, southern France: reconstruction of farming economy and environment. Vegetation History and Archaeobotany, 8, 1999, pp. 53-69.

Buxó 1999 : BUXO (R.) - Première approche des plantes exploitées au IVe siècle avant notre ère à Lattes. Lattara 12, 1999, pp. 525-535.

Casteel 1976 : CASTEEL (R.W.) - Fish remains in Archéology and Paleo-environmental Studies. London, Academic Press, 1976.

Colomer 1992 : COLOMER (A.), GARDEISEN (A.) - Premier bilan sur la consommation des animaux d'élevage et de chasse dans la ville de Lattara (fin du IVe s. av. n. è.- milieu du Irer s. de n. è.). In : PY (M.) dir.-Recherches sur l'économie vivrière des Lattarenses, Lattara 5, Lattes, 1992, pp. 91-110.

Coulouma 1948 : COULOUMA (J.) - Les stations grecques du Rhône aux Pyrénées. Cahiers d'Histoire et d'Archéologie, 3, 1948, pp. 92-98.

Dedet 1980 : DEDET (B.) - Premières recherches sur l'oppidum du Plan de la Tour à Gailhan, Gard, sondages 1975-1977. Caveirac, ARALO, cahier $\mathrm{n}^{\circ} 8,1980$.

Dedet 1990 : DEDET (B.) - Une maison à absides sur l'oppidum de Gailhan (Gard) au milieu du Ve s. av. J.-C. La question du plan absidial en Gaule du sud. Gallia, 47, 1990, pp. 29-55.

Desse 1987 : DESSE (J.), DESSE-BERSET (N.), ROCHETEAU (M.) - Contribution à l'ostéologie du mulet, Liza ramada, Risso 1826 (Mugil capito Cuvier, 1829). Fiches d'ostéologie animale pour l'archéologie (Série A: Poissons), n ${ }^{\circ}$, Juan-les Pins, APDCA, 1987.

Desse 1993 : DESSE (J.), DESSE-BERSET (N.) - Pêche et surpêche en Méditerranée: le témoignage des os. Exploitation des animaux sauvages à travers le temps, IV e colloque international de l'Homme et de l'Animal, Juanles-Pins, APDCA, 1993.

Desse 1996 : DESSE (J.), DESSE-BERSET (N.), ROCHETEAU (M.) - Contribution à l'ostéologie de la daurade royale, Sparus aurata, Linné 1758. Fiches d'ostéologie animale pour l'archéologie (Série A: Poissons), ${ }^{\circ} 9$. Juan-les Pins, APDCA, 1996.

Dubosse 1998 : DUBOSSE (C.) - Corpus Vasorum Antiquorum, France, fasc. 37, Musée National d'Ensérune. Paris, 1998.

Erroux 1966 : ERROUX (J.) - Les orges hallstattiennes du Lycée Technique de Montpellier, Hérault. Ogam, 18, 1966, pp. 454-456.

Fiches 1996 : FICHES (J.-L.), VEYRAC (A.) dir. - Nimes, Carte Archéologique de la Gaule, 30/1. Paris, 1996.

Forest, à paraître: FOREST (V.) - Vestiges fauniques et élevage en Bas Languedoc oriental, communication à la table ronde de Saint-Martin-de-Crau, Bouches-du-Rhône, 1995 : "L'élevage dans l'économie rurale galloromaine : état des questions", à paraître.

Gallet de Santerre 1980 : GALLET DE SANTERRE (H.) - Ensérune, les silos de la terrasse est. Paris, 1980 (suppl. à Gallia, 39).

Gantès 1992 : GANTES (L.-F.) - L'apport des fouilles récentes à l'étude quantitative de l'économie massaliète. In : Marseille grecque et la Gaule, Études Massaliètes 3, 1992, pp. 171-178.

Garcia 1990 : GARCIA (D.) - La diffusion des amphores massaliètes vers le Massif Central (vallée de l'Hérault et département de l'Aveyron). In : Les amphores de Marseille grecque, Etudes Massaliètes 2, 1990, pp. 111-117.

Garcia 1995 : GARCIA (D.), MARCHAND (G.) - À propos du faciès céramique d'Agde (Hérault). In : Sur les pas des Grecs en Occident, Études Massaliètes 4, 1995, pp. 99-103.

Gardeisen 1993 : GARDEISEN (A.) - État de l'élevage en Camargue et en milieu lagunaire de la fin de l'Antiquité au Moyen Age. In : L'Homme et l'animal domestique et l'environnement du Moyen Age au XVII siècle. Enquêtes et documents 19. Centre de recherche sur l'histoire du monde atlantique, Université de Nantes, Ouest éditions, Nantes, 1993, pp. 141-162.
Gardeisen 1999 : GARDEISEN (A.) - Économie de production animale et exploitation du milieu à Lattes au cours du $\mathrm{IV}^{\mathrm{e}}$ siècle avant notre ère. In : PY (M.) dir. - Recherches sur le IVe siècle avant notre ère à Lattes, Lattara 12, Lattes, 1999, pp. 537-568.

Garmy 1981 : GARMY (P.), PEY (J.) - Deux chenets zoomorphes découverts au Cailar, Gard. DocAMérid, 4, 1981, pp. 185-188.

Germer-Durand 1868 : GERMER-DURAND (E.) - Dictionnaire topographique du département du Gard. Paris, 1868.

Germer-Durand 1893 : GERMER-DURAND (E. et F.), ALLMER (A.) - Inscriptions antiques de Nimes. Toulouse, 1893.

Jannoray 1955 : JANNORAY (J.) - Ensérune, contribution à l'étude des civilisations préromaines de la Gaule méridionale. Paris, 1955 (BEFAR, fasc. 181).

Jolivet 1980 : JOLIVET (V.) - Exportations étrusques tardives (IV ${ }^{\mathrm{e}} \mathrm{III}^{\mathrm{e}} \mathrm{s}$.) en Méditerranée occidentale, MEFRA, 92, 1980, pp. 681-724.

Le Gall 1984 : LE GALL (O.) - L'ichtyofaune d'eau douce dans les sites préhistoriques. Cahiers du quaternaire $\mathrm{n}^{\circ}$ 8, Paris, 1984.

Leenhardt 1993 : LEENHARDT (M.), RAYNAUD (Cl.), SCHNEIDER (L.) éd. - Céramiques languedociennes du haut Moyen Age ( $\mathrm{VII}^{\mathrm{e}}-\mathrm{XI}^{e}$ s.), études micro-régionales et essai de synthèse. Archéologie du Midi Médiéval, 11, 1993, pp. 111-228.

Leenhardt 1995 : LEENHARDT (M.) dir. - Poteries d'Oc, céramiques languedociennes, $V I^{e}-X V I I^{e}$ s. Nimes, Musée Archéologique, 1995.

Lezzi-Hafter 1988 : LEZZI-HAFTER (A.) - Der Eretriamaler, Werke und Weggefährten. Kerameus, 6, 1988.

Moore 1997 : MOORE (M. B.) - The Athenian Agora, XXX, Attic red-figured and white-ground pottery. Princeton, 1997.

Nickels 1976 : NICKELS (A.) - Les maisons à abside d'époque grecque archaïque de La Monédière à Bessan (Hérault). Gallia, 34, 1976, pp. 95 128.

Nickels 1983 : NICKELS (A.) - Les Grecs en Gaule: l'exemple du Languedoc. In: Modes de contacts et processus de transformation dans les sociétés anciennes. Pise-Rome, 1983, pp. 409-428.

Paquette 1984 : PAQUETTE (D.) - L'instrument de musique dans la céramique de la Grèce antique, études d'organologie. Publications de la Bibliothèque Salomon Reinach, IV, Paris, 1984.

Piqués à paraître: PIQUES (G.) - Contribution à l'ostéologie de l'anguille, Anguilla anguilla, Linné 1758, Fiches d'ostéologie animale pour l'archéologie (Série A: Poissons), Juan-les Pins, APDCA (à paraître).

Py 1975 : PY (M.), TENDILLE (C.) - Villevieille antique, Gard. ARALO, Cahier n 3, Caveirac, 1975.

Py 1978 : PY (M.) - Une production massaliète de céramique pseudo-attique à vernis noir. Rivista di Studi Liguri, 44, 1978, pp. 175-198.

Py 1979 : PY (M.) - Ensayo de clasificación de un estilo de ceramica de Occidente: los vasos pseudo-jonios pintados. Ampurias, 41-42, 1979-1980, pp. 155-202.

Py 1981 : PY (M.) - Recherches sur Nimes préromaine, habitats et sépultures. Paris, CNRS, 1981 (suppl. à Gallia, 41).

Py 1985 : PY (M.) - Les amphores étrusques de Gaule méridionale. In : Il commercio etrusco arcaico, Quaderni del Centro di Studio per l'Archeologia Etrusco-Italica, 9, Rome, 1985, pp. 73-94

Py 1989 : PY (M.), LEBEAUPIN (D.) - Stratigraphie du Marduel. IV- Les niveaux des $\mathrm{IV}^{\mathrm{e}}$ et $\mathrm{III}^{\mathrm{e}} \mathrm{s}$. av. n. è. sur le Chantier Central. DocAMérid, 12, 1989, pp. 121-190.

Py 1990 : PY (M.) - Culture, économie et société protohistoriques dans la région nimoise. Rome-Paris, 1990, 2 vol. (Collection de l'École Française de Rome, 131).

Py 1990a: PY (M.), LOPEZ (J.) - Histoire de l'îlot 4-nord. Stratigraphie, architecture et aménagements (II ${ }^{\mathrm{e}} \mathrm{s}$. av. n. è.-- $\mathrm{I}^{\mathrm{er}} \mathrm{s}$. de n. è.). In : Fouilles dans la ville antique de Lattes, les îlots 1, 3 et 4-nord du quartier Saint-Sauveur. Lattara 3, 1990, pp. 211-246.

Py 1992 : PY (M.), LEBEAUPIN (D.) - Stratigraphie du Marduel. V- Les niveaux de la seconde moitié du Ve s. av. n. è. sur le Chantier Central. DocAMérid, 15, 1992, pp. 261-326. 
Py 1993 : PY (M.) dir. - Dicocer[1], Dictionnaire des céramiques antiques (VII ${ }^{e}$ s. av. n. è.-VII ${ }^{e}$ s. de n. è.) en Méditerranée nord-occidentale (Provence, Languedoc, Ampurdan). Lattara 6, 1993, 624 p.

Py 1993a: PY (M.), GARCIA (D.) - Bilan des recherches archéologiques sur la ville portuaire de Lattara (Lattes, Hérault). Gallia, 50, 1993, pp. 1-93.

Py 1996 : PY (M.) - Les maisons protohistoriques de Lattara (IVe- I $^{\text {er }}$ s. av. n. è.), approche typologique et fonctionnelle. In : Urbanisme et architecture dans la ville antique de Lattes, Lattara 9, 1996, pp. 141-258.

Py 1997 : PY (M.) - SYSLAT 3.1, Système d'Information Archéologique, Manuel de référence. Lattara 10, Lattes, 1997, 384 p.

Py 1999 : PY (M.) - Le faciès de la céramique lattoise du IVe s. av. n. è. In: PY (M.) dir. - Recherches sur le IVe siècle avant notre ère à Lattes. Lattara 12, Lattes, 1999, pp. 287-438.

Py 2000 : PY (M.), SABATINI (B.) - La céramique attique de Lattes (Hérault, France) au IVE s. av. n.è. In : La céramique attique $d u I V^{e} s$. en Méditerranée Occidentale. Collection du Centre Jean Bérard, Naples, 2000, pp. 167-200.

Py 2001 : PY (M.), ADROHER AUROUX (A.), SANCHEZ (C.) - Dicocer [2], Corpus des céramiques de l'âge du Fer de Lattes (fouilles 1963-1999). Lattara 14, Lattes, 2001, 2 volumes, 1306 p.

Raux 1999 : RAUX (S.) - Les objets de la vie quotidienne à Lattes au IVe siècle avant notre ère. In: PY (M.) dir. - Recherches sur le IVe siècle avant notre ère à Lattes. Lattara 12, Lattes, 1999, pp. 439-518.

Raynaud à paraître : Raynaud (C.) - Le Cailar (Gard) : le Castellas, les Virunes et la question de Virinnae. In : FICHES (J.-L.) dir. - Les agglomérations gallo-romaines en Languedoc-Roussillon. Monographies d'Archéologie Méditerranéenne, Lattes, à paraître.

Reille 1999 : REILLE (J.-L.) - Détermination pétrographique de l'origine des meules de Lattes au IV ${ }^{\mathrm{e}}$ siècle avant notre ère, changements et contrastes dans les importations. In: PY (M.) dir. - Recherches sur le IVe siècle avant notre ère à Lattes. Lattara 12, Lattes, 1999, pp. 519-522.
Reille 2001 : REILLE (J.-L.) - L'origine des meules à grains dans l'oppidum protohistorique de Montlaurès (Narbonne, Aude) du $\mathrm{VI}^{\mathrm{e}}$ au $\mathrm{I}^{\text {er }}$ s. av. n. è. DocAMérid, 24, 2001, pp. 201-206.

Rondi-Costanzo 1997 : RONDI-COSTANZO (C.) - Corail de Béziers, du Midi de la Gaule et de Méditerranée. In : Languedoc occidental protohistorique, fouilles et recherches récentes, $V I^{e}-I V^{e}$ s. av. J.-C. Publication de l'Université de Provence, Aix, 1997, pp. 197-239.

Roux 1990 : ROUX (J.-C.) - Histoire de l'îlot 1. Stratigraphie, architecture et aménagements ( $\mathrm{III}^{\mathrm{e}}-\mathrm{II}^{\mathrm{e}}$ s. av. n. è.). In: Fouilles dans la ville antique de Lattes, les îlots 1, 3 et 4-nord du quartier Saint-Sauveur, Lattara 3, 1990, pp. 17-70.

Simon 1997 : SIMON (E.) - Mythen und Menschen, Griechische Vasenkunst aus einer deutschen Privatsammlung. Mainz, 1997.

Sparkes 1970 : SPARKES (B. A.), TALCOTT (L.) - The Athenian Agora, XII, Black and plain pottery of the 6th, 5th and 4th centuries B.C. Princeton, 1970, 2 vol.

Sternberg 1992 : STERNBERG (M.) - Contribution à l'ostéologie du loup, Dicentrarchus labrax, Linné 1758, Fiches d'ostéologie animale pour l'archéologie (Série A: Poissons), n 7, Juan-les Pins, APDCA, 1992.

Sternberg 1995 : STERNBERG (M.) - La pêche à Lattes dans l'antiquité à travers l'analyse de l'ichtyofaune. Lattara 8, Lattes, 1995.

Sternberg 1995a : STERNBERG (M.) - Essai de caractérisation de la pêche entre le Bronze Final et la romanisation à partir des restes d'ichtyofaune issus de sites provençaux et languedociens. L'Homme préhistorique et la mer, $120^{\mathrm{e}}$ congrès CTHS, Aix-en-Provence, octobre 1995.

Tendille 1978 : TENDILLE (C.) - Fibules protohistoriques de la région nimoise. DocAMérid, 1, 1978, pp. 77-112.

Ugolini 1991 : UGOLINI (D.), OLIVE (Chr.), MARCHAND (G.), COLUMEAU (Ph.) - Béziers au V's. av. J.-C., étude d'un ensemble de mobilier représentatif et essai de caractérisation du site. DocAMérid, 14, 1991, pp. 141-203. 